\title{
UNIVERSITY OF HOHENHEIM
}

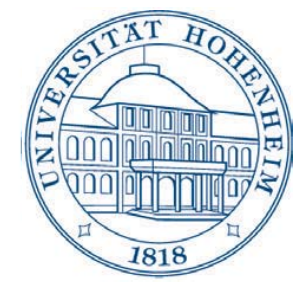

HOHENHEIM DISCUSSION PAPERS

IN BUSINESS, ECONOMICS AND SOCIAL SCIENCES

Institute of Economics

DISCUSSION PAPER 16-2016

ILLUMINATING THE WORLD CUP EFFECT: NIGHT LIGHTS EVIDENCE FROM SOUTH AFRICA

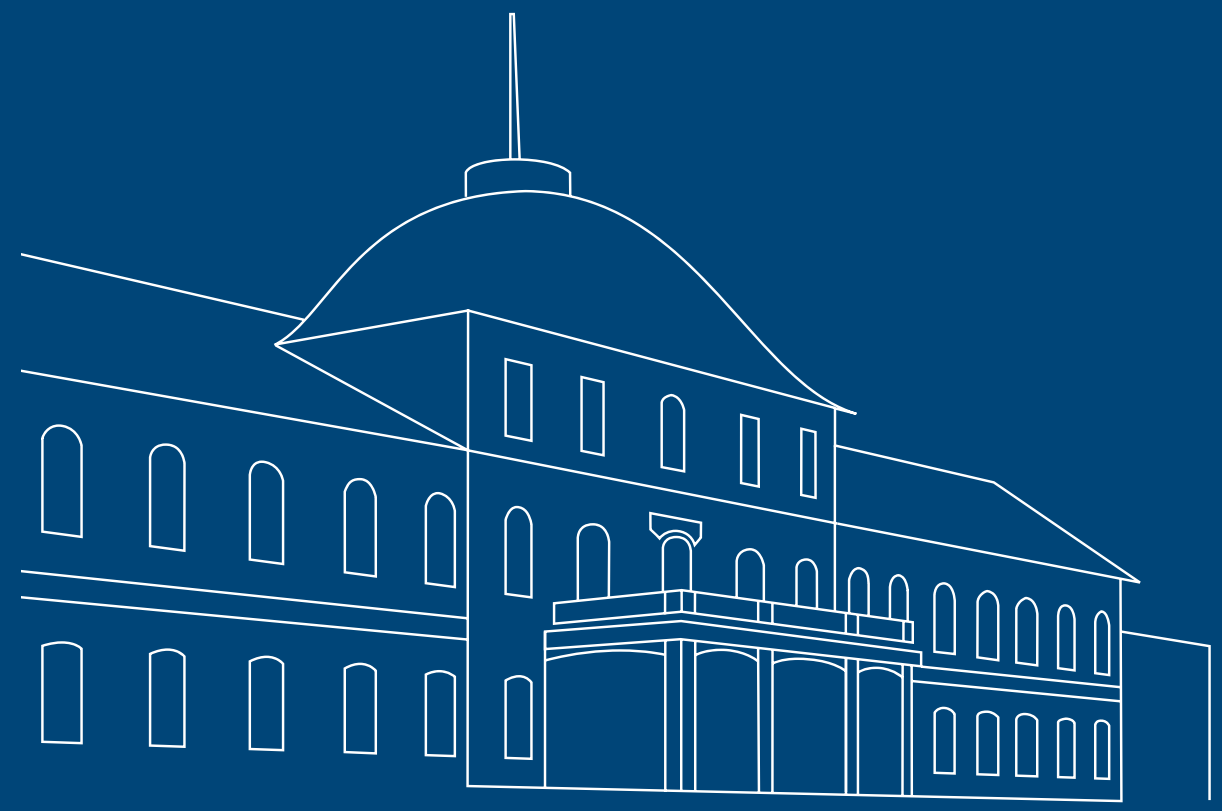

Gregor Pfeifer University of Hohenheim

Fabian Wahl University of Hohenheim Martyna Marczak University of Hohenheim 
Discussion Paper 16-2016

\title{
Illuminating the World Cup Effect: Night Lights Evidence from South Africa
}

\author{
Gregor Pfeifer, Fabian Wahl, Martyna Marczak
}

Download this Discussion Paper from our homepage:

https://wiso.uni-hohenheim.de/papers

ISSN 2364-2076 (Printausgabe)

ISSN 2364-2084 (Internetausgabe)

\begin{abstract}
Die Hohenheim Discussion Papers in Business, Economics and Social Sciences dienen der schnellen Verbreitung von Forschungsarbeiten der Fakultät Wirtschafts- und Sozialwissenschaften. Die Beiträge liegen in alleiniger Verantwortung der Autoren und stellen nicht notwendigerweise die Meinung der Fakultät Wirtschafts- und Sozialwissenschaften dar.
\end{abstract}

Hohenheim Discussion Papers in Business, Economics and Social Sciences are intended to make results of the Faculty of Business, Economics and Social Sciences research available to the public in order to encourage scientific discussion and suggestions for revisions. The authors are solely responsible for the contents which do not necessarily represent the opinion of the Faculty of Business, Economics and Social Sciences. 


\title{
Illuminating the World Cup Effect: Night Lights Evidence from South Africa
}

\author{
Gregor Pfeifer * \\ University of Hohenheim
}

\author{
Fabian Wahl ${ }^{\dagger}$ \\ University of Hohenheim
}

\author{
Martyna Marczak $\ddagger$ \\ University of Hohenheim
}

September 29, 2016

\begin{abstract}
This paper evaluates the economic impact of the $\$ 14$ billion preparatory investments for the 2010 FIFA World Cup in South Africa. We use satellite data on night light luminosity at municipality and electoral district level as a proxy for economic development, applying synthetic control methods for estimation. For the average World Cup municipality, we find significantly positive, short-run effects before the tournament, corresponding to a reduction of unemployment by 1.3 percentage points. At the electoral district level, we reveal distinct effect heterogeneity, where especially investments in transport infrastructure are shown to have long-lasting, positive effects, particularly in more rural areas.
\end{abstract}

JEL Codes: H54; O18; R11; R42; Z28

Keywords: Football World Cup; Public Infrastructure; Development; Night Lights Data; Synthetic Control Methods; Mega Sports Events; South Africa

\footnotetext{
${ }^{*}$ Corresponding author: University of Hohenheim, Department of Economics (520B), D-70593 Stuttgart, Germany; E-mail: g.pfeifer@uni-hohenheim.de; Phone: +49 71145922193.

${ }^{\dagger}$ University of Hohenheim, Department of Economics (520J), D-70593 Stuttgart, Germany; E-mail: fabian.wahl@uni-hohenheim.de; Phone: +49 71145924405.

${ }^{\ddagger}$ University of Hohenheim, Department of Economics (520G), D-70593 Stuttgart, Germany; E-mail: marczak@uni-hohenheim.de; Phone: +49 71145923823.

The authors are grateful for valuable remarks from Martin Gassebner, Christian Leßmann, M. Daniele Paserman, Eric Strobl, and Stijn van Weezel as well as seminar participants at the Annual Conference of the German Economic Association's Research Group on Development Economics, the IAAE Annual Conference, the Meeting of the German Economic Association, and the ifo Workshop on Regional Economics. The authors declare that they have no relevant or material financial interests that relate to the research described in this paper.
} 


\section{Introduction}

The men's FIFA World Cup is, next to the Olympic Games, the most popular sporting event worldwide that attracts several hundreds of thousands of visitors and features the highest TV audience. Predominantly, the organization of this tournament was reserved for rather wealthy countries. For example, between 1990 and 2006, it took place in Italy, the U.S., France, South Korea/Japan, and Germany, respectively. This tradition was interrupted in 2010, when South Africa became the first country on the African continent to host the Football World Cup.

The aim of this paper is to evaluate the World Cup in South Africa in terms of its overall economic effects with a special emphasis on the impact of the enormous transport and sports infrastructure investments made in preparation for the tournament. Particularly, we want to shed light on the heterogeneity of such potential impact not only with respect to the type of investment, but also its scale and the precise treatment location within the country. These questions are of special importance from a policy point of view, since the resulting evidence can be used to derive practical recommendations regarding the organization of future mega events in developing economies.

South Africa is characterized by low income per capita and high unemployment. Additionally, as a legacy of the apartheid past, its population suffers from extreme levels of poverty and income inequality. ${ }^{1}$ In view of such overwhelming problems, large-scale investments made in the aftermath of FIFA's official World Cup announcement in 2004 have been expected to serve as a catalyst for economic growth in South Africa. Total expenditures for World Cup related projects are estimated to have totaled about $\$ 14$ billion, what is equivalent to roughly $3.7 \%$ of South Africa's GDP in $2010 .^{2}$ This included expenditures on transportation of about

\footnotetext{
${ }^{1}$ Over the decade preceding the World Cup, the gap in GDP per capita relative to the 17 leading OECD countries amounted to more than 75\% (OECD, 2012). Moreover, the consumption-based Gini coefficient features a time-corresponding average of about 62, i.e., South Africa belonged to the most unequal countries in the world. The underlying data for 2000, 2006, and 2008 have been retrieved from the World Bank database: http://data.worldbank.org/indicator/SI.POV. GINI/, last accessed on January 19, 2106. Lastly, the unemployment rate persisted at around $25 \%$, peaking at over $40 \%$ in the first three deciles of the income distribution (Leibbrandt et al., 2010).

2 Throughout the paper, all figures originally given in the national currency 'Rand' have been translated into U.S. dollars (\$) using the average exchange rate of 2010. Data on expenditure comes from our own research on World Cup related projects. Detailed information on the sources and costs of particular projects is provided
} 
$\$ 11.4$ billion, which have been allocated to the upgrade of airports ( $\$ 3.8$ billion), rail projects ( $\$ 3.6$ billion), and road projects ( $\$ 2.9$ million), whereas the remainder has been invested in public transport. Another $\$ 2.5$ billion have been spent on constructing six new football arenas, upgrading four existing ones, and upgrading training stadiums.

Taking into account the scale of this policy intervention, surprisingly little research has been conducted to analyze the overall effects on the economy or to explicitly investigate the effects of infrastructure investments connected to the 2010 World Cup. ${ }^{3}$ Most of this work has been done in advance of the tournament or only shortly thereafter, and merely confines to verbal evaluations and reporting descriptive evidence (Sport and Recreation South Africa, 2013; Human Sciences Research Council, 2011), from which the overall conclusion is that potential (positive) impacts were only short-lived. This skeptical view on the longer-lasting effects for economic growth and development is, in general, shared in the literature on mega events (Baade and Matheson, 2004; du Plessis and Maennig, 2011; Hagn and Maennig, 2008, 2009; de Nooij et al., 2011). Even though, according to this research, net benefits of mega (sports) events are typically non-significant or even negative, Rose and Spiegel (2011) show that the hard international competition for the right to host such an event can be linked to a permanent increase in trade. Moreover, irrespective of the event context, other studies have found that investments in transport infrastructure have long-lasting, positive effects on economic development by creating a market access advantage to those places that, e.g., are connected to a railroad or were connected earlier (Berger and Enflo, 2016; Cogneau and Moradi, 2014; Donaldson, 2016; Donaldson and Hornbeck, 2016; Hornung, 2015; Jedwab et al., 2016). Furthermore, other studies show the importance of public infrastructure for the decision of firms to locate in a particular country or region (Martin and Rogers, 1995; Holl, 2004) and for urban growth in (Sub-Saharan) Africa (Storeygard, 2016). Another strand of literature in Appendix B.2. According to the World Bank, South Africa's GDP in 2010 was $\$ 375.35$ billion (http: //data. worldbank.org/indicator/NY. GDP.MKTP.CD/countries/ZA?display=graph, last accessed on June 16, 2016).

${ }^{3}$ In contrast, intangible legacy or specific tangible aspects have been extensively studied in the literature. Examples are analyses focusing on the environment (Death, 2011), social values (Desai and Vahed, 2010), tourism (du Plessis and Maennig, 2011; Peeters et al., 2014), small enterprises (Rogerson, 2009), urban development (Pillay and Bass, 2008), or stadium utilization (Molloy and Chetty, 2015). 
deals with the impact of place-based policies on regional economic development and finds positive effects in both the short- and the long-run (Becker et al., 2010, 2012; Kline and Moretti, 2014). Carrying over these arguments to the World Cup context, one particularly can expect transport infrastructure investments made for the tournament to have exerted significantly positive and long-lasting economic effects.

Given the scarcity of evidence with respect to such important issues, there is a need for a thorough re-assessment of the 2010 World Cup that is able to provide a more detailed picture. The present paper fills this gap and makes several contributions to the literature. To begin with, we are first to present causal evidence on the overall economic influence of the tournament. Our study also allows to track the effect at different time horizons starting in 2004, when South Africa was announced the host country of the 2010 World Cup.

Second, we resort to night lights intensity (luminosity) data, that have been recently acknowledged in the literature as a suitable proxy for economic development (Henderson et al., 2012; Michalopoulos and Papaioannou, 2014). Data on night lights are collected by satellites and are available for the whole globe at a high level of geographical precision. ${ }^{4}$ Therefore, their usefulness as an economic proxy is of particular relevance in the case of developing countries, where administrative data on GDP or other economic indicators are often of bad quality, not given for a longer time span, and/or not provided at a desired sub-national level. We harness this advantage of the luminosity data, which enables us to precisely identify the effects in treated regions of the country, i.e., regions affected by the investments related to the World Cup, in that we can easily extract information for a chosen, sometimes very small administrative unit. In particular, we conduct our analysis both by looking across municipalities and also within municipalities - using information on the next smaller unit, i.e., electoral districts (so-called wards). Variation in the data on this very dissected administrative level enables us to precisely localize specific interventions and depict potential heterogeneity across treatment

\footnotetext{
4 The economic literature using high-precision satellite data, also on other outcomes than night lights, is growing. For instance, Axbard (2016) exploits satellite data on specific oceanographic conditions to study the effect of fishermen's income opportunities on sea piracy. Gröger and Zylberberg (2016) use geophysical satellite data while analyzing whether internal labor migration facilitates shock coping in rural economies.
} 
effects.

Third, precise identification of such World Cup effects was only possible due to thorough research on infrastructure investments conducted in South Africa for the time span 2004-2013 (our treatment period). As a result of this research, we have created a comprehensive list encompassing 127 investment projects divided into different categories: airports, stadiums, roads, rail, public transport, etc. To the best of our knowledge, such an attempt to summarize investment projects in South Africa in a particular time span has never been undertaken before. The investment list can also act as a stand-alone document and be useful for researchers dealing with South Africa in other regards. Based on this full list, we have selected as treatments for our analysis those 72 projects which, according to the information sources, are clearly classified as World Cup related and could be localized.

Fourth, we evaluate such treatments by applying synthetic control methods (SCM), an approach introduced by Abadie and Gardeazabal (2003) and Abadie et al. (2010). SCM provides intuitive identification of causal effects by comparing an appropriate counterfactual to the actual development of the outcome after the intervention. The counterfactual is constructed by an algorithm-derived combination of optimally weighted comparison units, which best resemble the characteristics of the treated one according to economic predictors pre-treatment. Hence, one great advantage of SCM is that it is not based on ad hoc choices of control units. Instead, it lets the data speak regarding the selection and respective weights of control units, which is particularly helpful in the presence of many potential candidates, like municipalities or electoral districts. SCM has already proven successful in the quantification of treatment effects across a wide range of fields. ${ }^{5}$ However, to the best of our knowledge, this paper is the first one that employs SCM in the context of mega (sports) events. Moreover, by combining SCM with night lights intensity data, we offer a framework for evaluation of various policy programs aimed at stimulating economic growth, especially-but not solely-in developing countries.

\footnotetext{
5 See, for instance, Cavallo et al. (2013) (natural disasters), Kleven et al. (2013) (taxation of athletes), Gobillon and Magnac (2016) (enterprise zones), Acemoglu et al. (2015) (political connections), or Pinotti (2015) (crime).
} 
Finally, to facilitate the interpretation of our SCM results, we translate the obtained luminosity effects into values expressed in terms of standard economic outcomes, which policy makers are usually more interested in. For that purpose, we derive unemployment, GDP, and income effects by using corresponding conversion factors obtained through OLS regressions. Importantly, by converting night light impacts into effects in terms of the unemployment rate, we go beyond the existing literature which so far has only explored the relationship between night lights and GDP per capita or income per capita (Henderson et al., 2012; Pinkovskiy and Sala-i-Martin, 2016). The reason for choosing the unemployment rate is that, in South Africa, it is available at a finer regional level than GDP and thus offers a more precise basis for deriving a conversion factor. We additionally consider GDP and income as reference economic measures for the sake of completeness and to compare our conversion factors to those of the related literature.

The findings of this paper show a considerable difference between short- and longer-run effects associated with the tournament, and point to the sources of these differences. Based on the average World Cup venue on municipality level, we find a significant and positive short-run impact between 2004 and 2009, that is equivalent to a 1.3 percentage points decrease in the unemployment rate or an increase of around \$335 GDP per capita. Taking the costs of the investments into account, we derive a net benefit of $\$ 217$ GDP per capita. Starting in 2010, the average effect becomes insignificant. However, by zooming in on respective municipalities and using variation on the next finer level (wards), we are able to show that the average picture obscures heterogeneity related to the sources of economic activity and the locations within the treated municipalities. More specifically, we demonstrate that around and after 2010, there has been a positive, longer-run economic effect stemming from new and upgraded transport infrastructure. These positive gains are particularly evident for smaller towns, which can be explained with a regional catch-up towards bigger cities. For example, in Rustenburgone of the smaller World Cup venues - we find a very large effect of the World Cup related investment equivalent to an increase in GDP per capita of around $\$ 3,642$, what is roughly the 
difference between the GDP per capita of the richest province and the average one. Contrarily, the effect of stadiums is generally less significant and no longer-lasting economic benefits are attributed to the construction or upgrade of the football arenas. Those are merely evident throughout the pre-2010 period. Importantly, our results appear not to be simply driven by the light of airports or stadiums themselves and they are insensitive to a battery of robustness checks, like altering the set of covariates, differently composed synthetic control groups, or different definitions of the treatment group. Eventually, our findings underline the importance of investments in transport infrastructure, particularly in rural areas, for longer-run economic prosperity and regional catch-up processes.

The remainder of this paper is organized as follows. Section 2 gives details on the 2010 World Cup, describes the night lights data set, and provides first descriptive evidence. In Section 3, we outline the SCM approach and how we derive conversion factors to translate our SCM estimates into standard economic measures. Section 4 presents and discusses the findings of the empirical analysis on different levels of aggregation. Finally, Section 5 concludes.

\section{Background of the Analysis and Data}

\subsection{The 2010 World Cup in South Africa}

On May 15, 2004, the FIFA executive committee announced its decision to award the 2010 mens' football World Cup to South Africa. This $19^{\text {th }}$ FIFA World Cup, taking place between June 11 and July 11, 2010, was the first such tournament being hosted on the African continent. The matches were allocated across 10 stadiums located in nine different cities: Bloemfontein (Mangaung Metropolitan Municipality), Cape Town (City of Cape Town Metropolitan Municipality), Durban (eThekwini Metropolitan Municipality), Johannesburg with two stadiums (City of Johannesburg Metropolitan Municipality), Nelspruit (Mbombela Local Municipality), Polokwane (Polokwane Local Municipality), Port Elizabeth (Nelson Mandela Bay Metropolitan Municipality), Pretoria (City of Tshwane Metropolitan Municipality), and Rustenburg 
(Rustenburg Local Municipality). The corresponding venues constitute our treated municipalities.

These municipalities are scattered across eight (out of all nine) provinces and nine (out of all 52) districts, which differ with respect to their economic performance and the regional distribution of sectors. Johannesburg and Pretoria lie in the province Gauteng, whose average real annual growth rate of $4.6 \%$ in the periods $2001-2011$ and contribution of about $34 \%$ to the overall South African economic activity are the highest across all nine provinces. Gauteng's contribution to the South African output in manufacturing, construction, and finance amounted (in 2011) to 40.5\%, 43.3\%, and 41.1\%, respectively. A counterexample to Gauteng is the province Limpopo (with Polokwane as one of the World Cup venues), that recorded an average annual real growth rate of $3.2 \%$ in $2001-2011$ and $6.5 \%$ average contribution to the country's GDP. While the contribution of Limpopo to the South African manufacturing sector amounted to only $1.5 \%$, the province plays (with $23.7 \%$ ) a very important role in the mining and quarrying sector. As regards the socio-economic situation of the World Cup municipalities, some of them are large centers, like the City of Johannesburg Metropolitan Municipality or the City of Cape Town Metropolitan Municipality, both with around three million inhabitants and the average household income in 2001 of $\$ 12,317$. This is in contrast to smaller municipalities among the World Cup venues (population mostly less than 200,000), e.g., the Polokwane Local Municipality or the Mbombela Local Municipality, where the average household income in 2001 amounted to about $\$ 5,200 .^{6}$

It is important to note that we consider the treatment to begin in 2004, when the International Football Federation officially selected South Africa over Egypt and Morocco as the host country. After this date, a battery of preparations, like the construction and upgrade of new and existing stadiums, the renewal and extension of transport infrastructure, the con-

\footnotetext{
6 Socio-economic data for the City of Johannesburg Metropolitan Municipality, Polokwane Local Municipality, and Mbombela Local Municipality are taken from the Census 2011 Municipal Reports (download at: http://www.statssa.gov.za/?page_id=3955; last accessed on January 19, 2016). Data on provincial economic activity are retrieved from the document of Statistics South Africa available at: http: //www.statssa.gov.za/economic_growth/16\%20Regional\%20estimates.pdf; last accessed on January 19, 2016.
} 
struction of hotels, etc., began. ${ }^{7}$ Overall, the South African investments totaled about $\$ 14$ billion, of which $\$ 11.4$ billion were spent on transport and communication infrastructure. An example for a major investment in transport infrastructure is the construction of King Shaka International Airport in Durban that cost around $\$ 930$ million. The largest investment in sports infrastructure was the First National Bank Stadium (aka Soccer City) in Johannesburg, hosting the opening and final game, that underwent major refurbishments and upgrades (i.a., extension of capacity to 94,736 seats) for a total of $\$ 451.6$ million that were shared by the central government, the provincial government, and the municipality. ${ }^{8}$

\subsection{Data Set}

In the subsequent empirical analysis, we will consider municipalities and wards (electoral districts) as observational units. Panel (a) of Figure 1 shows all 234 South African municipalities including the nine venues of the 2010 World Cup colored in gray. Municipal borders are drawn according to a shapefile downloaded from the DIVA-GIS website. ${ }^{9}$ The map also comprises the country of Lesotho (the large white area in the middle-right of the map), a landlocked country considerably less developed than South Africa. Panel (b) of Figure 1 depicts all 4, 277 South African wards and the World Cup municipalities indicated by bold-type, light-blue borders.

The variable of interest in our analysis is economic development as proxied by the night light intensity (luminosity) of an observational area. We resort to luminosity since, in South Africa, GDP data are only available for the nine provinces but not for municipalities or wards. Furthermore, luminosity is widely used as proxy for economic development, especially in countries where GDP data are either not available or of bad quality (Henderson et al., 2012;

\footnotetext{
7 To the best of our knowledge, there were no significant investments related to the 2010 World Cup undertaken before 2004, e.g., during the bidding process. We test for this throughout our robustness checks in Appendix A and find our assumption to be confirmed.

${ }^{8}$ Capacity figures are taken from Chapter four of the FIFA World Stadium Index, available here: http: //www.playthegame.org/fileadmin/documents/world_stadium_index_4_fifa_wc.pdf, last accessed on February 5, 2016. Information on overall expenditures and costs regarding the two mentioned projects is provided in Appendix B.2.

${ }^{9}$ Downloadable at: http://biogeo.ucdavis.edu/data/diva/adm/ZAF_adm.zip, last accessed on January $19,2106$.
} 


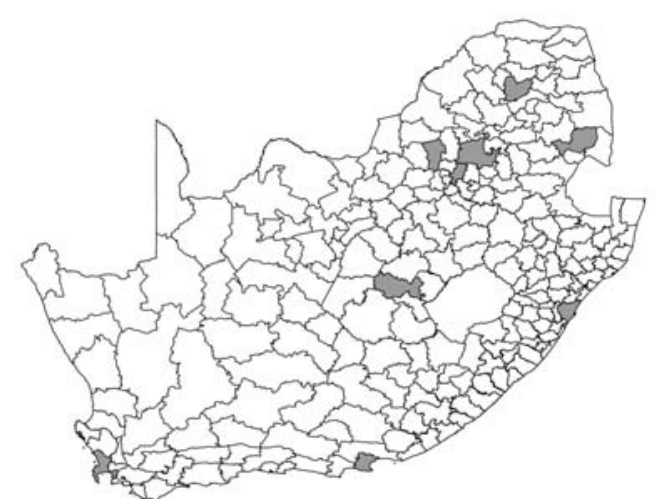

(a) South African Municipalities and World Cup Venues

Note: Panel (a) shows the municipalities of South Africa and the World Cup venues depicted in gray. Panel (b) shows the South African wards and the World Cup venues depicted in light-blue.

Figure 1: Municipalities, Wards, and World Cup Venues in South Africa Mveyange, 2015; Elliot et al., 2015; Wahl, 2016). It is found to be highly correlated with GDP per capita and other measures of prosperity, like electricity provision (Baskaran et al., 2015; Min et al., 2013), and can therefore be considered as a valid proxy (Chen and Nordhaus, 2011; Henderson et al., 2012). ${ }^{10}$ In the context of our study, night light luminosity is expected to correspond to, e.g., buildings of firms that settle next to newly founded infrastructure, construction activity done at night, private buildings in newly created settlements around the treatment areas, or the upgrade and refurbishment of existing buildings and industrial facilities. Such expectations are supported by the literature, according to which night lights are related with, among others, the expensiveness of roofing material (Jean et al., 2016) or the number and density of industrial facilities as well as wages in a grid cell (Mellander et al., 2015).

Night light intensity is measured by an integer ranging from 0 (unlit) to 63. The data are made available by the National Geophysical Data Center (NGDC) of the National Oceanic and Atmospheric Administration of the U.S., and originate from images taken by satellites of the

\footnotetext{
${ }^{10}$ Limitations of luminosity as a proxy for economic development are discussed, among others, in Kulkarni et al. (2011).
} 
Defense Meteorological Satellite Program (DMSP) of the U.S. Department of Defense. We use shapefiles containing the average visible, stable nighttime lights and cloud-free coverage, where ephemeral events (fires, etc.) as well as background noise are removed and only light from sites with persistent lightning is included. ${ }^{11}$ Night light intensity data are available on pixel (grid cell) level, with each pixel corresponding to 30x30 arc seconds, i.e., one value represents the average night light intensity of an area of 0.86 square kilometer (on the equator). Moreover, data are available for each of the 22 years between 1992 and 2013, leaving us with a panel data set of 5, 148 municipality-year pairs and 92, 884 ward-year pairs, respectively. ${ }^{12}$ Panel (a) of Figure 2 shows the spatial distribution of pixel level luminosity in South Africa in 2013. Municipal borders are colored in light-blue and the World Cup venues are depicted in boldtype red.

For our empirical analysis, luminosity data are aggregated from pixel level to the respective observational unit by averaging the pixel values in the area of each municipality/ward and assigning this value to the respective (whole) area. ${ }^{13}$ Panel (b) of Figure 2 shows the distribution of average luminosity across South African municipalities in 2013. The nine municipalities

\footnotetext{
${ }^{11}$ We use the latest version (4.0) of the data. It can be downloaded at: http://ngdc.noaa.gov/eog/dmsp/ downloadV4composites.html, last accessed on January 19, 2016. A common problem with these data is that the light of gas flares is included and could be mistaken for lights of settlements. However, in the area studied in this paper, no gas flares exist.

12 From all 4,277 wards, we are able to use 4, 222 of them in the empirical analysis as some wards are too small to calculate exact luminosity or elevation values. When using the luminosity series pooled over time, a potential issue is that a portion of the temporal variation in the data can be due to the fact that this data is collected by different satellites, which are not calibrated on a common level. To make luminosity values more comparable over satellites, the data can be inter-calibrated manually following, e.g., a procedure suggested by Elvidge et al. (2009). However, Chen and Nordhaus (2011) find that results only marginally change when using inter-calibrated luminosity. In line with this, after inter-calibrating our data set based on the values given by Elvidge et al. (2014), we find a correlation with the original data of 0.991. Consequently, for our empirical analysis, inter-calibration did not affect our results noticeably.

13 Alternatively, we could have drawn on luminosity per capita. However, population figures on municipality or ward level are only available for a very few years throughout our observation period, which would lead to distinctly reduced number of observations. The same problem occurs with alternative luminosity datathe so-called 'radiance calibrated at night data' (available at: http://ngdc.noaa.gov/eog/dmsp/download_ radcal.html, last accessed on January 19, 2016), that has been used by, e.g., Gonzalez-Navarro and Turner (2016). This data does not feature the cap at 63, but comprises seven cross sections, out of which only three correspond to the analyzed post-treatment time span 2004-2013 (2004, 2006, 2011). Furthermore, the literature sometimes uses the log of luminosity as dependent variable in OLS regressions (Henderson et al., 2012; Hodler and Raschky, 2014). Usually, this is done because the distribution of night lights is skewed with small values of luminosity being most frequent. However, for our SCM analysis to be valid, it is not necessary that the outcome of interest is normally distributed, so we follow Elliot et al. (2015) and Strobl and Valfort (2015) using untransformed levels of luminosity.
} 


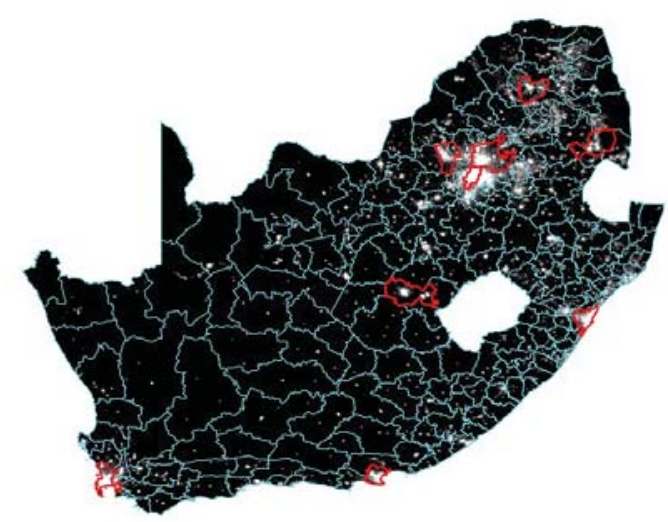

(a) Pixel Level Distribution of Luminosity

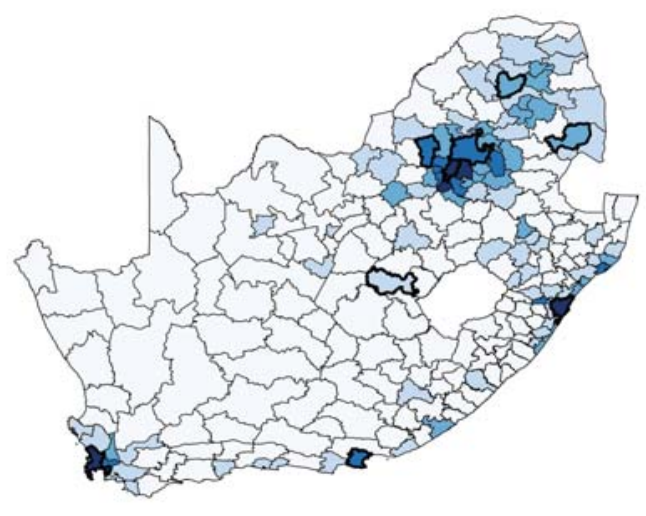

(b) Municipal Average of Luminosity

Note: Panel (a) shows pixel level luminosity with municipality borders (colored in light-blue) and World Cup venues (colored in bold-type red). Luminosity is depicted by colors ranging from black (unlit) to white (level 63). Panel (b) shows the average luminosity of a municipality and the World Cup venues depicted by bold-type borders. Average luminosity of a municipality is depicted by colors ranging from white to dark blue, where darker colors indicate higher luminosity.

Figure 2: Pixel and Average Municipality Level Distribution of Luminosity in 2013

hosting the 2010 World Cup are indicated by bold-type borders. Luminosity ranges from 0.01 in the Mier Local Municipality (Province North Cape), ${ }^{14}$ that is almost unsettled, to 57.3 in the Johannesburg Metropolitan Municipality. Luminosity is, in general, larger in coastal municipalities and in the north, where also the largest agglomerations and the most important economic centers of South Africa can be found. This supports its validity as an indicator of economic development.

\subsection{Descriptive Evidence}

A descriptive look at the temporal development of luminosity between 1992 and 2013 can provide us with some first suggestive evidence regarding the effect of the FIFA announcement on economic development across the nine hosting municipalities. If there is a positive effect of this treatment in 2004, or follow-up treatments thereafter, we should see an increase in luminosity somewhere between 2005 and 2010. Figure 3 depicts luminosity as a time series

\footnotetext{
14 Especially within the municipalities located in the western South African wastelands, there exist pixels which are zero throughout the entire sampling period. In one of the robustness checks in Appendix A, we follow Elliot et al. (2015) and remove such pixels prior to the aggregation on municipal level. Corresponding estimation results stay almost exactly identical to our baseline ones including the zero pixels.
} 


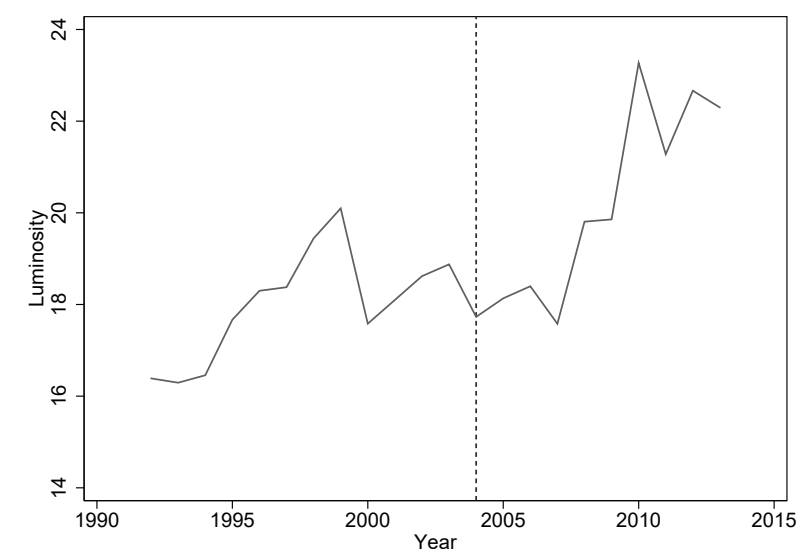

Note: The vertical dashed line represents the treatment cutoff in 2004.

Figure 3: Mean Luminosity in the World Cup Venues 1992-2013

for the average over all nine treatment municipalities throughout our observation period. The treatment cutoff in 2004 is marked by a dashed vertical line. While there is no clear trend in the development of luminosity prior to this year (level at around 18), after the cutoff, there emerges a strong increase lasting until 2010 when luminosity stabilizes at a distinctly higher level (at around 22). This suggests a boost of more than $20 \%$ compared with the last pre-treatment value. Hence, the time series pattern signals a substantial positive effect of the World Cup announcement - and/or measures thereafter - on economic development in the average hosting municipality. The temporal evolution of luminosity for each of the nine hosting municipalities (separately) is depicted in Figure C2.1 in Appendix C.2. While the overall pattern is similar, the size of the increase and the timing of its start is slightly different among the different venues.

\section{Empirical Approach}

For our inferential analysis, the advantage of being able to choose from many potential control units (e.g., as many as 225 at municipal level) comes at the difficulty of finding a systematic way to pick the most appropriate ones - or even the most appropriate combination of controls. 
Difference-in-Differences (DiD) approaches, seemingly suitable in a setting as ours, offer too much leeway in choosing the respective control unit, giving room for manipulation and questioning the external validity of corresponding results. Moreover, the common trend assumption needed for identification might be too restrictive in our context. Therefore, we employ an alternative identification strategy which, in contrast to DiD, still delivers reliable results when the common trend assumption is violated or when unobserved confounders vary with time: synthetic control methods (SCM). In Section 3.1, we will describe some theory related to the SCM approach, explaining how treatment effects can be derived in a general setting. Since policy makers are typically interested in more standard economic variables than luminosity, we want to make the interpretation of our prospective SCM results more straightforward. In Section 3.2, we will therefore show how to obtain suitable conversion factors, which can then serve to translate estimated SCM results of the World Cup expressed in luminosity into effects in terms of unemployment, GDP, and income.

\subsection{Synthetic Control Methods}

SCM, an approach introduced in Abadie and Gardeazabal (2003) and Abadie et al. (2010), is based on the idea that an optimally weighted average of available control units (comprising the so-called donor pool) is able to reproduce the trajectory of the outcome of interest of the treated unit in absence of the treatment. The treatment effect can then be calculated by taking the difference between the actual outcome of the treated unit in the post-intervention period(s) and the respective outcome of the so-called synthetic unit, i.e., the counterfactual built from the donor pool. Using an appropriate set of economic predictors and pre-treatment outcomes, SCM select the synthetic unit as the optimally weighted average of such comparison units that best resemble the characteristics of the respective treated one prior to the intervention. This yields unbiased identification of the causal effect of interest, even if treatment assignment is based on unobservable factors whose effects vary over time.

More formally, suppose that there exist $J+1$ units, indexed by $i$, and $T$ time periods, 
denoted by $t$. The univariate outcome of interest $Y_{i t}$ is observed for all units $i \in\{1, \ldots, J+1\}$ in all time periods $t \in\{1, \ldots, T\}$, and the treatment takes place in period $T_{0}$ such that the data can be divided into a pre-treatment period with $t<T_{0}$, and a post-treatment period with $t \geq T_{0}$. For simplicity, assume that only the first unit $i=1$ is treated. Following the potential outcome framework, we are interested in estimating a series of treatment effects on the treated, given as $\tau_{1 t}=Y_{1 t}-Y_{1 t}(0)$ for $t \geq T_{0}$, with $Y_{1 t}$ being the actual outcome of the treated unit at time $t$, and $Y_{1 t}(0)$ being the hypothetical outcome for the treated unit at time $t$ in absence of the treatment. It is now assumed that the potential outcome in absence of the treatment is given by:

$$
Y_{i t}(0)=\theta_{t} Z_{i}+\eta_{i t} \quad \text { with } \quad \eta_{i t}=\delta_{t}+\lambda_{t} \mu_{i}+\epsilon_{i t},
$$

where $Z_{i}$ is a $(r \times 1)$ vector consisting of $r$ observable characteristics with predictive power for the outcome of interest. $\theta_{t}$ illustrates that these outcome-relevant characteristics are not restricted to being time-constant. ${ }^{15}$ The error term $\eta_{i t}$ is decomposed into an unknown periodspecific factor $\delta_{t}$ common to all units, an $(F \times 1)$ vector of unobservable unit-specific factors $\mu_{i}$, whose effect may vary over time, and a unit- and time-specific transitory shock $\epsilon_{i t}$ with $\mathbb{E}\left(\epsilon_{i t}\right)=0$, being independently and identically distributed across units. ${ }^{16}$ Under standard assumptions and with a sufficient number of pre-intervention periods (Abadie et al., 2010), the estimator for the treatment effects is given as:

$$
\hat{\tau}_{1 t}^{*}=Y_{1 t}-\sum_{i=2}^{J+1} w_{i}^{*} Y_{i t} \quad \text { for } \quad t \geq T_{0}
$$

if there exists a weighting vector $W^{*}=\left(w_{2}^{*}, \ldots, w_{J+1}^{*}\right)^{\prime}$, with $w_{i}^{*} \geq 0$ and $w_{2}^{*}+\ldots+w_{J+1}^{*}=1$, such that the observable and unobservable characteristics of the treated unit can be reconstructed

\footnotetext{
${ }^{15}$ However, if these characteristics vary over time, the usual proceeding in the literature is to build averages over time. Contrarily, Klößner and Pfeifer (2015) develop an extended SCM approach allowing to incorporate whole time series of such characteristics.

${ }^{16}$ Note that $\lambda_{t} \mu_{i}$ can also be interpreted as relaxing the common trend assumption and, moreover, if $\lambda_{t}$ (a $(1 \times F)$ vector of unknown common factors) is constant over time, the model collapses to a DiD approach.
} 
by a weighted average of the controls. As $\mu_{i}$ is a vector of unobserved factors, the idea of SCM is to match on pre-intervention outcomes in addition to the observables $Z_{i}$.

For the implementation of the SCM estimator, define a $(k \times 1)$ column vector $X_{1}=$ $\left(Z_{1}^{\prime}, \bar{Y}_{1}^{L_{1}}, \ldots, \bar{Y}_{1}^{L_{M}}\right)^{\prime}$ containing the (average) values of the observable characteristics as well as $M$ linear combinations of the pre-intervention outcomes for the treated unit. Each of these $M$ linear combinations corresponds to a $\left(\left(T_{0}-1\right) \times 1\right)$ vector $L=\left(l_{1}, l_{2}, \ldots, l_{T_{0}-1}\right)^{\prime}$ with $\bar{Y}_{1}^{L}=\sum_{t=1}^{T_{0}-1} l_{t} Y_{1 t}$. Analogously, define the $(k \times J)$ matrix $X_{0}$ to be the counterpart of $X_{1}$ for the unexposed units. The standard SCM method chooses $W$ to minimize $\sqrt{\left(X_{1}-X_{0} W\right)^{\prime} V\left(X_{1}-X_{0} W\right)}$, with $V$ being a positive semi-definite diagonal $(k \times k)$ matrix, whose elements are the weights reflecting their relative predictive power. The most common approach to determine $V$ is a data-driven procedure proposed by Abadie and Gardeazabal (2003) and Abadie et al. (2010): it chooses $V$ among all positive definite and diagonal matrices such that the root mean squared prediction error (RMSPE) of the outcome variable is minimized over the pre-intervention periods. ${ }^{17}$

Thus, the main task of SCM is to find non-negative control unit weights $W$, summing up to unity, for given predictor weights $V$ such that:

$$
\min _{W} \sqrt{\left(X_{1}-X_{0} W\right)^{\prime} V\left(X_{1}-X_{0} W\right)}
$$

while we denote the solution to this problem by $W^{*}(V)$.

\subsection{Converting Night Lights into Standard Economic Outcomes}

When translating our prospective SCM effects expressed in luminosity into those expressed in terms of standard economic outcomes, we resort to three such variables: the unemployment

\footnotetext{
17 When analyzing the new cross-validation method proposed by Abadie et al. (2015), which is supposed to determine predictor weights $V$, Klößner et al. (2016) show that this method is flawed since it hinges on predictor weights which are not uniquely defined and, consequently, might lead to ambiguous estimation results. This is why, in the following, we abstain from using cross-validation techniques and stick to the 'standard' SCM framework.
} 
rate, GDP per capita, and income per capita. ${ }^{18}$ For each of these three measures, we obtain a corresponding conversion factor by estimating an OLS regression using the respective outcome as the dependent variable and luminosity as the regressor of interest. If applicable, we include district/municipality and year fixed effects as well as several controls (area, distance to railway, elevation, soil quality).

First, we estimate the following regression equation for the conversion of night light effects into unemployment:

$$
U N_{i j k, t}=\alpha+\beta N L_{i j k, t}+\theta_{k}+\lambda_{t}+\epsilon_{i j k, t}
$$

where $U N_{i j k, t}$ and $N L_{i j k, t}$ are the unemployment rate and night light luminosity, respectively, in province $i$, district $j$, municipality $k$, and year $t$. $\theta_{k}$ denotes municipality fixed effects, whereas $\lambda_{t}$ describes year fixed effects introduced to account for the business cycle, and $\epsilon_{i j k, t}$ is the error term. The coefficient of the luminosity measure $\beta$ is the conversion factor.

Second, as GDP per capita is only available on province level, the respective conversion factor is computed based on the estimation of a modified specification. Here, GDP per capita and luminosity vary on province level, while the control variables are still given on municipality level:

$$
G D P_{i, t}=\alpha+\beta N L_{i, t}+\gamma^{\prime} X_{i j k}+\lambda_{t}+\epsilon_{i j k, t}
$$

where $G D P_{i, t}$ and $N L_{i, t}$ are GDP per capita and luminosity, respectively, in province $i$ in year t. $X_{i j k}$ denotes the controls in province $i$, district $j$, and municipality $k . \lambda_{t}$ and $\epsilon_{i j k, t}$ are as in Equation (4).

Finally, income per capita is available on municipality level, but solely for the year 2007 . Consequently, we cannot include year or municipality fixed effects when estimating the conversion factor from luminosity to income per capita. Formally, we thus estimate the following equation:

$$
I N C_{i j k, t}=\alpha+\beta N L_{i j k, t}+\gamma^{\prime} X_{i j k}+\theta_{j}+\epsilon_{i j k, t},
$$

\footnotetext{
18 Sources and exact definitions of all variables are available in Appendix B.1. A descriptive overview of the data is provided in Table C1.1.
} 
Table 1: Relationship between Night Lights and Economic Outcomes ${ }^{\text {a) }}$

\begin{tabular}{lccc}
\hline \multirow{2}{*}{$\begin{array}{l}\text { Characteristics/ } \\
\text { Regressors }\end{array}$} & $(1)$ & $(2)$ & $(3)$ \\
\cline { 2 - 4 } & Unemployment Rate & GDP per capita & Income per capita \\
\hline Level of Variation & Municipality & Province & Municipality \\
Years in Sample & $1996,2001,2007,2011$ & $1996,2001,2007$ & 2007 \\
\hline Luminosity & $-0.723^{* *}$ & $1,400.699^{* * *}$ & $911.555^{* * *}$ \\
Conversion Factor ${ }^{\mathbf{b})}$ & $(0.282)$ & $(38.543)$ & $(270.819)$ \\
\hline District Dummies & $-\mathbf{0 . 7 2 3}$ & $\mathbf{1 9 1 . 6 9 0}$ & $\mathbf{1 2 4 . 7 4 9}$ \\
Municipality Dummies & No & No & Yes \\
Year Dummies & Yes & No & No \\
Controls & Yes & Yes & No \\
Observations & No & Yes & Yes \\
$R^{2}$ & 936 & 702 & 234 \\
\hline
\end{tabular}

a) Robust standard errors are reported in parentheses. Coefficient is statistically different from zero at the $* * * 1 \%, * * 5 \%$, and ${ }^{*} 10 \%$ level. Unit of observations in all three columns is a municipality. However, the dependent variable and luminosity do only vary on provincial level in Column (2). The set of controls includes a municipality's area in square kilometers, its distance to the closest railway, its elevation, and soil quality. Each regression includes a constant not reported.

b) Conversion factors related to GDP per capita and income per capita are obtained by translating the corresponding luminosity effects expressed in the national currency 'Rand' into U.S. dollars (\$) using the average exchange rate of 2010.

where $I N C_{i j k, t}$ is income per capita in province $i$, district $j$, municipality $k$, and year $t$, $N L_{i j k, t}$ denotes the corresponding night lights, and $\theta_{j}$ are district fixed effects. The remainder is analogous to Equations (4) and (5).

The results of the OLS estimations are summarized in Table 1. Column (1) provides the estimates of Equation (4): we find a statistically significant conversion factor of -0.723 , implying that a one unit increase in luminosity translates into a reduction in the unemployment rate of 0.723 percentage points. Column (2), corresponding to Equation (5), yields a conversion factor of around 1,401, meaning that a one unit increase in luminosity increases the provincial GDP per capita by around 1,401 Rand (\$192). As the average provincial GDP per capita is $\$ 3,680$ and its standard deviation is $\$ 1,345$, an increase by $\$ 192$ seems to be a reasonable quantity. If we alternatively regress logarithmized GDP per capita on logarithmized luminosity, we end up with an estimated elasticity of around 0.21 , what is broadly in line with-but at the lower end of - elasticities found by other studies (Henderson et al., 2012; Lessmann and 
Seidel, 2015). ${ }^{19}$ Finally, in Column (3), we estimate Equation (6), resulting in a conversion factor of 911.555. Hence, a one unit increase in luminosity is equivalent to an increase in per capita income of around 912 Rand (\$125).

\section{Estimation Results and Effect Heterogeneity}

A major aspect and prerequisite with respect to our study is the identification of municipalities and wards treated by the measures designated for the World Cup. To do this in a systematic way, we have first detected all projects potentially relevant for our analysis, i.e., those projects which were conducted in South Africa during the period from 2004 (our treatment start) until 2013 (when our sample ends). In so doing, we have considered four different project types: construction and upgrade of (i) railway, metro, and bus stations, (ii) airports, (iii) stadiums (main World Cup stadiums and training stadiums), and (iv) water infrastructure (e.g., dams or pipelines). We have collected a list of such projects, including (when available) information on their location, construction period, and costs. Overall, we have identified 127 different infrastructure projects. Since, in the subsequent empirical analysis, we will focus on World Cup related projects only, this leaves us with 72 projects in overall 16 municipalities. ${ }^{20}$ Out of those 72 projects, 61 took place in nine World Cup venues and 11 in seven non-World Cup venues. Throughout our baseline analysis that assumes World Cup venues as the only treated municipalities, we will therefore consider 61 projects as treatments. ${ }^{21}$

In the first step of this analysis (Section 4.1), we will look at the average luminosity of World Cup venues at municipality level. To be more specific, we will pool luminosity for all

\footnotetext{
19 If we follow Pinkovskiy and Sala-i-Martin (2016) and estimate the elasticities of luminosity with respect to GDP per capita instead, we arrive at an elasticity of around $1(1.17)$, which is roughly what they find in their baseline estimates.

${ }^{20}$ A list reporting these 72 projects, information on them, as well as the sources of the information, is available in Appendix B.2. The full list including 127 projects can be downloaded at: http://www . martynamarczak . com/research/SA_AllProjects.pdf.

${ }^{21}$ Note that in one of the robustness checks in Appendix A, we extend the treated units by the seven nonWorld Cup venues affected by World Cup investments, and thus include all 72 projects in the set of treatments. The remaining 55 projects from the whole set of 127 projects were not World Cup related, or we are not able to gather enough information to be sure that they are directly related to the World Cup, to locate them, or they were not even partly finished.
} 
World Cup municipalities using the arithmetic mean and then conduct a single-case study applying SCM, which will result in a treatment effect given in the average World Cup venue's luminosity. ${ }^{22}$ Additionally, we have to exclude potential spillovers from treated regions to nontreated ones as these would invalidate the identifying assumptions of SCM. We do this, as is standard in the regional policy evaluation literature (Alder et al., 2016; Aragon and Rud, 2015; Becker et al., 2010; Dettmann et al., 2016), by considering spillovers to be a function of proximity to the treated locations and, hence, exclude regions neighboring World Cup venues (and Lesotho) from the donor pool. Under the hypothesis of no indirect effects on non-treated regions, using a donor pool stemming from the same country as the treated unit does should be a first best solution, since this offers better comparability than a donor pool from any another country. ${ }^{23}$ However, this also implies that we are not after quantifying or explicitly modeling spillover effects, which would also require a different identification approach. Contrarily, we are solely interested in the direct effects of the World Cup and its related infrastructure projects.

In a second step (Section 4.2), we will zoom in on several treated wards within a particular treated municipality, which, e.g., harbor a stadium or an airport, and for which we expect heterogeneous effects depending on the type of infrastructure as well as the size and location of the respective city. Using information on 72 treatments, we are able to localize 102 wards that are affected by World Cup measures. 85 of these wards are located within a World Cup venue and 17 within a non-World cup venue. ${ }^{24}$ Throughout these SCM analyses, we will consider

\footnotetext{
${ }^{22}$ An alternative approach would be to conduct a respective SCM study for each of the treated units and subsequently pool over the individual treatment effects as it is done in, e.g., Acemoglu et al. (2015) or Dube and Zipperer (2015). In their pooling procedure, Acemoglu et al. (2015) re-weight the individual treatment effects based on the goodness of the pre-treatment fit for the corresponding treated unit. Dube and Zipperer (2015) pool over multiple case studies using the mean percentile rank.

23 However, we also conduct the municipality level SCM analysis using alternative donor pools from two other countries, respectively: Mozambique, a neighboring country of South Africa, and Morocco, a country in Northern Africa that also applied for hosting the 2010 World Cup. Detailed information on these countries, the composition of the corresponding synthetic unit, as well as the obtained results and their discussion are presented in Appendix A.2. For both alternative donor countries, we find a positive, albeit insignificant treatment effect, presumably stemming from the fact that the synthetic unit does not sufficiently represent the case of the average World Cup venue in South Africa.

${ }^{24}$ Especially in the Gauteng province, some wards have more than one treatment so that the number of treatment wards is not identical to the number of treatments identified. The location of the treatments is assigned according to the coordinates given by wikipedia, http://www.geonames.org, google maps, and the website http://www. mbendi.com (for railway and metro stations); last accessed on January 19, 2016.
} 
treated wards in a given treated municipality separately. This is in contrast to our study at municipality level, where the subject of the analysis is the average effect over all World Cup venues. Analogous to the study at municipality level, however, we will exclude neighbors of the respective treatment ward and all other treatment wards including their neighbors within the same municipality (to ensure that there are no spillovers). ${ }^{25}$ Finally, regarding the conversion of our SCM estimates, we have to note that the three outcomes of interest (as reported in Table 1) are not available on ward level. This makes a respective conversion in Section 4.2 somewhat less precise since the underlying conversion factor stems from municipality level data.

\subsection{The Average World Cup Venue}

As we have 234 municipalities in South Africa, out of which there are nine 'treated' ones, the potential donor pool $J$ consists of 225 non-treated municipalities. However, to avoid the problem of potential spillovers that could result from the proximity to the treatment, we will exclude from the donor pool all municipalities directly neighboring a respective treated one (45) or bordering Lesotho (14). Additionally, we will exclude those seven municipalities with World Cup related infrastructure projects (airports and training stadiums) that were no World Cup venues (like Buffalo City Metropolitan Municipality or George Local Municipality) and their respective neighbors (28). ${ }^{26}$ This leaves us with a donor pool consisting of 131 control units. Moreover, throughout our analysis, we will use pre-treatment averages of the following economic predictors: area of municipality in square kilometer, distance to next railway in kilometer, average elevation of municipality above sea level in meters, 2001 share of people

\footnotetext{
25 Overall, there are 336 such neighboring wards, whose quantity varies across municipalities.

26 This should yield a compromise to the 'dilemma' discussed in Gobillon and Magnac (2016): on the one hand, choosing areas in the neighborhood of treated areas as controls might be problematic due to spillovers or contamination effects; on the other hand, non-neighbors might be located too far away from the treated areas to be good matches and therefore good controls. Note, however, that we relax such exclusion rules throughout our sensitivity checks reported in Appendix A. Also note that there is a significant amount of overlap between municipalities neighboring a World Cup venue and another municipality with World Cup measures. In above figures, those are allocated to the neighbors of the World Cup venues. Municipalities neighboring both Lesotho and one of the municipalities with World Cup related investments (either a World Cup venue or another affected municipality) are counted as neighboring Lesotho.
} 
with indigenous heritage per municipality, 2001 share of people with tertiary education per municipality, average municipality's soil quality, and the 2001 percentage of people unemployed in municipality. ${ }^{27}$ Those variables are chosen because they were identified as robust predictors of luminosity and regional development by previous studies (Gennaioli et al., 2013, 2014; Henderson et al., 2016) and because they reflect the particular determinants of agglomeration and development in South Africa. ${ }^{28}$

\section{Synthetic Unit}

Our municipality level SCM analysis finds a combination of non-treated units that sufficiently replicates the luminosity evolution of the average World Cup venue before the official FIFA announcement in 2004 - the corresponding RMSPE is 0.877 . To be more specific, the average World Cup venue is synthesized by the following municipalities: Msunduzi, uMhlathuze, and Govan Mbeki, which are attributed $w$-weights of about 3.5\%, 80.8\%, and $15.7 \%$, respectively. ${ }^{29}$ Before discussing our SCM results based on the graphical representation depicted in Figure 4, we have a more detailed look at the three weighted municipalities in order to show that their combination provides a plausible counterfactual for the average World Cup venue.

The uMhlathuze Local Municipality, that obtains by far the greatest weight in the synthetic unit, is the third largest municipality in the province KwaZulu-Natal. Its strategic location at the harbor and in the proximity of Durban, the largest deep-water port in South Africa as well as an industrial development zone, make uMhlathuze an important economic center with

27 A more detailed description of these variables can be found in Appendix B.1 (and Appendix C.1, Table C1.1). The predictors are elements of vector $Z_{1}$, that constitutes one part of vector $X_{1}$, both introduced in Section 3.1. Another part of vector $X_{1}$, the linear combination $\bar{Y}_{1}^{L}$, is represented in this paper by one value only - the last pre-treatment luminosity value. For a discussion on the use of pre-treatment outcomes in the SCM context, see Kaul et al. (2015), who show that the weights for the (other) observable characteristics will be zero if all pre-intervention outcome periods are included as separate economic predictors.

28 As a robustness check, we also include a municipality's population density (of the year 1996) as covariate (see Appendix A.1.1), as the relationship between luminosity and development could be considered being more plausible when the effect of population density is controlled for. However, corresponding results do not change.

29 This optimization result is attained by utilizing a valid combination of $v$-weights, with all predictors receiving positive values. The pre-treatment predictor balance is provided in Appendix C.1, Table C1.2. Therein, actual numbers of the treated unit's pre-treatment characteristics are compared with those of the synthetic one. As Klößner et al. (2016) show, one should be careful with interpreting such $v$-weights with respect to 'importance' since they are not uniquely defined. 
the largest city_Richards Bay-being an industrial and tourism hub. The main economic sectors are: manufacturing (45.9\%); mining and quarrying (11.6\%); financial, real estate, and business services (10.7\%); community, social, and personal services (10.4\%); as well as transport and communication (9.1\%). ${ }^{30}$ With its strong performance in the manufacturing sector, uMhlathuze resembles the most developed World Cup venues, like Johannesburg, Cape Town, and Durban. The average household income (2001) was about $\$ 8,316$, which is comparable with the eThekwini Metropolitan Municipality and Nelson Mandela Bay Metropolitan Municipality with Durban and Port Elizabeth as World Cup venues, respectively. ${ }^{31}$ For the sake of completeness, it has to be noted that during the treatment period, the uMhlathuze Local Municipality experienced an upgrade of the Coal Terminal in the deep-water port in Richards Bay (see Table B2.1 in Appendix B.2). Even though this investment has been unrelated to the World Cup, it could still pose a problem since control units should ideally be free of large influences. To address this potential issue, in Appendix A, we perform a robustness check in which we eliminate uMhlathuze from the donor pool, showing that our results still hold.

The municipality with the second largest weight — the Govan Mbeki Local Municipalitylies in the province Mpumalanga. As regards the sectoral composition, the most important role play agriculture (20.2\% contribution to the local output), manufacturing $(12.4 \%)$, and mining (9.2\%). The main sectors generating jobs are mining and manufacturing. ${ }^{32}$ Particularly with respect to mining, Govan Mbeki shows similarities with World Cup venues located in provinces that are also concentrated on activities in this sector (Polokwane, Rustenburg, and Nelspruit).

The Msunduzi Local Municipality - the third municipality contributing to the synthetic unit-lies in the district uMgungundlovu of the province KwaZulu-Natal. The largest city of Msunduzi is Pietermaritzburg, which is the capital of KwaZulu-Natal and the main economic

\footnotetext{
30 See http://www.localgovernment.co.za/locals/view/110/City-of-uMhlathuze-LocalMunicipality\#economic-development; last accessed on January 19, 2016.

31 For data on household income, see the Census 2011 Municipal Reports, available at: http://www. statssa.gov.za/?page_id=3955; last accessed on January 19, 2016.

32 Data is taken from the Water Development Plan 2010-2014 of the Govan Mbeki Local Municipality, downloadable at: http://gsibande.com/index.php?option=com_docman\&task=doc_download\&gid=32\&Itemid= 65; last accessed on January 19, 2016.
} 
hub of the district. Msunduzi benefits from good transport infrastructure in an 'advantageous' location as it is situated on the N3 highway at the intersection of an industrial corridor from Durban to Pietermaritzburg, and an agro-industrial corridor from Pietermaritzburg to Estcourt. Its most important economic sectors are community services (29\%) and finance (24\%). ${ }^{33}$ From this point of view, Msunduzi is similar to two World Cup municipalities: the City of Tshwane Metropolitan Municipality (Pretoria) and the Mangaung Metropolitan Municipality (Bloemfontein).

Taken together, we could see that the three weighted, non-treated units comprise a good mix of characteristics specific to different World Cup venues, which, as has been emphasized in Section 2.1, are themselves heterogenous with respect to several aspects of economic performance.

\section{Effects and Significance}

Panel (a) of Figure 4 displays the evolution of luminosity of the average South African World Cup venue and its synthetic counterfactual for the 22 years from 1992 until 2013. The vertical dashed line corresponds to the last pre-treatment year (2003). The synthetic unit adequately reproduces actual luminosity during the pre-treatment period and the fit improves towards the cutoff. ${ }^{34}$ From the beginning of the treatment on, actual luminosity rises to a level distinctly above its synthetic equivalent. The overall pattern of both paths is very similar, so that it appears as if the treated timeline is shifted upwards relatively to the untreated one. However, after 2009, this gap closes and, from there on, both series move closely together until the end of our observation period. During the six years for which we observe a big difference in luminosity, this gap ranges between 1.3 and 2.2 with an average of 1.75 . This implies that the average gap relative to the last actual pre-treatment luminosity level is about $9 \%$. The gap of 1.75 is also equivalent to a decrease in the unemployment rate by 1.3 percentage points, an

\footnotetext{
33 See http://www.localgovernment.co.za/locals/view/88/Msunduzi-Local-Municipality; last accessed on January 19, 2016.

34 The pre-treatment fit could be improved even more by using additional pre-treatment values of the dependent variable as economic predictors. Again, for reasons explained in Kaul et al. (2015), we restrain from such practices.
} 


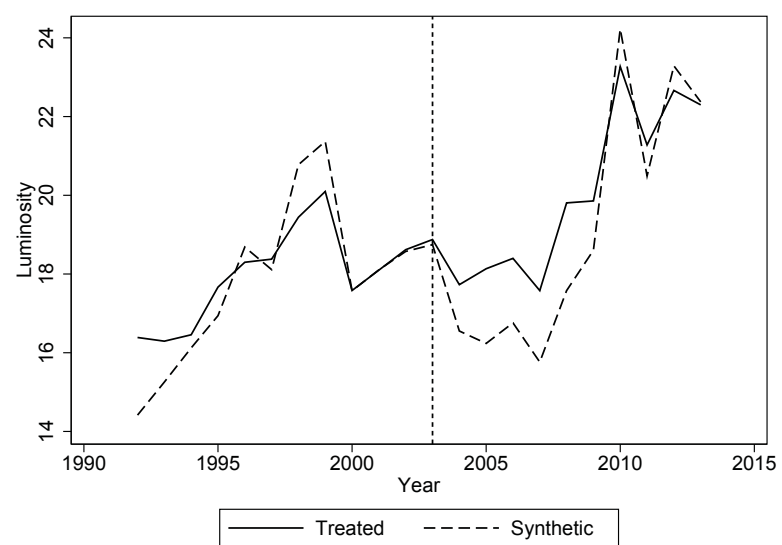

(a) Trends in Luminosity: Treated vs. Synthetic

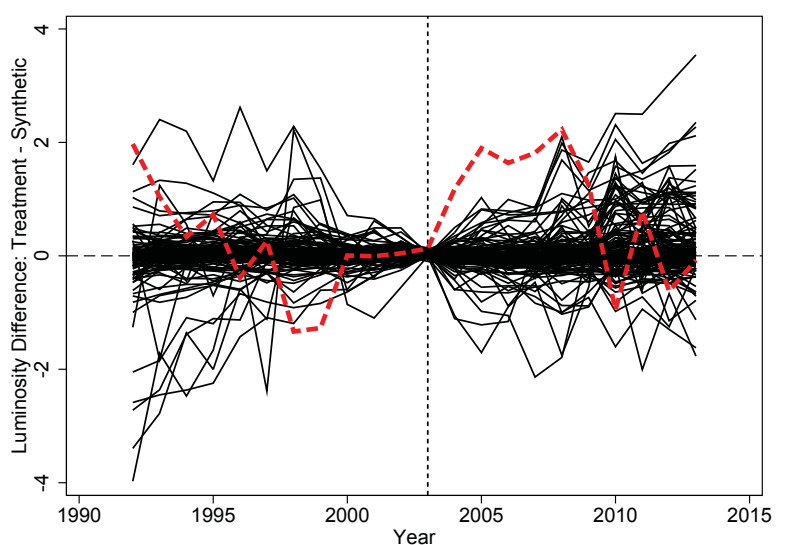

(b) Luminosity Gaps: World Cup Venue vs. Placebos

Note: The vertical dashed line indicates the end of the pre-treatment period (2003). Panel (a) displays the average World Cup venue and its synthetic counterpart. Panel (b) plots luminosity gaps (treatment minus synthetic) for the average World Cup venue and placebo units: the black solid lines and the red dashed line represent the placebos and the treated unit, respectively.

Figure 4: Estimation Results for the Average World Cup Venue: Benchmark Case

increase in GDP per capita by around $\$ 335$, and an increase in income per capita by around \$218. While these effects are sizable, we should also consider the large costs associated with the treatment to derive the net benefits of the World Cup. To do so, we follow Becker et al. (2010) and conduct a back-of-the-envelope style cost-benefit analysis: for the average World Cup venue, we find the net effect to be around $\$ 391.41$ million additional GDP per year (or $\$ 217$ GDP per capita); if we do the same calculation for the total net effect for the nine World Cup venues (or by simply multiplying the average effect by nine), we arrive at an additionally generated GDP of $\$ 3.5$ billion per year. ${ }^{35}$ Hence, even when taking into account the enormous costs of the treatment, we still find economically substantial, positive net effects for the World Cup venues.

Those numbers appear to be impressive, but nevertheless we want to test the significance of our estimates. For that purpose, we conduct a so-called placebo study, which is standard

\footnotetext{
35 The average net effect per year is calculated as follows: the SCM estimate of $\$ 335$ is multiplied by the number of inhabitants of the average World Cup venue in 2007 (1.8 million) what is then multiplied by six (the number of years with a significant treatment effect; for the significance analysis, see the following paragraph). From this figure, the average World Cup venue's expenditures are subtracted (around $\$ 1.27$ billion) and the resulting number is eventually divided by six to yield the net effect per year. We also conduct analogous calculations for the case where we consider all 'treated' municipalities and not only those which are directly related to World Cup investments: here we find a total net effect of $\$ 4.7$ billion of additional GDP per year. Corresponding SCM findings are discussed throughout the robustness checks in Appendix A.
} 
in the SCM context: for each of the comparison units from the donor pool, we compute the respective placebo treatment effect, i.e., the difference (gap) between the corresponding actual and synthetic outcome. This yields $J$ estimated placebo treatment effects, which are then compared with the gap between the actual and synthetic path for the treated unit. ${ }^{36}$ Panel (b) of Figure 4 shows the result of this placebo exercise, where the estimates corresponding to the donor units are represented by black solid lines and the estimate corresponding to the treated unit is given by the red dashed line. ${ }^{37}$ The World Cup venues' pre-treatment error is completely covered by a band consisting of 131 placebo municipalities' pre-treatment gaps. After the cutoff, though, the treatment's impact on luminosity clearly stands out of the bulk of control units, featuring an evidently significant treatment effect. This effect is remarkable not only because it simply stands out of the mass of placebo outcomes but, above all, how it is shaped. There is a steep rise in luminosity, which then flattens for a while before it even increases a little further. This movement — at least until the years 2009/2010 - is notably different from some slowly increasing or decreasing trends within the control pool. In fact, most of the control units just move slightly below the zero-line. Hence, our confidence that the World Cup venues' sizable synthetic control estimate actually reflects the effect of the World Cup preparatory measures is strengthened. No similar or larger estimates arose for around six years after the cutoff when the treatment was artificially re-assigned to units not directly exposed to the intervention. More specifically, under the null hypothesis of no differences in luminosity, we can expect (such) an effect to appear in only 1/131 of all cases, featuring an extremely small pseudo p-value. Overall, the results imply a pronounced but short-lived, positive effect of the World Cup on economic development in the hosting municipalities, that begins to be visible from the official allocation of the tournament to South Africa in 2004 until the actual

\footnotetext{
36 This placebo exercise is also called 'placebos-in-space'. Alternatively, one can conduct 'placebos-in-time', where the unit of interest remains the treated one, but the cutoff is artificially assigned to periods where no treatment took place, i.e., to several pre-treatment years. We will discuss such exercises when testing for robustness in Appendix A.

37 Note that, throughout the paper, we exclude placebo units due to inadequately large pre-treatment errors of more than three times the error of the unit of interest (altering this RMSPE-threshold does not affect our findings). This is important because placebo studies of this type do not consider that the units in the donor pool may not have an adequate synthetic control group. A large placebo treatment effect is meaningless if the fit in the pre-intervention period between the respective unit and its synthetic control is insufficient.
} 
event took place in 2010.

\section{Discussion}

Despite the useful insights from the estimation based on the average World Cup venue, this aggregate perspective could mask differences across (World Cup related) investments conducted in different World Cup locations with respect to several dimensions. By looking at individual projects, it immediately becomes clear that the respective interventions differ with regard to their monetary costs and the resulting qualitative improvements (e.g., sometimes a stadium or airport was constructed completely from scratch, while sometimes there were only minor upgrades of existing ones), what might lead to different impacts. Interventions also differ with

respect to the kind of infrastructure they are aiming at. The construction and upgrade of sports arenas, for instance, might have short-run, positive effects on local economic development as the construction activities lower unemployment. However, whether the construction of a respective football stadium - which is often not re-used regularly after the event-has a longer-lasting effect at all is not a priori clear. Yet, for projects targeting transportation infrastructure, this can be expected to be quite different.

Moreover, heterogenous effects obscured in the average result may also stem from the fact that World Cup venues themselves differ from each other. For instance, the Johannesburg Metropolitan Municipality, that hosted the opening and the final game, is the largest agglomeration in southern Africa and the most vibrant economic center of the whole continent. Nelspruit, a city that hosted four group stage games, contrarily, only has around 60,000 inhabitants and its economy is mainly characterized by agricultural production and tourism (as it is close to the famous Kruger National Park). For such small and relatively remote municipalities, the effect of infrastructure investments could be much larger than for Johannesburg, Pretoria, or Cape Town. These latter (large) cities are the political and economic centers of South Africa and, hence, should already comprise a comparatively good infrastructure. Thus, the 2010 World Cup can be expected to have fostered regional catch-up by allowing peripheral 
regions to gain upon the core regions.

Consequently, to draw a more precise picture of the potentially heterogeneous treatments connected to the World Cup and their corresponding effects, we zoom in on respective venues and consider different wards within the municipalities as observational units. The focus on a more disaggregated observational level allows for pinpointing the exact location of different treatments within a particular municipality and, thus, for separate identification of their effects. Moreover, exploiting the within-treatment-municipality variation can also reduce unobserved heterogeneity that could arise from-among other things - unobserved shocks that hit treatment and control municipalities differently.

\subsection{Zooming in on World Cup Venues}

In this section, we focus on the effect of infrastructure improvements on the development of a treated ward within a respective World Cup municipality. We run separate SCM analyses for each of such treatments in a given World Cup venue. In so doing, we use the same set of economic predictors as outlined above, except for the share of people with indigenous heritage, the share of people with tertiary education, and the percentage of people unemployed, since these variables are not available on ward level. In all cases, we employ the treatment cutoff in 2004, which is the same as at municipality level. This is done for the sake of consistency and comparability, and because for some treatments we were not able to pin down the exact period of occurrence. In what follows, we will present and discuss several of these cases, representing different kinds of investments, scales, and locations. ${ }^{38}$

\section{Durban}

The first case is the construction of the King Shaka International Airport in Durban, that took place between August 2007 and May 2010 and cost $\$ 930.6$ million. It was built 35km away from Durban City in the suburb La Mercy, one of the wards in the eThekwini Metropolitan

\footnotetext{
${ }^{38}$ A descriptive overview of the respective ward level data for each of the discussed municipalities is provided in Tables C1.3-C1.5 in Appendix C.1. Information on the individual projects can be found in Table B2.1.
} 


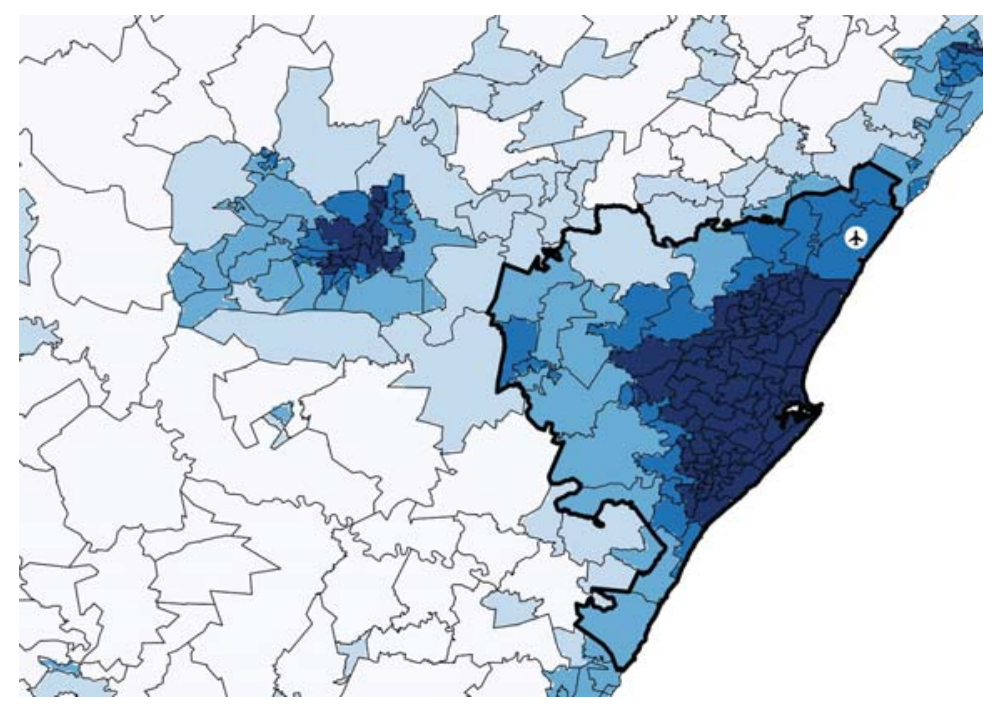

Note: The figure shows the borders of the eThekwini Metropolitan Municipality, its wards, as well as the location of the King Shaka International Airport. The 2013 average luminosity of a ward is indicated by colors ranging from white to dark blue, where darker colors indicate higher luminosity.

Figure 5: King Shaka International Airport within the eThekwini Metropolitan Municipality

Municipality, where luminosity more than doubled throughout the construction period (from 3.755 in 2007 to 7.93 in 2010). ${ }^{39}$ The borders of eThekwini, its wards, the location of the airport, and the luminosity level of each ward in 2013 are shown in Figure 5. ${ }^{40}$

SCM results in Panel (a) of Figure 6 illustrate that the pre-treatment fit is extremely precise. It is also evident that luminosity substantially rises from 2007 onwards, developing to a far higher level than its synthetic equivalent. At its peak in 2013, luminosity was around 20 units higher in the airport ward as compared with a scenario without the treatment, corresponding to 14.46 percentage points lower unemployment or $\$ 2,495$ more income per capita. Panel (b) shows the difference between the treated ward and its synthetic counterpart as well as respective placebo results, implying that the effect becomes and remains strongly significant throughout the three years after the tournament. This suggests a longer-lasting, positive impact of the airport investment on economic development in La Mercy-up to a

\footnotetext{
39 The eThekwini Metropolitan Municipality is divided into 103 wards. Among them are 14 with treatments and 43 wards surrounding them. Therefore, the donor pool for the SCM analysis consists of 46 wards.

40 A comparison between the luminosity pixel level distribution within eThekwini in the last pre-treatment year, 2003, and the last post-treatment year, 2013, is provided in Appendix C.2, Figure C2.2. The treatment effect becomes clearly visible as luminosity increased substantially in the treatment ward, also when contrasted against non-treated wards.
} 
factor of two.

The case of King Shaka International Airport exemplifies the argument that transport infrastructure can have such desired effects when conducted in a previously remote and peripheral area rather than in (or close to) an already developed and prosperous region. This argument can be supported by a counterexample - the Cape Town International Airport, South Africa's second largest airport, which is located within the urban area of Cape Town and was upgraded with investments worth around $\$ 273.7$ million. SCM analyses for the respective ward suggest no positive effect of this investment, but rather that luminosity was higher in the airport ward compared with its synthetic control already very long before the year 2004, namely since about 1995. ${ }^{41}$ More precisely, we do not detect a declining or increasing gap between actual and counterfactual luminosity, not even when looking at the period between 2007 and 2010, where actual luminosity increased after a decline in the years before - probably due to the refurbishments done on the airport in preparation for the World Cup. Eventually, further examples show that the magnitude of the effect seems to depend not only on the respective location (rural vs. urban), but also on the extent of the infrastructure improvements since we did not find as strong effects as in Durban for smaller airport upgrades, like that in Bloemfontein. ${ }^{42}$

Finally, it could be argued that airports produce a lot of luminosity by themselves, e.g., through illuminated runways. Hence, we want to make sure that our results are not simply driven by the treatment project itself. To do so, we exclude the luminosity pixels in the area of the airport from our data set and re-run SCM. The results are shown in Figure A.5 of Appendix A.1.2: they remain virtually unchanged. Therefore, our findings are not solely driven by the airport itself, but (also) strongly by an increase in economic activity around it, e.g., by firms and people that settle nearby the airport due to its amenities.

\footnotetext{
${ }^{41}$ SCM results for the Cape Town airport are reported in Appendix C.2, Figure C2.3.

42 Results for the Bloemfontein airport are available upon request.
} 


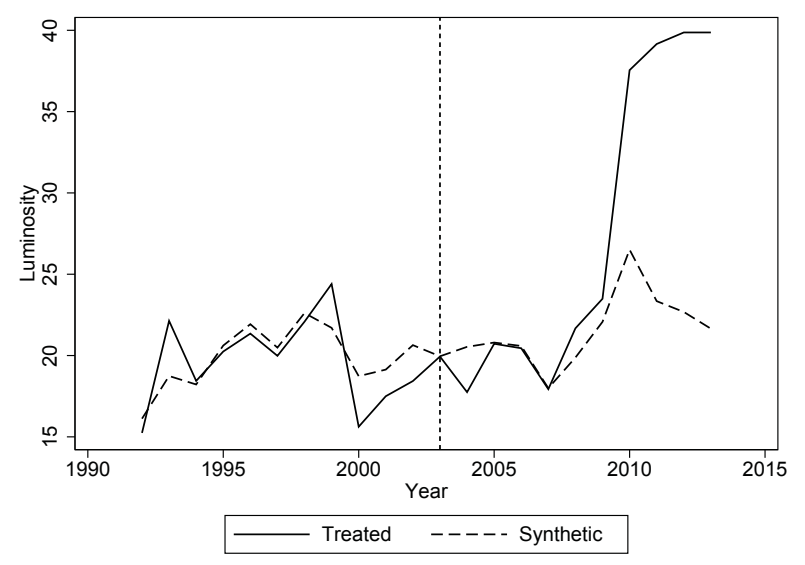

(a) Trends in Luminosity: Treated vs. Synthetic

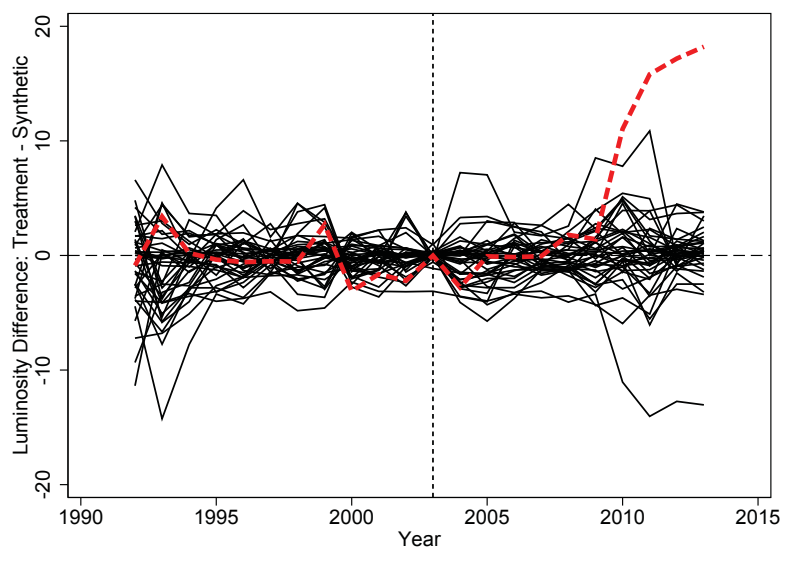

(b) Luminosity Gaps: Airport Ward vs. Placebos

Note: The vertical dashed line indicates the end of the pre-treatment period (2003). Panel (a) displays the airport ward and its synthetic counterpart. Panel (b) plots luminosity gaps (treatment minus synthetic) for the airport ward and placebo units: the black solid lines and the red dashed line represent the placebos and the treated unit, respectively.

Figure 6: Estimation Results: King Shaka International Airport Durban

\section{Polokwane}

The next case is the Polokwane Local Muncipality with both the Peter Mokaba Stadium and the Polokwane International Airport. ${ }^{43}$ The stadium was one of the few arenas that were newly constructed for the World Cup, its construction costs amounted to $\$ 169.7$ million. The South African government estimated its economic impact to be around $\$ 11$ million, what is the largest among stadiums lying outside the metropolitan municipalities. ${ }^{44}$ Polokwane with 166, 000 inhabitants was one of the smaller World Cup venues, but probably the one with the highest per capita investments in infrastructure of all the World Cup venues. This is because, next to the construction of a new stadium, the municipality experienced an update of the Polokwane International Airport for $\$ 10.4$ million. ${ }^{45}$ Figure 7 shows the Polokwane Local Municipality, the 2013 ward level luminosity, as well as the location of the stadium and the

\footnotetext{
43 The Polokwane Local Municipality consists of 38 wards. Among them are five with treatments and 16 wards neighboring them. Thus, we are left with a donor pool of 17 wards.

44 Figures regarding the economic impact are taken from the FIFA World Cup Country Report of the South African Department of Sport and Recreation (available at: http://www.srsa.gov.za/MediaLib/Home/ DocumentLibrary/SRSACountryReport2013-withcover.pdf, last accessed on February 11, 2016.)

45 Population figures are taken from http://econ.ufs.ac.za/dl/Userfiles/Documents/00001/588_eng. pdf, last accessed on February 11, 2016.
} 


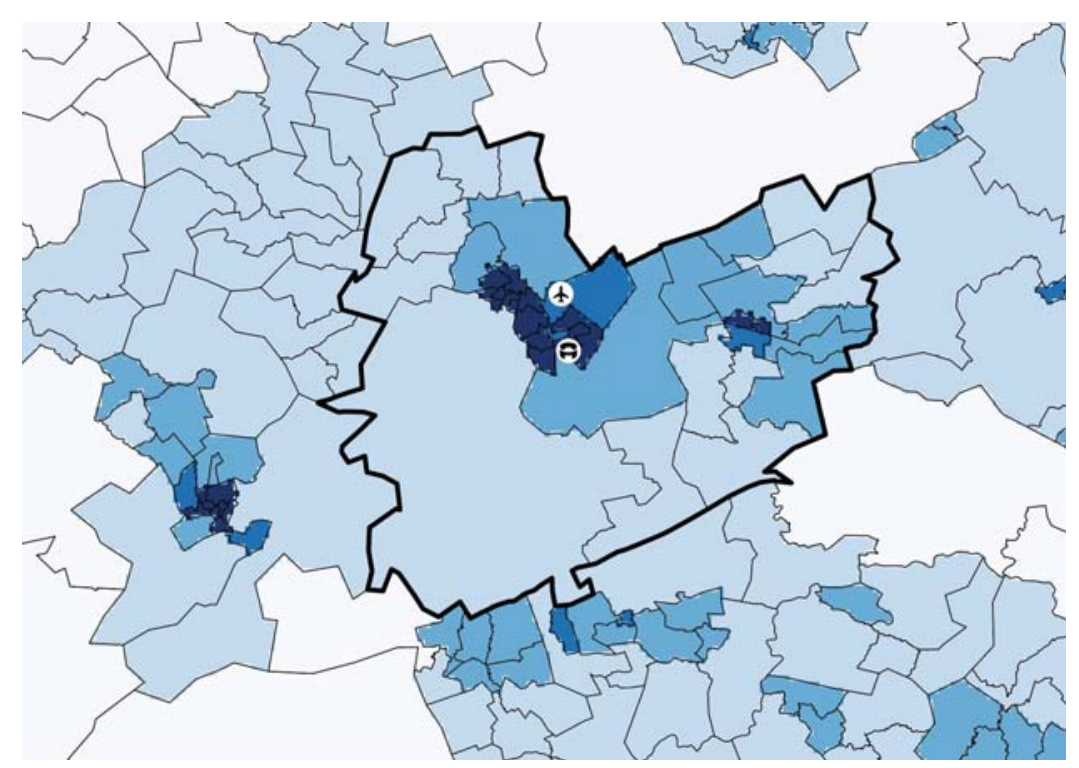

Note: The figure shows the borders of the Polokwane Local Municipality, its wards, as well as the location of the Peter Mokaba Stadium and Polokwane International Airport, respectively. The 2013 average luminosity of a ward is indicated by colors from white to dark blue, where darker colors indicate higher luminosity.

Figure 7: Peter Mokaba Stadium and Polokwane International Airport within the Polokwane Local Municipality

airport. ${ }^{46}$

SCM results for the Peter Mokaba Stadium are depicted in Figure 8, Panels (a) and (b), and those for the airport are reported in Figure 9, Panels (a) and (b). The luminosity trends for the stadium ward and its synthetic control ward indicate a widening, positive gap right with the beginning of the construction work in 2007. This difference rises to a maximum of five units in 2011, or, equivalently, a $83 \%$ gap relatively to the last actual pre-treatment luminosity value. This also corresponds to 3.6 percentage points lower unemployment, $\$ 624$ higher income per capita, and around $\$ 958$ higher GDP per capita. The placebo study summarized in Panel (b) suggests that the estimated treatment effect of the stadium ward becomes significant in 2008.

For the airport, we also see an increasing gap between luminosity of the treated ward and its synthetic counterpart beginning in 2007, which reaches its maximum in 2012. Here, actual luminosity is around eight units higher compared with the counterfactual (corresponding to, e.g., 5.78 percentage points lower unemployment). The placebo study for the airport

\footnotetext{
46 A comparison between the luminosity pixel level distribution within Polokwane in 2003 and 2013 is provided in Appendix C.2, Figure C2.4, featuring a clearly evident treatment effect.
} 


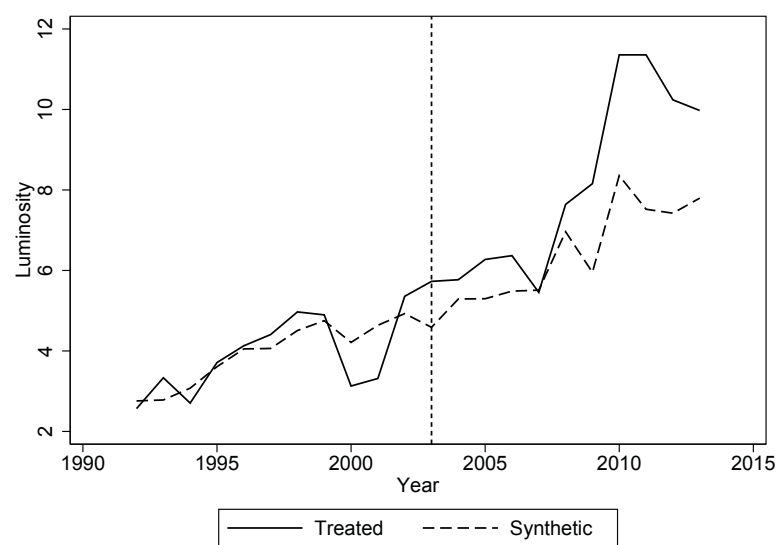

(a) Trends in Luminosity: Treated vs. Synthetic

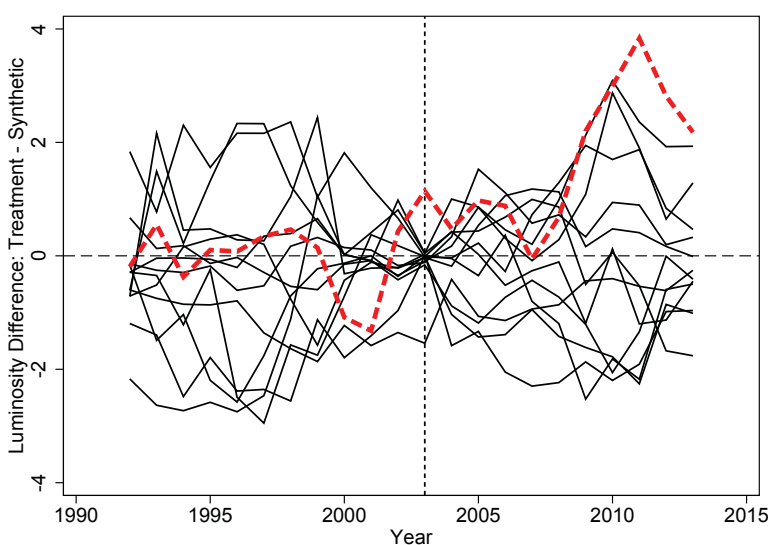

(b) Luminosity Gaps: Stadium Ward vs. Placebos

Note: The vertical dashed line indicates the end of the pre-treatment period (2003). Panel (a) displays the stadium ward and its synthetic counterpart. Panel (b) plots luminosity gaps (treatment minus synthetic) for the stadium ward and placebo units: the black solid lines and the red dashed line represent the placebos and the treated unit, respectively.

Figure 8: Estimation Results: Peter Mokaba Stadium in Polokwane

reveals a significantly positive impact from 2008 until 2013, what is in line with the fact that construction work on the airport started in 2008.

Using this knowledge, we challenge our default treatment cutoff, which refers to the year 2004, to check how results might change if we use more precise information on the timing of the airport upgrade. We re-run our SCM analysis for Polokwane International Airport, employing the year 2008 as the beginning of the treatment period. Corresponding results are shown in Figure 10, emphasizing that the generally defined treatment period from our initial SCM analysis has not led to misguided conclusions. Using the new, more precise cutoff, the airport effect is at least as pronounced as before. ${ }^{47}$ At its maximum, the luminosity gap relatively to the actual pre-treatment luminosity level amounts to 50\%, notably stronger and more stable than for the case of the Peter Mokaba Stadium.

To verify once more (as in the case of King Shaka International Airport in Durban) that the lights of the airport itself are not the main factor driving the positive effect, we reconsider the case of Polokwane where we exclude the luminosity pixels in the area of the airport. Again,

\footnotetext{
${ }^{47}$ Figure A.4 in Appendix A provides more evidence on the stability of our cutoff rule. In a nutshell, moving the cutoff further towards the actual intervention rather increases corresponding effects, so that our baseline results are always conservative, lower bounds.
} 


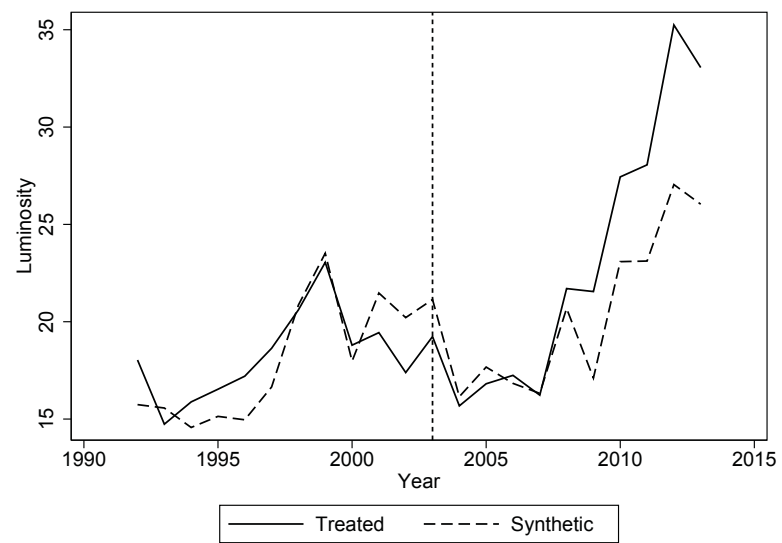

(a) Trends in Luminosity: Treated vs. Synthetic

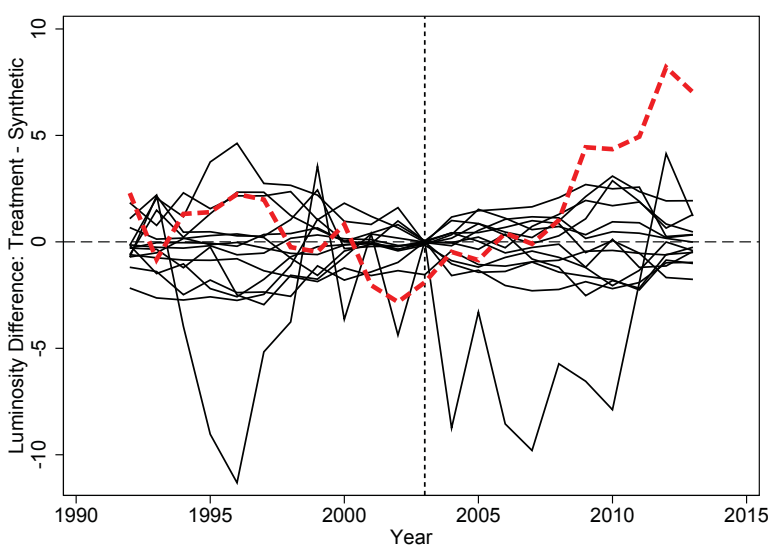

(b) Luminosity Gaps: Airport Ward vs. Placebos

Note: The vertical dashed line indicates the end of the pre-treatment period (2003). Panel (a) displays the airport ward and its synthetic counterpart. Panel (b) plots luminosity gaps (treatment minus synthetic) for the airport ward and placebo units: the black solid lines and the red dashed line represent the placebos and the treated unit, respectively.

Figure 9: Estimation Results: Polokwane International Airport

we find that results remain almost identical (see Figure A.6 of Appendix A.1.2).

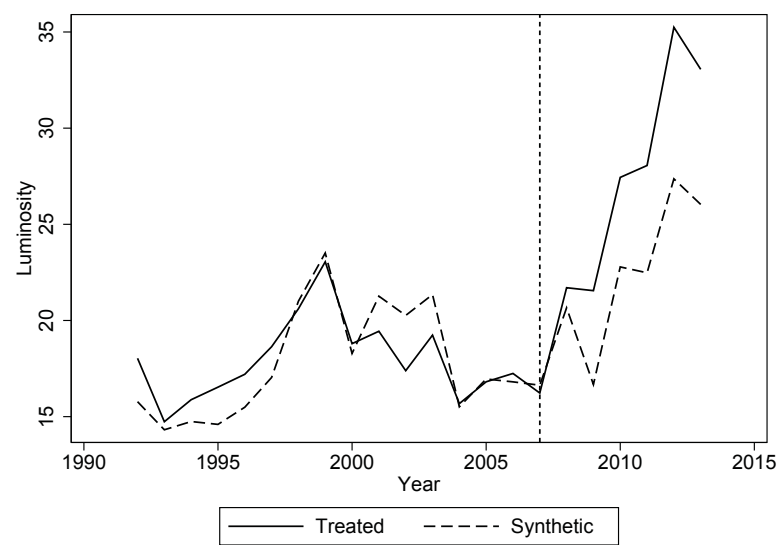

(a) Trends in Luminosity: Treated vs. Synthetic

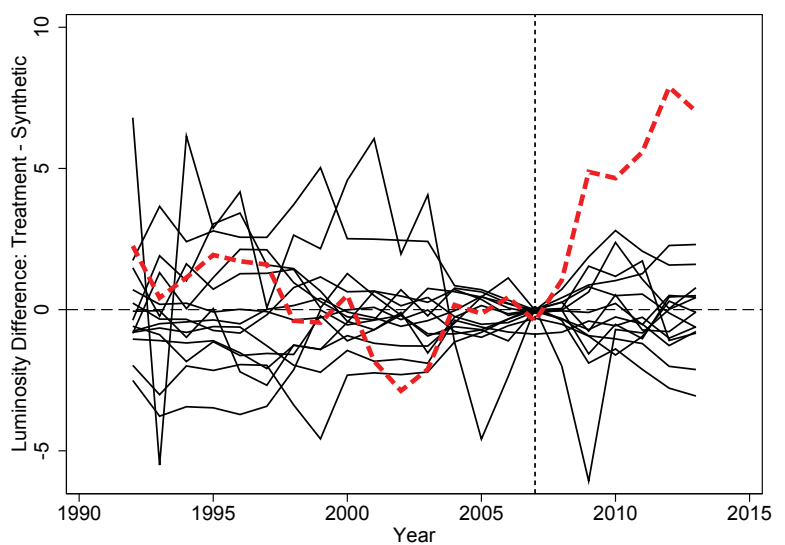

(b) Luminosity Gaps: Airport Ward vs. Placebos

Note: The vertical dashed line indicates the end of the pre-treatment period (2007). Panel (a) displays the airport ward and its synthetic counterpart. Panel (b) plots luminosity gaps (treatment minus synthetic) for the airport ward and placebo units: the black solid lines and the red dashed line represent the placebos and the treated unit, respectively.

Figure 10: Estimation Results: Polokwane International Airport-Treatment Beginning in 2008

\section{Rustenburg}

The last case is the Rustenburg railway station, which was upgraded and re-opened before

the World Cup. Similarly to Polokwane, Rustenburg, with 104,000 inhabitants, belongs to the 


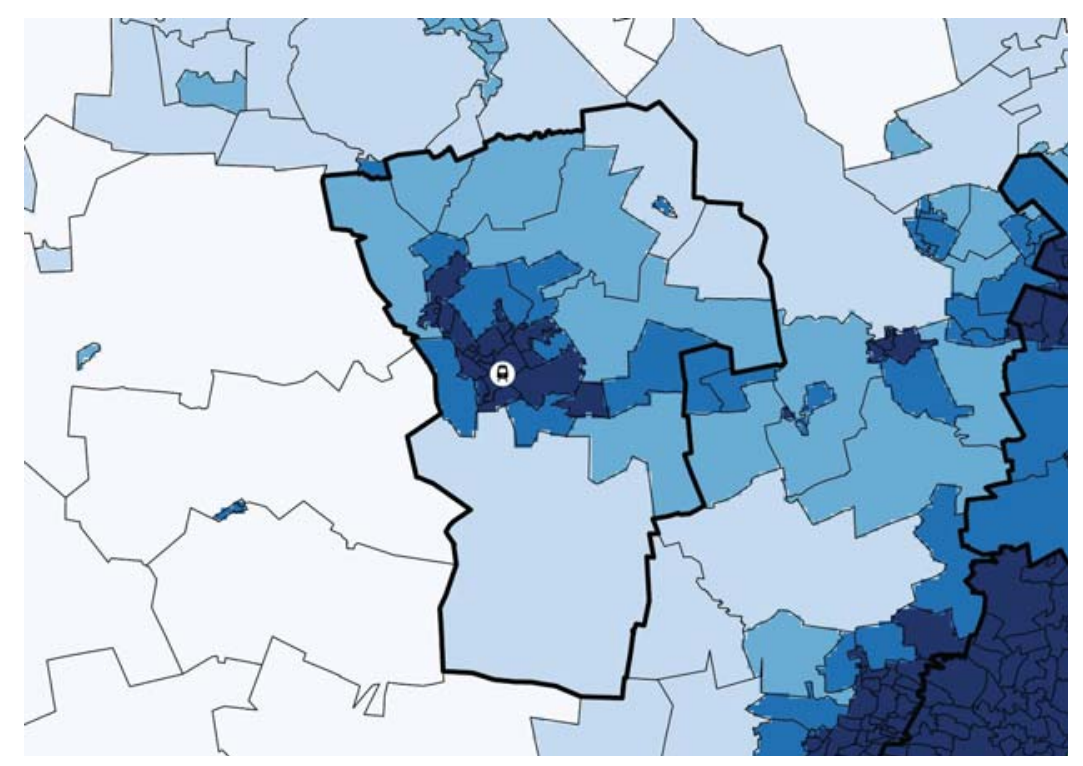

Note: The figure shows the borders of the Rustenburg Local Municipality, its wards, as well as the location of the Rustenburg railway station. The 2013 average luminosity of a ward is indicated by colors from white to dark blue, where darker colors indicate higher luminosity.

Figure 11: Rustenburg Railway Station within Rustenburg Local Municipality

smallest hosting cities. ${ }^{48}$ Figure 11 depicts the Rustenburg Local Municipality, the 2013 ward level luminosity, and the location of the railway station. ${ }^{49}$ Figure 12 shows the corresponding SCM findings. As in the case of Polokwane, Panel (a) documents a widening, positive gap between the luminosity trend of the actual ward and its synthetic counterpart beginning in 2007, that - according to the placebo test in Panel (b) - is significant from 2009 until around 2011. The maximum luminosity gap amounts to 19 units (or 50\% relatively to the last actual pre-treatment luminosity value), and corresponds to a 13.74 percentage points lower unemployment, $\$ 3,642$ higher GDP per capita, and $\$ 2,370$ more income per capita. After 2011, the gap declines but increases again in the last year of our observation frame. Hence, whether there is an actual longer-run effect is not quite clear from our evidence based on the sample that ends in 2013.

\footnotetext{
48 Population figures stem from the 2011 Census and are taken from the website: http://census2011. adrianfrith.com/place/662049, last accessed on February 11, 2016. In the Rustenburg Local Municipality, there are 38 wards and three treatment wards surrounded by 14 neighbor wards. Hence, 17 wards are excluded leaving us with a donor pool of 21 wards.

49 A comparison between the luminosity pixel level distribution within Rustenburg in 2003 and 2013 is provided in Figure C2.5 in Appendix C.2, again revealing a clear treatment effect, especially when contrasting the treated ward against several non-treated ones.
} 


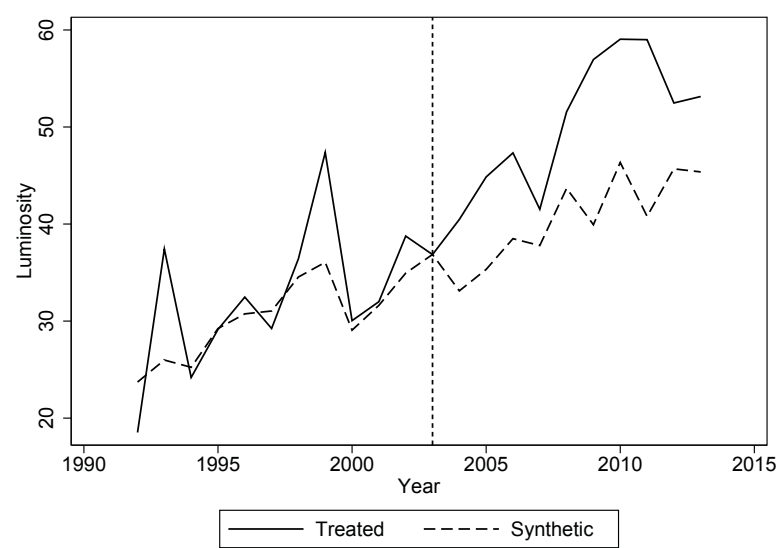

(a) Trends in Luminosity: Treated vs. Synthetic

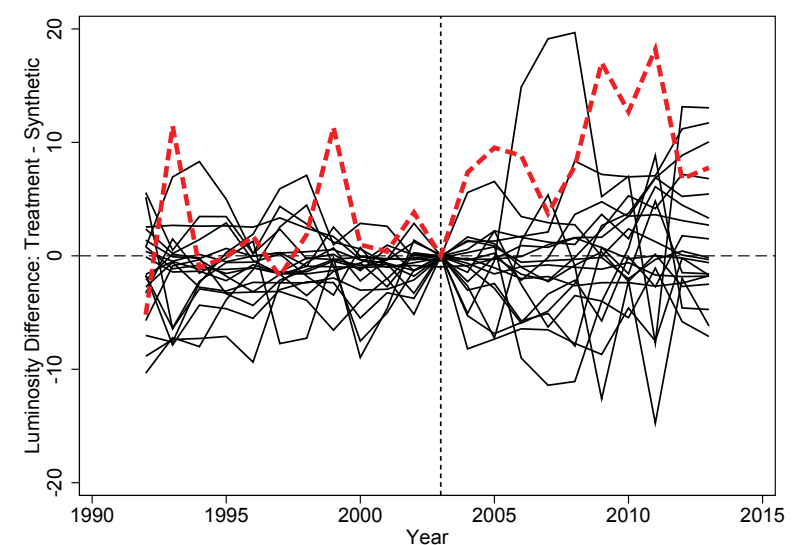

(b) Luminosity Gaps: Railway Station Ward vs. Placebos

Note: The vertical dashed line indicates the end of the pre-treatment period (2003). Panel (a) displays the railway station ward and its synthetic counterpart. Panel (b) plots luminosity gaps (treatment minus synthetic) for the station ward and placebo units: the black solid lines and the red dashed line represent the placebos and the treated unit, respectively.

Figure 12: Estimation Results: Rustenburg Railway Station

\section{Discussion}

The results of these ward level SCM analyses suggest that, indeed, the investments in preparation of the World Cup had positive effects - supporting our municipality level evidence. More precisely, however, the effects are significant most often in rather small World Cup cities or when the project was quite large (both, qualitatively and quantitatively). Such results therefore confirm the claim that a major effect of the World Cup was to foster regional catch-up processes and to close the development gap between the periphery and the core. They also show that, while on the aggregate, the effect of the World Cup might have been short-lived, particularly the effect of transportation infrastructure seems to last longer. In this regard, our findings indicate that such a positive, long-lasting impact as in the case of transport investments cannot be revealed for the other type of infrastructure treatments - sports arenas - confirming our ex-ante expectations. We do not find a significantly positive effect of stadium constructions in any of the World Cup municipalities apart from Polokwane. Even though such a positive effect could be identified in that city, it was of rather short-run nature as it occurred during the construction period only. This is in line with the fact that stadiums are not re-used frequently after the tournament. In some cases, we cannot be sure whether corresponding effects 
might still have taken place, which we are unable to identify due to the 63 luminosity cutoff. ${ }^{50}$ However, if we consider the Soccer City Stadium in Johannesburg - where this cutoff poses no restriction - we find an at best small and never significantly positive impact. This suggests that it is not the luminosity cap that prevents us from finding an effect, but rather the fact that construction of stadiums might not always induce an even short-run influence in larger cities. SCM results for the Soccer City Stadium are reported in Appendix C.2, Figure C2.6.

\section{Conclusion}

We have evaluated the economic effects of massive public investments made as preparatory measures for the 2010 FIFA World Cup in South Africa. Applying synthetic control methods to night lights intensity data, we reveal that it is non-trivial for governments to decide in favor of or against mega sports events when caring about longer-lasting economic effects in developing countries. It seems at least debatable whether the same amount of money invested in, say, health or education, could not have boosted economic development much further than the World Cup did. However, it is not feasible to compare the tournament with such hypothetical, potentially more effective interventions - at least within the same country at the same time. In any case, the debate on the effectiveness and efficiency of World Cup investments should not omit a crucial aspect: the symbolic importance of the tournament for South Africa, given the global appeal of football. The symbolic value as an intangible asset could indirectly generate benefits that are much higher than alternative treatments, but certainly also extremely difficult to quantify precisely.

Conditional on the intent of a developing country to host a mega event, our findings can have important political implications for development policies and future organization of mega (sports) events. Based on the results for an average World Cup venue on municipality level, we find a considerably positive, but only short-lived impact, becoming insignificant in the year

\footnotetext{
${ }^{50}$ One case in which the luminosity cap restricted our analysis was the Ellis Park Stadium in Johannesburg, where in all years but 2007 the luminosity of the stadium ward comprised a value of 63 . Results of the corresponding SCM analysis are available upon request.
} 
of the tournament. However, by looking at the next finer administrative level, we are able to identify large and positive effects from around 2007 onwards that persisted even until the end of our post-World Cup observation period and originate from investments in transport infrastructure, e.g., airports. On the contrary, investments in sports infrastructure primarily feature short-run effects throughout the construction period, probably due to the creation of temporary jobs. If there exist no plausible concepts regarding how stadiums could be regularly re-used after the actual event, such investments do not seem to pay off. Eventually, from a location point of view, infrastructure investments in smaller, less populous, and less developed locations feature the strongest increase in economic activity. They appear to trigger catch-up processes towards bigger cities in more wealthy regions and thus can help to reduce regional poverty as well as the urban-rural divide, both typical for developing countries. Hence, our findings suggest that mega events indeed can notably benefit the affected regions if public investments are directed on improving the 'right' infrastructure in the 'right' place. However, to come back to the initial argument, one can surely debate whether it would make more sense to invest the money directly in transport infrastructure in rural areas without going through the effort of building several new sports arenas with limited use, i.e., without organizing the mega event in the first place.

Future research in this area can gain from both the insights as well as methodological aspects of the present study. As regards the former, a reliable evaluation should be sufficiently disaggregated and differentiated in order to take potential multidimensional effect heterogeneity into account. As regards the latter, our proposed framework-combining SCM as an evaluation method and luminosity data as a measure of economic activity - offers a suitable tool for economic evaluation of mega events in developing countries. Certainly, it can also be applied in the context of other policy interventions that aim at stimulating economic growth. 


\section{References}

Abadie, A., Diamond, A., and Hainmueller, J. (2010). Synthetic Control Methods for Comparative Case Studies: Estimating the Effect of California's Tobacco Control Program. Journal of the American Statistical Association, 105(490):493-505.

Abadie, A., Diamond, A., and Hainmueller, J. (2015). Comparative Politics and the Synthetic Control Method. American Journal of Political Science, 59(2):495-510.

Abadie, A. and Gardeazabal, J. (2003). The Economic Costs of Conflict: A Case Study of the Basque Country. American Economic Review, 93(1):113-132.

Acemoglu, D., Johnson, S., Kermani, A., Kwak, J., and Mitton, T. (2015). The Value of Connections in Turbulent Times: Evidence from the United States. Journal of Financial Economics, forthcoming.

Alder, S., Shao, L., and Zilibotti, F. (2016). Economic reforms and industrial policy in a panel of chinese cities. Journal of Economic Growth, forthcoming.

Aragon, F. M. and Rud, J. P. (2015). Polluting industries and agricultural productivity. evidence from mining in ghana. Economic Journal, forthcoming.

Axbard, S. (2016). Income Opportunities and Sea Piracy in Indonesia: Evidence from Satellite Data. American Economic Journal: Applied Economics, 8(2):154-94.

Baade, R. A. and Matheson, V. A. (2004). The Quest for the Cup: Assessing the Economic Impact of the World Cup. Regional Studies, 38(4):343-354.

Baskaran, T., Min, B., and Uppal, Y. (2015). Election Cycles and Electricity Provision: Evidence from a Quasi-Experiment with Indian Special Elections. Journal of Public Economics, 126(6):64-73.

Becker, S. O., Egger, P. H., and von Ehrlich, M. (2010). Going NUTS: The Effect of EU Structural Funds on Regional Performance. Journal of Public Economics, 94(9-10):578590 .

Becker, S. O., Egger, P. H., and von Ehrlich, M. (2012). Too Much of A Good Thing? On the Growth Effects of the EU's Regional Policy. European Economic Review, 56(3):648-668.

Berger, T. and Enflo, K. (2016). Locomotives of Local Growth: The Short- and Long-Term Impact of Railroads in Sweden. Journal of Urban Economics, forthcoming.

Cavallo, E., Galiani, S., Noy, I., and Pantano, J. (2013). Catastrophic Natural Disasters and Economic Growth. Review of Economics and Statistics, 95(5):1549-1561.

Chen, X. and Nordhaus, W. D. (2011). Using Luminosity Data as a Proxy For Economic Statistics. Proceedings of the National Academy of Sciences of the United States of America, 108(21):8589-8594. 
Cogneau, D. and Moradi, A. (2014). Borders that Divide: Education and Religion in Ghana and Togo Since Colonial Times. Journal of Economic History, 74(3):694-729.

Conselho Municipal de Maputo (2010). Perfil Estatístico do Município de Maputo 2007-2008.

de Nooij, M., van den Berg, M., and Koopmans, C. (2011). Bread or Games? A Social CostBenefit Analysis of the World Cup Bid of the Netherlands and the Winning Russian Bid. Journal of Sports Economics, 14(5):521-545.

Death, C. (2011). 'Greening' the 2010 FIFA World Cup: Environmental Sustainability and the Mega-Event in South Africa. Journal of Environmental Policy and Planning, 13(2):99-117.

Desai, A. and Vahed, G. (2010). World Cup 2010: Africa's Turn or the Turn on Africa? Soccer and Society, 11(1-2):154-167.

Dettmann, E., Brachert, M., and Titze, M. (2016). Identifying the Effects of Place-based Policies - Causal Evidence from Germany. IWH Discussion Papers, (18).

Donaldson, D. (2016). Railroads of the Raj: Estimating the Impact of Transportation Infrastructure. American Economic Review, forthcoming.

Donaldson, D. and Hornbeck, R. (2016). Railroads and American Economic Growth: A "Market Access" Approach. Quarterly Journal of Economics, 131(2):799-858.

du Plessis, S. and Maennig, W. (2011). The 2010 FIFA World Cup High-Frequency Data Economics: Effects on International Tourism and Awareness for South Africa. Development Southern Africa, 28(3):349-365.

Dube, A. and Zipperer, B. (2015). Pooling Multiple Case Studies Using Synthetic Controls: An Application to Minimum Wage Policies. IZA Discussion Papers, (8944).

Elliot, R. J., Strobl, E., and Sun, P. (2015). The Local Impact of Typhoons on Economic Activity in China: A View from Outer Space. Journal of Urban Economics, 88:50-66.

Elvidge, C. D., Hsu, F.-C., Baugh, K. E., and Ghosh, T. (2014). National trends in satelliteobserved lighting 1992-2012. In Weng, Q., editor, Global Urban Monitoring and Assessment through Earth Observation, pages 595-622. CRC Press, Boca Ranton, FL.

Elvidge, C. D., Ziskin, D., Baugh, K. E., Tuttle, B. T., Ghosh, T., Pack, D. W., Erwin, E. H., and Zhizhin, M. (2009). A fifteen year record of global natural gas flaring derived from satellite data. Energies, 2:595-622.

Gennaioli, N., La Porta, R., Lopez Di Silanes, F., and Shleifer, A. (2013). Human Capital and Regional Development. Quarterly Journal of Economics, 128(1):105-164.

Gennaioli, N., La Porta, R., Lopez Di Silanes, F., and Shleifer, A. (2014). Growth in Regions. Journal of Economic Growth, 19(3):259-309.

Gobillon, L. and Magnac, T. (2016). Regional Policy Evaluation: Interactive Fixed Effects and Synthetic Controls. Review of Economics and Statistics, 98(3):535-551. 
Gonzalez-Navarro, M. and Turner, M. A. (2016). Subways and Urban Growth: Evidence from Earth. SERC Discussion Paper 195.

Gröger, A. and Zylberberg, Y. (2016). Internal Labor Migration as a Shock Coping Strategy: Evidence from a Typhoon. American Economic Journal: Applied Economics, 8(2):123-53.

Hagn, F. and Maennig, W. (2008). Employment Effects of the Football World Cup 1974 in Germany. Labour Economics, 15(5):1062-1075.

Hagn, F. and Maennig, W. (2009). Large Sport Events and Unemployment: The Case of the 2006 Soccer World Cup in Germany. Applied Economics, 41(25):3295-3302.

Henderson, J. V., Squires, T. J., Storeygard, A., and Weil, D. N. (2016). The Global Spatial Distribution of Economic Activity. Nature, History and the Role of Trade. NBER Working Paper No. 22145.

Henderson, V. J., Storeygard, A., and Weil, D. N. (2012). Measuring Economic Growth from Outer Space. American Economic Review, 102(2):994-1028.

Hodler, R. and Raschky, P. A. (2014). Regional Favoritism. Quarterly Journal of Economics, 129(2):995-1033.

Holl, A. (2004). Manufacturing Location and Impacts of Road Transport Infrastructure: Empirical Evidence from Spain. Regional Science and Urban Economics, 34(3):341-363.

Hornung, E. (2015). Railroads and Growth in Prussia. Journal of the European Economic Association, 13(4):699-736.

Human Sciences Research Council (2011). Impact of the 2010 World Cup on Social Cohesion, Nation Building and Reconciliation. Final Report.

Jean, N., Burke, M., Xie, M., Davis, M. W., Lobell, D. B., and Ermon, S. (2016). Combining satellite imagery and machine learning to predict poverty. Science, 353(6301):790-794.

Jedwab, R., Kerby, E., and Moradi, A. (2016). History, Path Dependence and Development: Evidence from Colonial Railroads, Settlers and Cities in Kenya. Economic Journal, forthcoming.

Kaul, A., Klößner, S., Pfeifer, G., and Schieler, M. (2015). Synthetic Control Methods: Never Use All Pre-Intervention Outcomes as Economic Predictors. Working Paper.

Kleven, H. J., Landais, C., and Saez, E. (2013). Taxation and International Migration of Superstars: Evidence from the European Football Market. American Economic Review, 103(5):1892-1924.

Kline, P. and Moretti, E. (2014). Local Economic Development, Agglomeration Economics, and the Big Push. 100 Years of Evidence from the Tennessee Valley Authority. Quarterly Journal of Economics, 129(1):275-331.

Klößner, S., Kaul, A., Pfeifer, G., and Schieler, M. (2016). Comparative Politics and the Synthetic Control Method Revisited: A Note on Abadie et al. (2015). Working Paper. 
Klößner, S. and Pfeifer, G. (2015). Synthesizing Cash for Clunkers: Stabilizing the Car Market, Hurting the Environment. Working Paper.

Kulkarni, R., Haynes, K. E., Stough, R. R., and Riggle, J. D. (2011). Revisiting Night Lights as Proxy for Economic Growth: A Multi-Year Light Based Growth Indicator (LGBI) for China, India and the U.S. GMU School of Public Policy Research Paper 2011-12.

Leibbrandt, M., Woolard, I., Finn, A., and Argent, J. (2010). Trends in South African Income Distribution and Poverty since the Fall of the Apartheid. OECD Social, Employment and Migration Working Papers 101.

Lessmann, C. and Seidel, A. (2015). Regional Inequality, Convergence, and its DeterminantsA View from Outer Space. CESifo Working Paper No. 5322.

Martin, P. and Rogers, C. A. (1995). Industrial Location and Public Transport. Journal of International Economics, 39(3-4):335-351.

Mellander, C., Lobo, J., Stolarick, K., and Matheson, Z. (2015). Night-time light data: A good proxy measure for economic activity? PLOS One, 10(10):1-18.

Michalopoulos, S. and Papaioannou, E. (2014). National Institutions and Subnational Development in Africa. Quarterly Journal of Economics, 129(1):151-213.

Min, B., Gaba, K. M., Sarr, O. F., and Agalassou, A. (2013). Detection of Rural Electrification in Africa Using DMSP-OLS Night Lights Imagery. International Journal of Remote Sensing, 34(22):8118-8141.

Molloy, E. and Chetty, T. (2015). The Rocky Road to Legacy: Lessons from the 2010 FIFA World Cup South Africa Stadium Program. Project Managament Journal, 46(3):88-107.

Mveyange, A. (2015). Night Lights and Regional Income Inequality in Africa. WIDER Working Paper 2015/085.

OECD (2012). Economic Policy Reforms 2012: Going for Growth. OECD Publishing.

Peeters, T., Matheson, V., and Szymanski, S. (2014). Tourism and the 2010 World Cup: Lessons for Developing Countries. Journal of African Studies, 23(2):290-320.

Pillay, U. and Bass, O. (2008). Mega-Events as a Response to Poverty Reduction: The 2010 FIFA World Cup and its Urban Development Implications. Urban Forum, 19(3):329-346.

Pinkovskiy, M. and Sala-i-Martin, X. (2016). Lights, Camera,...Income! Illuminating the National Accounts-Household Surveys Debate. Quarterly Journal of Economics, 131(2):579631.

Pinotti, P. (2015). The Economic Costs of Organised Crime: Evidence from Southern Italy. Economic Journal, 125(586):F203-F232.

Rogerson, C. M. (2009). Mega-Events and Small Enterprise Development: The 2010 FIFA World Cup Opportunities and Challenges. Development Southern Africa, 26(3):337-352. 
Rose, A. K. and Spiegel, M. M. (2011). The Olympic Effect. Economic Journal, 121(553):652677.

Sport and Recreation South Africa (2013). 2010 World Cup Country Report. Technical Report.

Storeygard, A. (2016). Farther On Down the Road: Transport Costs, Trade and Urban Growth in Sub-Saharan Africa. Review of Economic Studies, 83(3):1263-1295.

Strobl, E. and Valfort, M.-A. (2015). The Effect of Weather-Induced Internal Migration on Local Labor Markets. Evidence from Uganda. World Bank Economic Review, 29(2):385-412.

Wahl, F. (2016). The Long Shadow of History. Roman Legacy and Economic DevelopmentEvidence from the German Limes. Working Paper.

Zabel, F., Putzenlechner, B., and Mauser, W. (2014). Global Agricultural Land Resources. A High Resolution Suitability Evaluation and its Perspectives until 2100 under Climate Change Conditions. PLOS One, 9(9):1-12. 


\section{Appendix}

\section{A Robustness}

\section{A.1 Donor Country: South Africa}

\section{A.1.1 Analysis on the Municipality Level}

We examine the robustness of our results by conducting several sensitivity checks. First, the average municipality result from Section 4.1 does not change if we compute our unit of interest as being the World Cup venue average of six municipalities instead of nine. The excluded municipalities are those with the highest luminosity level: Johannesburg Metropolitan Municipality, eThekwini Metropolitan Municipality, and Cape Town Metropolitan Municipality. Figure A.1 provides corresponding results, assuring that our findings are not driven by only a few locations which feature a high level of luminosity anyway.

Second, we try the opposite, namely including more 'treated' municipalities in addition to the nine in which the football stadiums were located at. These additional seven municipalities affected by World Cup measures are listed in Appendix B.2 along with their corresponding treatments. We adjust our donor pool by excluding the additional neighboring municipalities according to the same rules as in the main analysis in Section 4. Figure A.2 provides corresponding SCM results, showing that our findings stay robust and are in fact even stronger. Alternatively, we also find our results to be confirmed if we additionally include the border regions of Lesotho into the original donor pool an re-run the baseline SCM analysis.

Third, we conduct a version of so-called 'leave-one-out' checks (Abadie et al., 2015), where a control unit that received positive weight during the original SCM optimization procedure is excluded from the donor pool. In our case, we pick the uMhlathuze Local Municipality which received a weight of over $80 \%$ when synthesizing the average World Cup municipality. In uMhlathuze, Africa's largest coal export facility (Richards Bay Coal Terminal) was constructed parallel and independent of the World Cup, a fact that could disqualify this region as a valid control unit. When removing this municipality from the donor pool, SCM still delivers extremely robust results, which becomes evident when looking at Figure A.3. Now, the synthetic average World Cup venue is comprised of Msunduzi and Govan Mbeki, with corresponding $w$-weights of $84.5 \%$ and $15.5 \%$, respectively.

Fourth, we try altering the predictor set. Particularly, we restrict the predictors to the same set as we had to work with on ward level, i.e., without the share of people with indigenous heritage, the share of people with tertiary education, and the percentage of people unemployed. We find our results to be confirmed. Adding more predictors, e.g., the respective distance to 
coast, does not affect our findings either. The same holds true if we additionally add population density in 1996 to the set of predictors. Results turn out to be almost identical. Hence, the estimated effects do not simply reflect the correlation between luminosity and agglomeration but can really be interpreted as being due to differences in wealth.

Fifth, we follow Elliot et al. (2015) and remove all pixels from the data set that were unlit (0) over the entire sampling period, as one could assume that in the corresponding areas there was no economic activity at all. The fact that most of these pixels are located in sparsely populated municipalities in the western South African wastelands could lead to an underestimation of averaged night lights in the actually settled areas. However, when we rerun our SCM framework using the alternative luminosity measure where all such pixels were removed before the aggregation on municipality level, our results remain virtually identical.

Taken together, all of the above-mentioned sensitivity checks strongly support the credibility of our findings in Section 4.1, revealing positive, short-run effects for the average World Cup municipality.

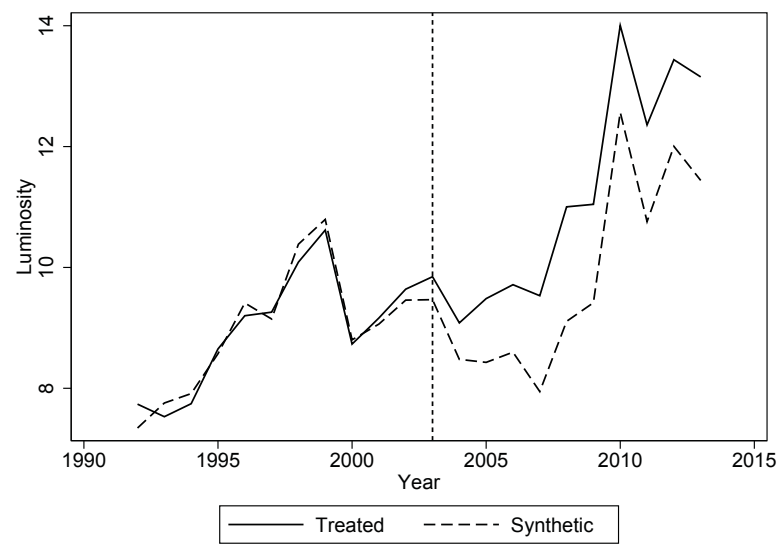

(a) Trends in Luminosity: Treated vs. Synthetic

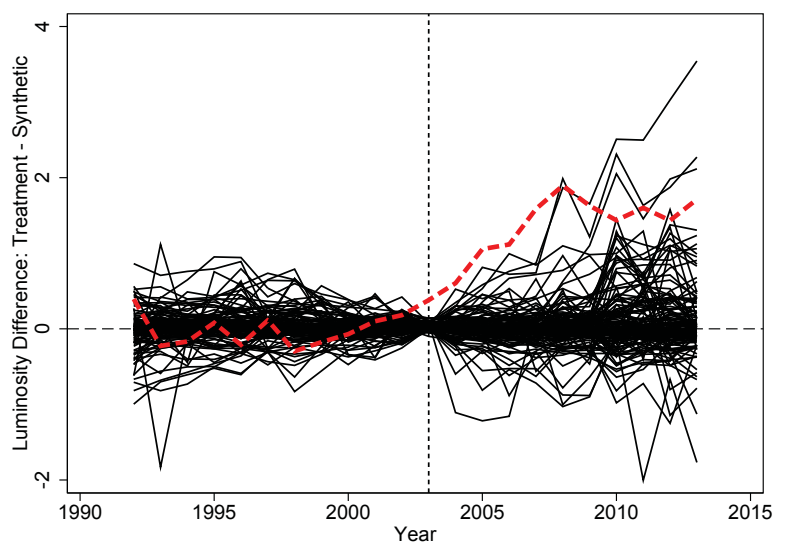

(b) Luminosity Gaps: Cup Venue vs. Placebos

Note: The vertical dashed line indicates the end of the pre-treatment period (2003). Panel (a) displays the average World Cup venue and its synthetic counterpart. Panel (b) plots luminosity gaps (treatment minus synthetic) for the average World Cup venue and placebo units: the black solid lines and the red dashed line represent the placebos and the treated unit, respectively.

Figure A.1: Estimation Results: The Average World Cup Venue w/o Johannesburg, Durban, and Cape Town 


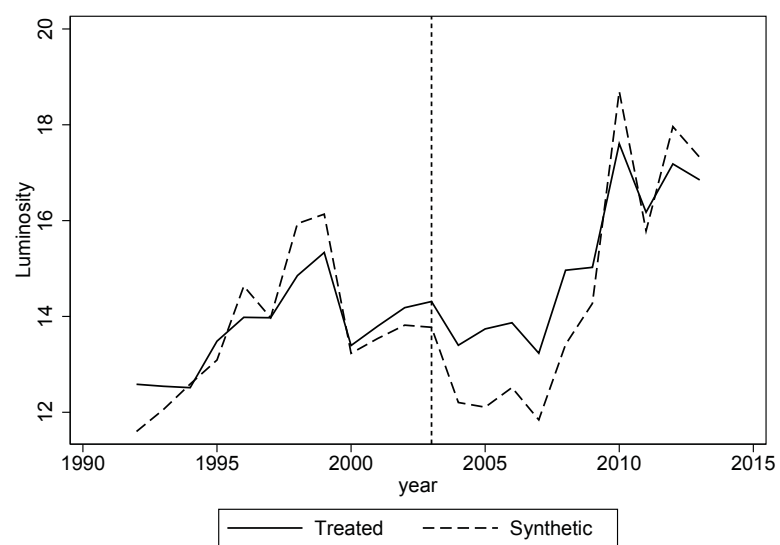

(a) Trends in Luminosity: Treated vs. Synthetic

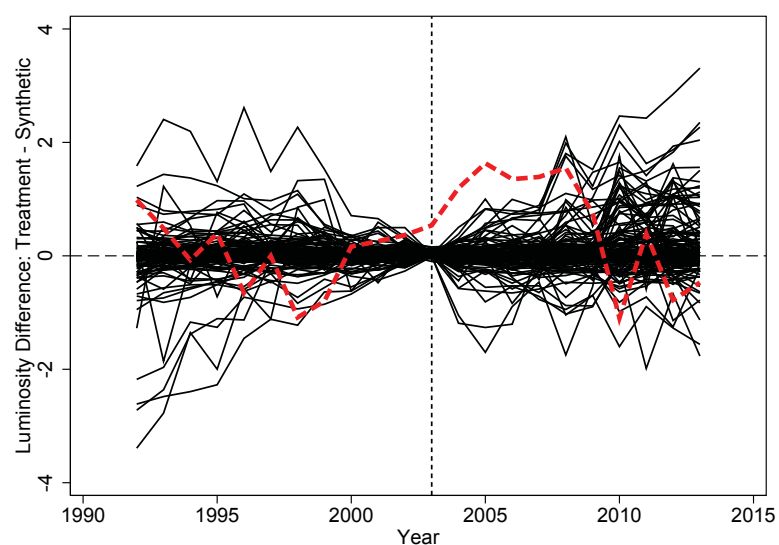

(b) Luminosity Gaps: Cup Venue vs. Placebos

Note: The vertical dashed line indicates the end of the pre-treatment period (2003). Panel (a) displays the average World Cup venue and its synthetic counterpart. Panel (b) plots luminosity gaps (treatment minus synthetic) for the average World Cup venue and placebo units: the black solid lines and the red dashed line represent the placebos and the treated unit, respectively.

Figure A.2: Estimation Results: The Average World Cup Venue including more Treated Municipalities

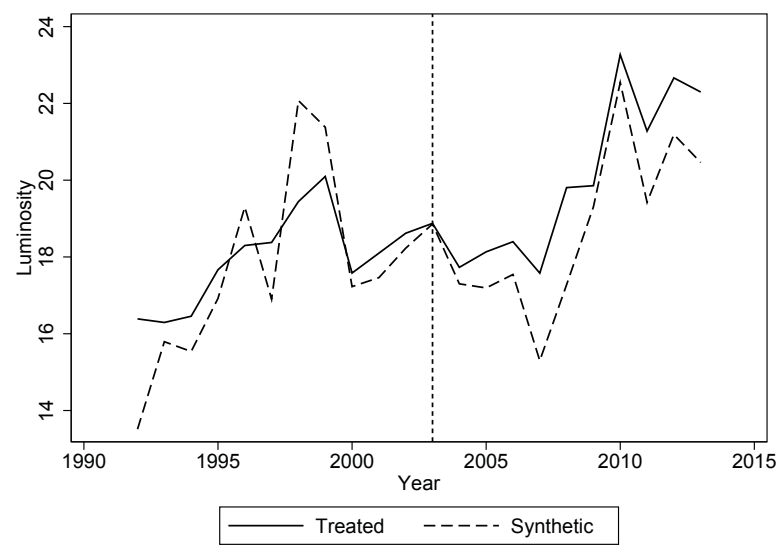

(a) Trends in Luminosity: Treated vs. Synthetic

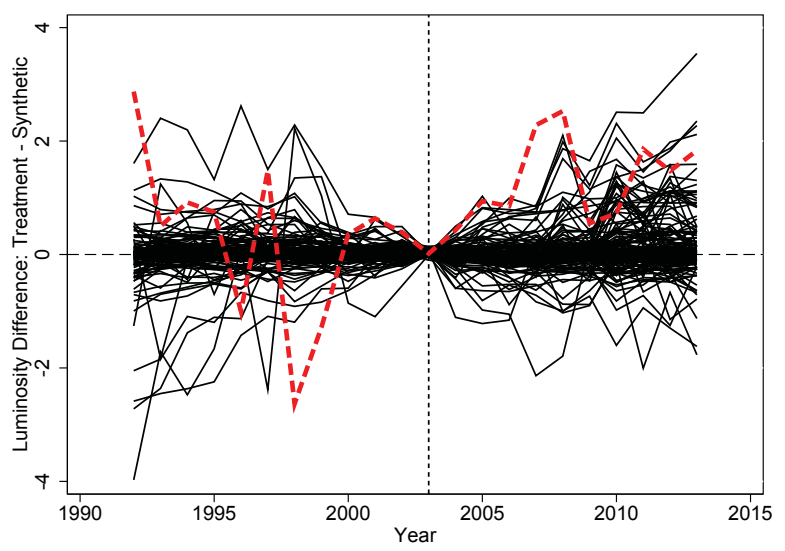

(b) Luminosity Gaps: Cup Venue vs. Placebos

Note: The vertical dashed line indicates the end of the pre-treatment period (2003). Panel (a) displays the average World Cup venue and its synthetic counterpart. Panel (b) plots luminosity gaps (treatment minus synthetic) for the average World Cup venue and placebo units: the black solid lines and the red dashed line represent the placebos and the treated unit, respectively.

Figure A.3: Estimation Results: The Average World Cup Venue without Control Unit 'uMhlathuze Local Municipality'

\section{A.1.2 Analysis on the Ward Level}

In the following, we check the robustness of the results from Section 4.2, that are based on ward level. In particular, analogous to the case of Polokwane International Airport, we shift the treatment cutoff towards the actual beginning of a respective infrastructure project. This is exemplified in Figure A.4, Panels (a) and (b), showing the case of the Durban King Shaka 
International Airport. From this evidence, it can be inferred that the results look virtually identical to the baseline case, which assumes the treatment to start in 2004. However, the figure also suggests that using 2007 as treatment year enables us to identify the actual onset of the increasing luminosity gap between the actual and synthetic airport ward much more precisely than before. For all examples shown in Section 4.2, moving the cutoff towards later periods rather increases corresponding effects, and never undermines our previous findings. Thus, the results reported throughout the main analysis are always conservative, lower bounds. Contrarily, moving the (placebo) cutoff to an early pre-treatment period, e.g., 1997, delivers zero-results as expected.

Moreover, recall that we discussed the potential argument that our results might simply be driven by a treatment project itself. To check this, we excluded the luminosity pixels in the area of, e.g, an airport treatment from our data set and re-run SCM. Results for Durban and Polokwane airport are shown in Figures A.5 and A.6, respectively. One can easily see that they remain virtually unchanged compared with the initial results of Section 4.2.

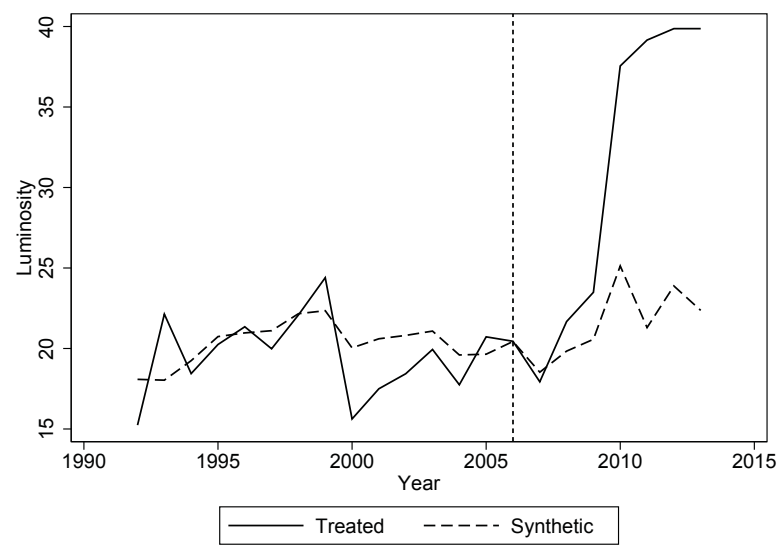

(a) Trends in Luminosity: Treated vs. Synthetic

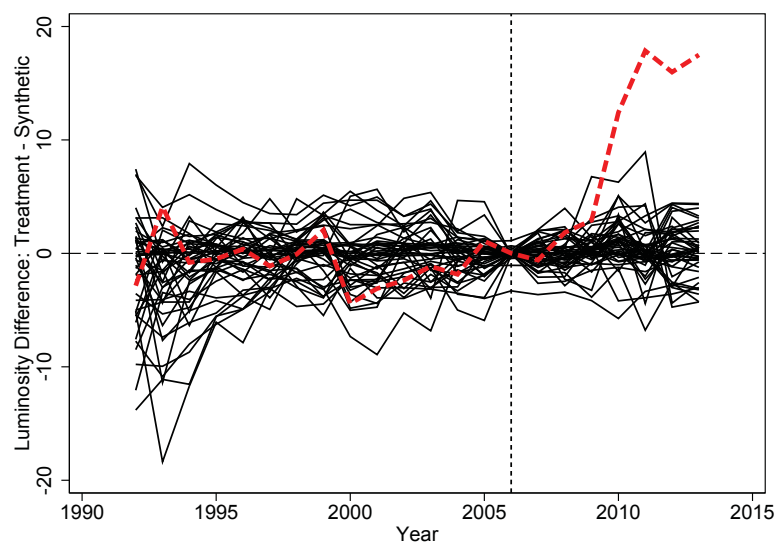

(b) Luminosity Gaps: Airport Ward vs. Placebos

Note: The vertical dashed line indicates the end of the pre-treatment period (2006). Panel (a) displays the airport ward and its synthetic counterpart. Panel (b) plots luminosity gaps (treatment minus synthetic) for the airport ward and placebo units: the black solid lines and the red dashed line represent the placebos and the treated unit, respectively.

Figure A.4: Estimation Results: King Shaka International Airport Durban—Treatment Beginning in 2007 


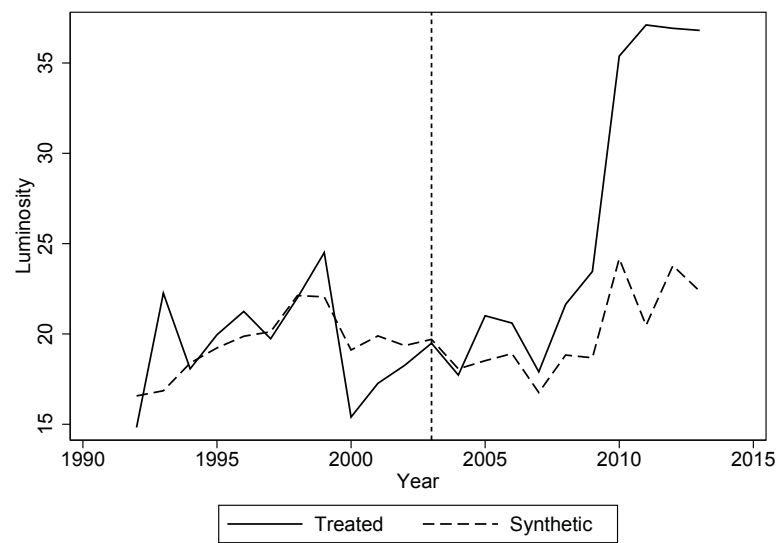

(a) Trends in Luminosity: Treated vs. Synthetic

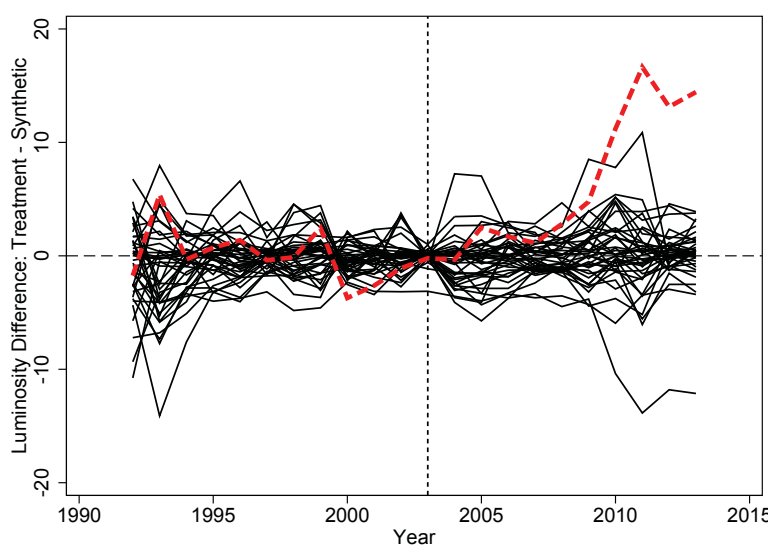

(b) Luminosity Gaps: Stadium Ward vs. Placebos

Note: The vertical dashed line indicates the end of the pre-treatment period (2003). Panel (a) displays the airport ward and its synthetic counterpart. Panel (b) plots luminosity gaps (treatment minus synthetic) for the airport ward and placebo units: the black solid lines and the red dashed line represent the placebos and the treated unit, respectively.

Figure A.5: Estimation Results for King Shaka International Airport Durban Without Airport Lights

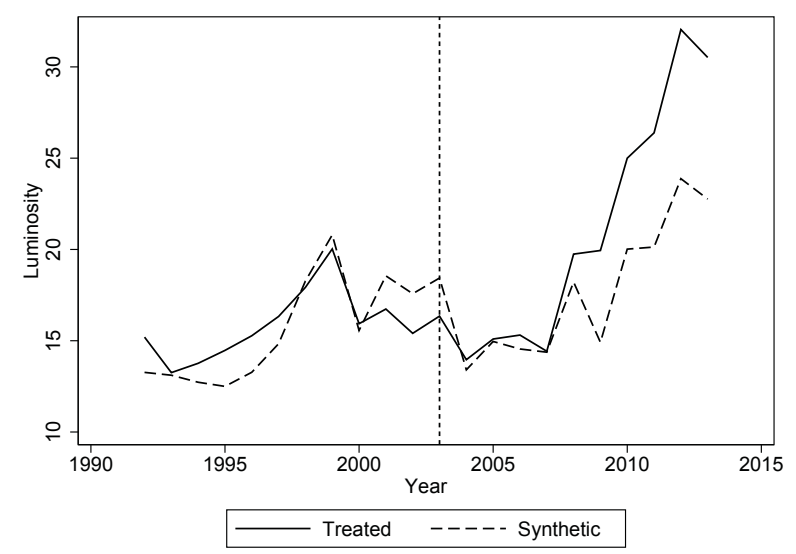

(a) Trends in Luminosity: Treated vs. Synthetic

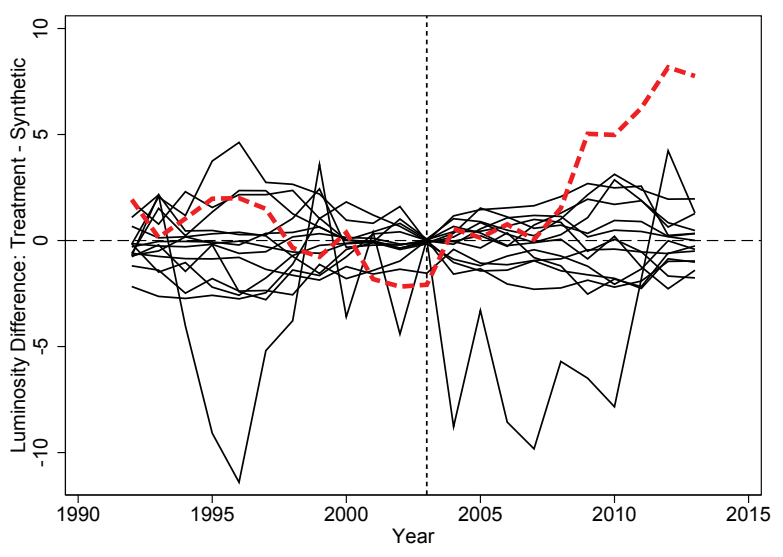

(b) Luminosity Gaps: Stadium Ward vs. Placebos

Note: The vertical dashed line indicates the end of the pre-treatment period (2003). Panel (a) displays the airport ward and its synthetic counterpart. Panel (b) plots luminosity gaps (treatment minus synthetic) for the airport ward and placebo units: the black solid lines and the red dashed line represent the placebos and the treated unit, respectively.

Figure A.6: Estimation Results for Polokwane International Airport Without Airport Lights

\section{A.2 Other Donor Countries}

As has been emphasized in Section 4, to reduce the possibility of spillovers of World Cup related measures to non-World Cup venues, we exclude those municipalities from the donor pool that are bordering World Cup municipalities (and Lesotho). In this appendix, we additionally address the issue of potential spillovers in another way-instead of the donor pool based on South African municipalities we construct alternative donor pools from regions of two different 
African countries, respectively. These countries have been carefully selected using two alternative, mutually exclusive criteria. According to the first one - geographical proximity - we have chosen Mozambique as it is a direct neighbor of South Africa, which makes it more comparable with South Africa than other, more distant, countries. Similarly to South Africa, Mozambique has also a long coast with several important sea ports, such as Beira, Inhambane, Maputo, Nacala, Pemba, and Quelimane. ${ }^{1}$ The alternative approach we follow in this robustness check is to draw on another country bidding, along with South Africa, to host the 2010 World Cup. We have decided to consider Morocco - a runner-up candidate in this competition. In the following, we will give more information on the two selected donor countries and discuss in detail the analysis for both cases.

\section{A.2.1 Mozambique}

Mozambique still belongs to the poorest countries in the world. Over the examined period 1992-2013, its average GDP per capita amounted to about $\$ 333$ (compared with the average GDP per capita of $\$ 4,758$ in South Africa over the same period). However, Mozambique experienced a large transformation after the end of the civil war in 1992, that is marked with impressive growth rates peaking at 26.8\% in 1996 and stabilizing around 7\% from 2007 on. Much of the development has been fueled with reconstruction and extensive foreign investment. Projects involving foreign investment have been carried out in agriculture as well as in the industry sector, that grew from $16 \%$ in 1996 to $27 \%$ in 2004 (the year of the considered treatment effect). The most prominent example of the industrial mega-projects in the early phase of the economic transition is the Mozal aluminum smelter in Maputo province, thanks to which Mozambique has become one of the world's leading exporters of aluminum. Other megaprojects that followed are, e.g., the Moma titanium minerals mine (Nampula province) and the Moatize coal mine (Tete province). As regards transport infrastructure, the strategic position of Mozambique along the coastline gave rise to the development of three main corridors. Two of them connect Malawi and Zimbabwe with the ports of Nacala and Beira, respectively, and the other one links South Africa and Swaziland to the Maputo port. ${ }^{2}$

\footnotetext{
1 Other countries bordering South Africa that could be potential candidates to provide a donor pool are: Namibia, Botswana and Zimbabwe (note that Lesotho and Swaziland are too small in terms of area and population size). However, Namibia and Botswana have a population density of $2.54 / \mathrm{km}^{2}$ and $3 / \mathrm{km}^{2}$, respectively, which is around 14 times lower than population density in South Africa; see Census 2011 for Namibia and Census for Botswana. Zimbabwe is, with a population density of 26/ $\mathrm{km}^{2}$ (Census 2012), similar to Mozambique $\left(28.7 / \mathrm{km}^{2}\right.$; Census 2007), but we have decided against considering it as a donor country merely because the Zimbabwean economy experienced dramatic losses in the period 2000-2008 (most of our examination period), which is reflected by negative growth rates dropping to $-17 \%$ in 2003 and 2008 as well as extraordinary high consumer price inflation rates culminating at 24,400\% in 2007 (database http://http: //data.worldbank.org; last accessed on September 10, 2016).

${ }^{2}$ Information on Mozambique has been taken from 1) the database http://http://data.worldbank.org; 2) Masha and Ross(2014) "Mozambique's Growth Experience, Macroeconomic Policy Mix, and Institutions" In
} 


\section{Synthetic Unit}

Based on the average population size, we focus on districts in Mozambique (128 districts with average population size of 167,164 ) as administrative units comparable to South African municipalities (234 municipalities with average population size of 221,242). ${ }^{3}$ The synthetic unit based on Mozambique consists of four districts: Gondola (41.3\%), Maputo City (28.4\%), Mandimba (29\%), and Angónia (1.3\%). None of these districts shares its borderline with South Africa, which additionally reduces the probability of spatial spillovers to the Mozambican synthetic unit. The largest contributor (total weight of ca. 72\%) of the control group are three districts dominated by agriculture and, in particular, subsistence farming: Gondola (province Manica), Mandimba (province Niassa), and Angónia (province Tete). Gondola's population size is 310,429 inhabitants (2012), the corresponding figure for Mandimba is 164,826 (2012). Infrastructure is in a disastrous state in these provinces: for example, in Niassa, only $14 \%$ of all roads are paved. The remaining component of the control group-Maputo City - is the capital and at the same time the biggest city of Mozambique (as well as an autonomous administrative unit), that lies at the harbor in the southern part of the country. It is the most densely populated region in the country (5,1 inhabitants per $\mathrm{km}^{2}$; Census 2007) and a dynamically developing city whose economy is concentrated around the port. Maputo City has the highest GDP per capita ranging from $\$ 894$ in 2000 to $\$ 1,531$ in 2010 - in comparison, the average GDP per capita over all provinces increased in the same period from $\$ 240$ to $\$ 426$. The contribution of the capital to total GDP amounted to about $19 \%$ in the years $2007-2008$, which underlines its role as the main economic hub of Mozambique. The most important sectors are: transport and communications, property and related services, commerce, financial services, and manufacturing. ${ }^{4}$

Ross, D. C., editor, "Mozambique's Rising: Building a New Tomorrow", Chapter 1, Pages 7-25. International Monetary Fund, Washington D.C. 3) AfDB/OECD (2006) "African Economic Outlook 2005-2006", downloadable at: http://www.oecd-ilibrary.org/development/african-economic-outlook-2006_aeo-2006-en. The URLs have been last accessed on September 10, 2016.

${ }^{3}$ Data on population size is taken from the 2007 Census for Mozambique and from the 2011 Census for South Africa, respectively.

4 Sources of the information are 1) the document by Instituto Nacional de Estatística (2012) "Estatísticas do Distrito Gondola", downloadable at: http://www.ine.gov.mz/estatisticas/ estatisticas-territorias-distritais/manica/marco-de-2012/distrito-de-gondola.pdf; 2) the document by Instituto Nacional de Estatística (2012) "Estatísticas do Distrito Mandimba", downloadable at: http://www.ine.gov.mz/estatisticas/estatisticas-territorias-distritais/niassa/ et-niassa.2012/marco/distrito-de-mandimba.pdf; 3) Silici, Bias and Cavane (2015) "Sustainable agriculture for small-scale farmers in Mozambique: A scoping report" IIED Country Report. IIED, London (downloadable at: http://www.rainwatertechcentres.net/images/PDF/Silci_et_al_Moza.pdf); 4) http://www.jica.go.jp/english/news/press/2013/131206_04.html; 5) Conselho Municipal de Maputo (2010); 6) the document by Instituto Nacional de Estatística (2012) "O Perfil de Desenvolvimento Humano am Moçambique, 1997-2011", downloadable at: http://www.ine.gov.mz/estatisticas/publicacoes/operfil-de-desenvolvimento-humano-em-mocambique-1997-2013-2011.pdf. All URLs have been last accessed on September 10, 2016. 


\section{Effects}

The evolution of luminosity for the average World Cup venue and the synthetic unit built based on districts from Mozambique are depicted in Figure A.7. It can be observed that in the first three years after the treatment cutoff both luminosity trends are nearly coincident. Only in 2008, the gap between treated and synthetic trend opens and becomes wider in the following years, also after 2010. However, Panel (b) of the figure indicates that the treatment gap is not significant, which prevents us from drawing conclusions based on the result in Panel (a). Moreover, both panels reveal that the pre-treatment fit is hardly satisfactory, definitely being worse compared with the case of the South African donor pool. This may already suggest that the Mozambican synthetic unit is less suitable to represent the average World Cup venue than the South African synthetic unit before 2004. This argument becomes even more perspicuous considering the above description of such Mozambican districts that form the control group: two underdeveloped and poor districts specialized in agriculture play the predominant role in the synthetic unit, which makes it hardly representative for the treated unit that, for the most part, consists of prosperous South African metropolises with their economic activity concentrated on financial services and manufacturing.

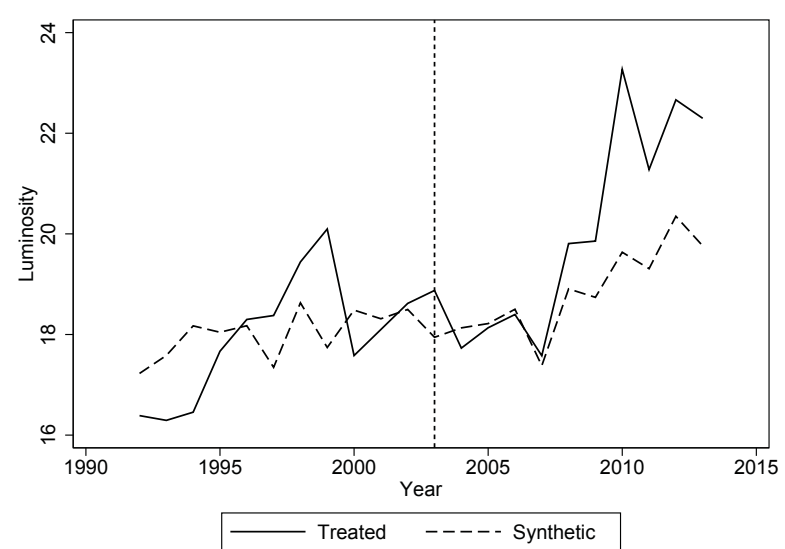

(a) Trends in Luminosity: Treated vs. Synthetic

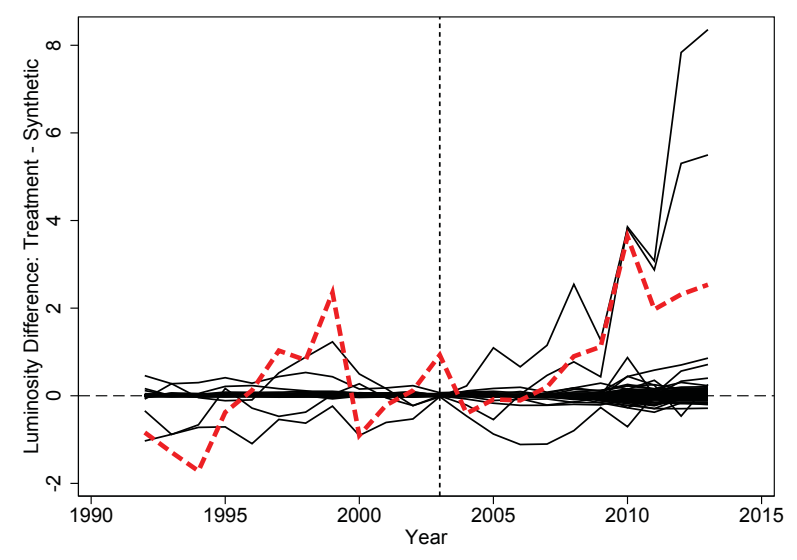

(b) Luminosity Gaps: World Cup Venue vs. Placebos

Note: The vertical dashed line indicates the end of the pre-treatment period (2003). Panel (a) displays the average World Cup venue and its synthetic counterpart. Panel (b) plots luminosity gaps (treatment minus synthetic) for the average World Cup venue and placebo units: the black solid lines and the red dashed line represent the placebos and the treated unit, respectively.

Figure A.7: Estimation Results for the Average World Cup Venue: Donor Pool Based on Mozambique

\section{A.2.2 Morocco}

Morocco is a constitutional monarchy situated in Northern Africa with 33.8 million inhabitants and a population density of 76 inhabitants per $\mathrm{km}^{2}$ in 2014 (29.8 million inhabitants and 67.4 inhabitants per $\mathrm{km}^{2}$ in 2004). Morocco's economy is dominated by the service sector (around 
$58 \%$ of total GDP in 2014), followed by industry (29\%) in which mining plays a key role. For example, in 2013, Morocco was the world's leader in phosphate exports and the world's third largest producer in phosphate rock. Agriculture still remains an important economic sector (13\% of total GDP in 2014). Until the early 1990s, the economy featured a large state-owned sector; at the beginning of 1990s, the government started with the process of privatization. After King Mohammed VI took over in 1999, Morocco has adopted a development model aimed at economic liberalization and increasing openness. Several structural reforms have been implemented, among others "Plan Emergence" in 2005, which stimulated growth and led to the reduction in unemployment. Morocco has recorded steady growth since the end of 1990 s - the annual GDP growth rate ranged from about $2 \%$ to $7.8 \%$ between 2000 and 2015. Average GDP per capita amounted to $\$ 1,970$ over the examined period 2004-2013. The unemployment rate fell from its peak at $16.6 \%$ in 1998 to ca. $9 \%$ in 2009-2013. Despite this positive development, the country is struggling with high inequality and high youth unemployment. In 2011, the political situation in Morocco became unstable due to protests across the whole country that were driven by demonstration in other North African countries (the so-called Arab spring) and were rooted in dissatisfaction of people with political issues, like lack of civil rights, and economical ones. As a result of the protests, the constitution has been adjusted so as to grant more power to the prime minister and parliament. ${ }^{5}$

\section{Synthetic Unit}

In our analysis, we consider municipalities as reference administrative units in Morocco (third level of administrative division). Note that Morocco underwent several changes in the administrative division in the last two decades, the last one in 2015. The considered division reflects the situation in 2009 (in the examined time span 2004-2013). The synthetic unit assembled by SCM from all Moroccan municipalities consists of: Tahla (46.3\%), Hamriya (33.5\%), Figuig (13.9\%), Bouarfa (4\%), Maknassat Azzaytoun (2\%), Jrada (0.1\%), and Khourigba (0.1\%). Three of them (Tahla, Hamriya, and Figuig) attain the highest weights and their total con-

\footnotetext{
${ }^{5}$ Information on Morocco has been taken from 1) the database http://http://data.worldbank.org; 2) Censuses 1994, 2004 and 2014 (see http://www.hcp.ma); 3) the document by AfDB/OECD (2007) "African Economic Outlook", downloadable at: https : //www . oecd.org/countries/morocco/38562905.pdf; 4) the document by AfDB/OECD/UNDP/UNECA (2012) "African Economic Outlook:", downloadable at: www.africaneconomicoutlook.org/sites/default/files/content-pdf/AE02012_EN.pdf; 5) Semmar (2012) "Corporate governance of stateowned enterprises in Morocco: evolution and perspectives", in OECD, Towards New Arrangements for State Ownership in the Middle East and North Africa, OECD Publishing (downloadable at: http://www.oecd-ilibrary.org/governance/towardsnew-arrangements-for-state-ownership-in-the-middle-east-and-north-africa/corporategovernance-of-state-owned-enterprises-in-morocco_9789264169111-8-en); 6) the document by U.S. Geological Survey (2015) "Minerals Yearbook 2013: Morocco and West Sahara", downloadable at: http://minerals.usgs.gov/minerals/pubs/country/2013/myb3-2013-mo-wi.pdf. All URLs have been last accessed on September 10, 2016.
} 
tribution to the synthetic unit amounts to about $94 \%$. These three municipalities are located in three different regions (first level of administrative division) that are direct neighbors to each other. Even though the regions lie in the northern part of the country, which, in general, has higher GDP per capita than the southern part, they are poorer compared with other regions in northern Morocco. This holds especially for the region Taza-Al Hoceïma-Taounate, which encompasses the main component of the synthetic unit - the urban municipality Tahla. The region is the poorest one in Morocco (about 3.6 times poorer than the wealthiest region Grand Casablanca); its average contribution to total GDP in the period 2001-2007 is 2.7\%, which is in contrast to the major contributors of the country-Grand Casablanca (18.8\%), Souss-Massa-Daraâ (12.2\%), and Rabat-Salé-Zemmour-Zaer (9.8\%). The region is especially underdeveloped with respect to industry - its contribution to the secondary sector amounts to $1.1 \%$ vis-à-vis $35.7 \%$ of region Grand Casablanca. Tahla itself, with its population size of 27,729 in 2014 (25,655 in 2004), is a small municipality compared with such South African World Cup venues as Johannesburg, Pretoria or Cape Town. Another major component of the synthetic unit-Figuig - is even smaller in terms of population and shows a downward tendency (population size of 14,245 in $1994 ; 12,577$ in $2004 ; 10,872$ in 2014). The superordinate region Oriental has a relatively strong developed agricultural sector, at least compared with the national average. The primary sector makes up about $33 \%$ of the economy in region Oriental and contributes with ca. $14 \%$ to the country's agricultural output. The last major municipality in the synthetic unit-Hamriya - is situated in region Fès-Boulemane for which, in contrast to region Oriental, agricultural production plays a minor role only ( $5 \%$ of the region's output). Instead, the service sector is over-represented in this region, given the national average. In terms of GNP per capita, the region is one of the poorest in the whole country (after Taza-Al Hoceïma-Taounate and Meknès-Tafilalet). ${ }^{6}$

\section{Effects}

The estimation results are depicted in Figure A.8. As is evident from Panel (a), the pretreatment fit is worse than in the case of the South African donor pool. Moreover, the treatment effect seems to start taking place in 2009 and to increase towards the end of the examined time span in 2013. Panel (b) makes clear that, similarly as for the Mozambican donor pool, this effect is not significant and inconclusive, which may be motivated by similar arguments as in the case of Mozambique. The Moroccan municipalities building up the synthetic unit

\footnotetext{
6 Source of the data on regional statistics for Morocco in the time span 2001-2007 is the document of the Ministry of Economy and Finance of Morocco, Department of Studies and Financial Forecasts (2010) "Regions in Morocco: Sector-based Contribution to National Wealth Creation", downloadable at: https://www.finances.gov.ma/Docs/2011/depf/6470_regionsinmoroccoenglishversion2.pdf (last accessed on September 10, 2016)
} 
appear not to be appropriate enough to reconstruct the average World Cup venue. First, as has been already discussed above, two of the major contributing municipalities are very small and underdeveloped, whereas the third one lies in a province specialized in agriculture. Second, Morocco is a country which strongly differs from South Africa in various respects, for example, location in Africa, geography of the country, climate, culture, and its political system.

The contrasting properties of the control groups from both Mozambique and Morocco and the South African World Cup cities lead to the conclusion that the results presented in this appendix are not reliable. Moreover, this illustrates that our choice for South Africa as the preferred donor pool for our SCM analyses can be justified. In fact, as has been explained in detail in Section 4.1, the South African control group provides a satisfactory mix of properties common to different World Cup venues, and is in this regard a reliable reference unit for establishing the World Cup effect.

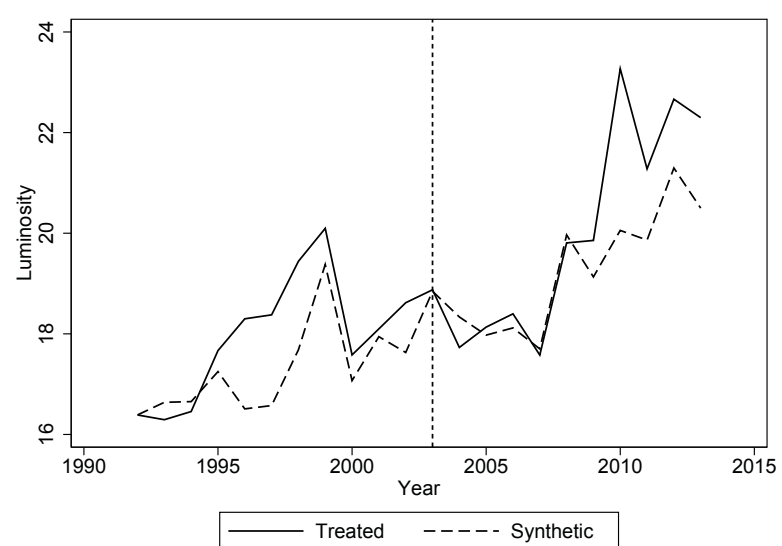

(a) Trends in Luminosity: Treated vs. Synthetic

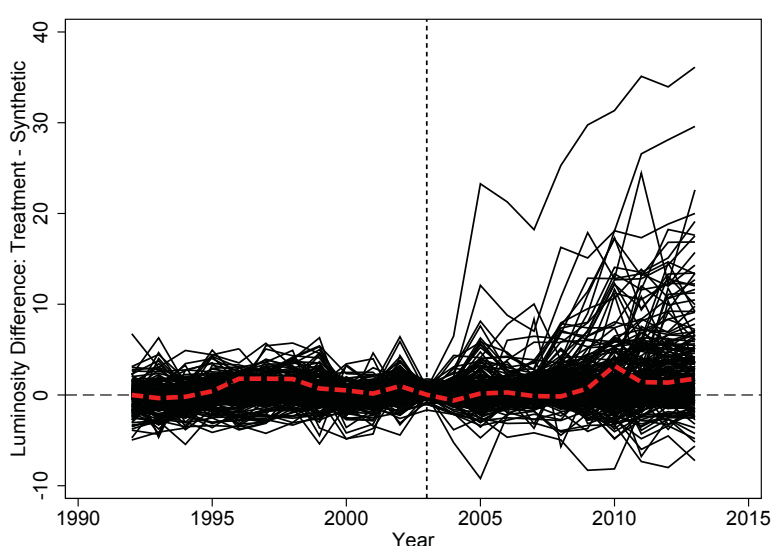

(b) Luminosity Gaps: World Cup Venue vs. Placebos

Note: The vertical dashed line indicates the end of the pre-treatment period (2003). Panel (a) displays the average World Cup venue and its synthetic counterpart. Panel (b) plots luminosity gaps (treatment minus synthetic) for the average World Cup venue and placebo units: the black solid lines and the red dashed line represent the placebos and the treated unit, respectively.

Figure A.8: Estimation Results for the Average World Cup Venue: Donor Pool Based on Morocco 


\section{B Data and Setting Details}

\section{B.1 Description of Variables}

Area. Area of a municipality in square kilometers. Calculated with ArcGIS Pro "Calculate Geometry" tool according to the shapefile of municipality territories from the DIVA-GIS database. It can be downloaded at: http://biogeo.ucdavis.edu/data/diva/adm/ZAF_adm. zip (last accessed on January 19, 2106).

Distance to Railway. Geodesic distance from the centroid (mid-point) of each municipality to the next railway in kilometers. The course of the railways in South Africa is taken from a shapefile provided by the DIVA-GIS database of UC Davies. It can be downloaded at: http://biogeo.ucdavis.edu/data/diva/rrd/ZAF_rrd.zip (last accessed on January 22, 2016). The centroids are calculated using the ArcGIS Pro "Calculate Centroids" tool.

Elevation. Elevation data are taken from the NASA SRTM (Shuttle Radar Topographic Mission) data set (Version 4.0). The spatial resolution of the data is 3 arc seconds (approx. $90 \mathrm{~m}$ on the equator). The data is provided by the Consortium for Spatial Information (CGIAR-CSI). A detailed description can be found at: http://srtm.csi.cgiar.org/ and here http://www . cgiar-csi .org/data/srtm-90m-digital-elevation-database-v41\#introduction. It can be downloaded from this webpage: http://srtm.csi.cgiar.org/ SELECTION/inputCoord . asp (last accessed on January 21, 2016).

Share Indigenous People. Share of a municipality's population with indigenous background. Data come from the project "Spatial Aspects of Unemployment in South Africa 1991-2011", conducted by the Human Sciences Research Council (HSRC). The data set covers the years 1991, 1996, 2001, and 2011. It merges information from the official South African Censuses in 1991, 1996, 2001, and 2011 and the Community Survey in 2007. The geographic units are defined according to the 2005 municipal boundaries. It can be downloaded (after free registration) at: http://curation.hsrc.ac.za/Dataset-342-datafiles.phtml (last accessed on January 22, 2016).

GDP per capita. GDP per capita (in Rand) on provincial level is calculated based on the official regional GDP estimates provided by Statistics South Africa (e.g., here http: //www.statssa.gov.za/publications/P0441/P04413rdQuarter2009.pdf, last accessed on January 8, 2016). We take GDP estimates in current Rand and deflate them in prices of 2005 using annual inflation rates from the website: http://www.inflation.eu/inflationrates/south-africa/historic-inflation/cpi-inflation-south-africa.aspx (last accessed on January 7, 2016). Finally, to obtain provincial GDP per capita, the deflated 
GDP is divided by provincial population. Provincial population figures come from the South African Census in 2011 (http://www.statssa.gov.za/census/census_2011/census_ products/Provinces $\% 20$ at $\% 20$ a\%20glance $\% 2016 \% 20$ Nov $\% 202012 \% 20$ corrected.pdf, last accessed on January 7, 2016).

Income per capita. Income per capita for the year 2007 originates from the HSRC data set "Spatial Aspects of Unemployment in South Africa 1991-2011" (see GDP per capita).

Share Tertiary Education. Share of a municipality's population with a degree from a university or another educational institution in the tertiary sector. Data originate from the HSRC data set "Spatial Aspects of Unemployment in South Africa 1991-2011" (see GDP per capita).

Soil Quality. Data on soil quality are taken from the Zabel et al. (2014) data set. The data set is described further at: http://geoportal-glues.ufz.de/stories/globalsuitability.html (last accessed on January 22, 2016). The measure used in the paper is the average agricultural suitability over the period 1961-1990. To measure suitability, Zabel et al. (2014) consider climate (temperature, precipitation, solar radiation), soil ( $\mathrm{pH}$, texture, salinity, organic carbon content, etc.), and topography (elevation and slope) of an area. They consider rain-fed conditions and irrigation. To construct the suitability measure, they contrast these factors with growing requirements of 16 plants (Barley, Cassava, Groundnut, Maize, Millet, Oilpalm, Potato, Rapeseed, Rice, Rye, Sorghum, Soy, Sugarcane, Sunflower, Summer wheat, Winter wheat).

Unemployment Rate. Share of a municipality's work force that is unemployed. Data originate from the HSRC data set "Spatial Aspects of Unemployment in South Africa 1991-2011" (see GDP per capita).

The variables of the ward level data set used in Section 4.2 originate from the same sources and are defined analogously to those of the municipality level data set.

\section{B.2 List of Considered Treatments}

Table B2.1 reports 72 treatments considered in this paper, i.e., projects that - according to our information - have been directly related to the 2010 World Cup and that we are able to locate using coordinates given by wikipedia, google maps, and the websites http://www.geonames . org and http://www.mbendi.com. ${ }^{7}$ In the baseline analysis of the paper, the definition of treated regions is restricted to nine municipalities comprising a World Cup venue and we thus

\footnotetext{
7 We only consider information on newly built or refurbished roads if the subject of the project was a national $(\mathrm{N})$ or regional $(\mathrm{R})$ route. All URLs referred to in this Appendix have been last accessed on February 12,2016 .
} 
consider as treatments those 61 projects out of 72 which have been conducted in World Cup venues. In one robustness check in Appendix A, we expand the definition of treated regions to all 16 municipalities that have experienced a World Cup investment, and in this case we use all 72 treatments. Using the listed treatments, we can identify treated wards within the treated municipalities. ${ }^{8}$ Apart from 72 treatments, Table B2.1 also provides information on the Richards Bay Coal Terminal project, a large investment project unrelated to the World Cup, that is taken into account in another robustness check in Appendix A.

The following list of 73 projects is a part of the large list of 127 projects we identified for South Africa for the time span 2004 - 2013 (in which our luminosity data are available). The large list is a result of our own extensive research and can be downloaded at: http: //www.martynamarczak.com/research/SA_AllProjects.pdf. Next to the 72 projects from Table B2.1, that are explicitly related to the 2010 World Cup, the large list also contains 55 other investments that

- have been made after the World Cup or

- have been made before/during the World Cup but no direct link with the event is mentioned in the information source, or

- were originally earmarked as World Cup projects but we exclude them from our analysis.

Infrastructure projects related to the 2010 World Cup but excluded in our study are:

- N4 Northern Bypass in Nelspruit, also called Nelspruit Ring Road (Municipality: Mbombela Local, Province: Mpumalanga): this project could not be localized.

- The Khulani Corridor and the Bus Rapid Transit (BRT) System in Port Elizabeth (Municipality: Nelson Mandela Bay Metropolitan, Province: Eastern Cape)

This project has been identified as one of the legacy projects of the World Cup. ${ }^{9}$ The Khulani Corridor should provide a link between Motherwell in the northern part of Port Elizabeth with the Central Business District (CBD) via an efficient public transport system, the so-called Bus Rapid Transit (BRT) System, and thus enhance integration of

\footnotetext{
${ }^{8}$ Note that the listed treatments are those for which explicit information could be obtained. We also assume in our study some additional treatments. In particular, we assume that railway stations within each of the World Cup municipalities were upgraded even if no specific information about upgrades can be found, e.g., in the case of the Nelspruit railway station. We also consider the upgrade of the Nelson Mandela Metropolitan University Stadium as a treatment. This stadium was utilized as a training stadium during the World Cup, but, in contrast to the training stadiums included in Table B2.1, we do not dispose of explicit information about such an upgrade.

9 http://www.gcis.gov.za/sites/www.gcis.gov.za/files/docs/resourcecentre/multimedia/ sa2010_govprep.pdf
} 
better developed with less developed areas of the city. ${ }^{10}$ However, by 2010 , only one part of the BRT system could be finalized - a route operated by a shuttle service and running between the CBD and the Nelson Mandela Bay Stadium (also in the city centre). ${ }^{11}$ In the years after the tournament, the implementation of the BRT system has been delayed by different factors, e.g., conflicts with the taxi industry, flawed construction of the fast bus lanes (as a consequence, newly built lanes have been demolished since busses bought in 2009 could not fit into the lanes), frequently changing city and municipality administration, as well as engineering firms contracted for the BRT project. Only in January 2013, a pilot project of the Integrated Public Transport System (IPTS), originally called the BRT system, was launched. ${ }^{12}$ The bus stops of the pilot project were provisional and new bus stations were at the design stage at that time. ${ }^{13}$ After the one-year pilot project, many issues have still not been resolved, like the agreement with the taxi industry $^{14}$ or flaws in the construction and design. ${ }^{15}$ Moreover, despite the grant support by the National Treasury, the municipality has not managed to finance the next project phases. ${ }^{16}$ All these developments show that the IPTS in Port Elizabeth was not fully functioning by the end of 2013 (the end of our data sample), so that we decided not to take into account this project in our study.

Total expenditures of all listed World Cup related projects amount to $\$ 14$ billion and are disaggregated as follows:

1. $\$ 2.5$ billion: Stadiums (World Cup stadiums and training stadiums)

2. $\$ 11.4$ billion: Transport infrastructure

- $\$ 3.8$ billion: Airports

- $\$ 3.6$ billion: Rail

- $\$ 2.9$ billion: Roads

- $\$ 1.1$ billion: Public transport

\section{3. $\$ 88.3$ million: Water projects}

\footnotetext{
${ }^{10}$ http://www.nelsonmandelabay.gov.za/datarepository/documents/QDL3C_IDP\%20-\%20Chapter\% 203.pdf

${ }^{11}$ http://www . 2010worldcupimpact.info/2010/06/24/fast-bus-lanes-for-port-elizabeth/

${ }^{12}$ http: //legacy .nelsonmandelabay $\cdot$ gov $\cdot$ za/Content. aspx?objID $=547$

${ }^{13}$ http: //www . nelsonmandelabay .gov.za/NewsView . aspx?ID=1684

${ }^{14}$ Laphum'ilanga (2014, June 2) "Newsflash", No. 1. Available at: http://laphumilanga.co.za/docs/ Laphumilanga\%20newsletter1-2June2014.pdf

${ }^{15}$ http://ewn.co.za/2016/02/03/Multi-million-rand-buses-too-big-for-PE-roads

${ }^{16}$ http://www.heraldlive.co.za/bus-plan-bleeding-money/
} 
This figure substantially exceeds the official figure that has been published by Grant Thornton, an independent accounting and consulting firm, whose findings are referred to in reports of the South African government; see, for example, the report by Sport and Recreation South Africa (2013). According to Grant Thornton, total expenditures on stadiums and infrastructure directly related to the World Cup were $\$ 5.5$ billion, with $\$ 4.1$ spent by the government and $\$ 1.4$ billion spent by cities and provinces. ${ }^{17}$ A potential explanation for the difference between the figures provided by Grant Thornton and that corresponding to the treatments in Table B2.1 could be the fact that Grant Thornton might have followed a narrow definition of projects directly related to the 2010 World Cup in their calculations. In our study, on the contrary, each project for which we found a link to the World Cup (in any potential information source) counts as World Cup related.

\footnotetext{
17 See http://mg.co.za/article/2015-06-11-was-world-cup-2010-worth-it.
} 


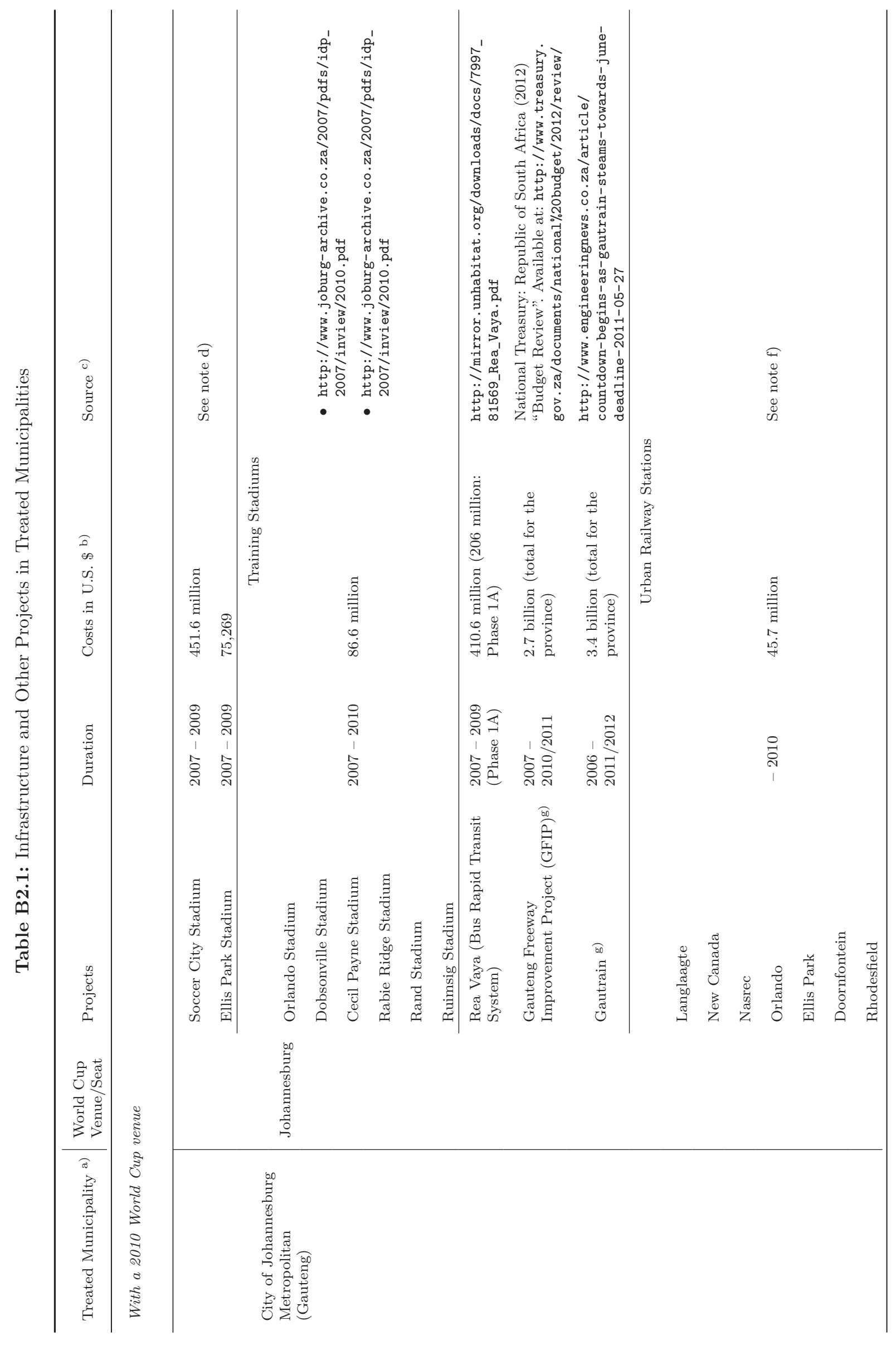




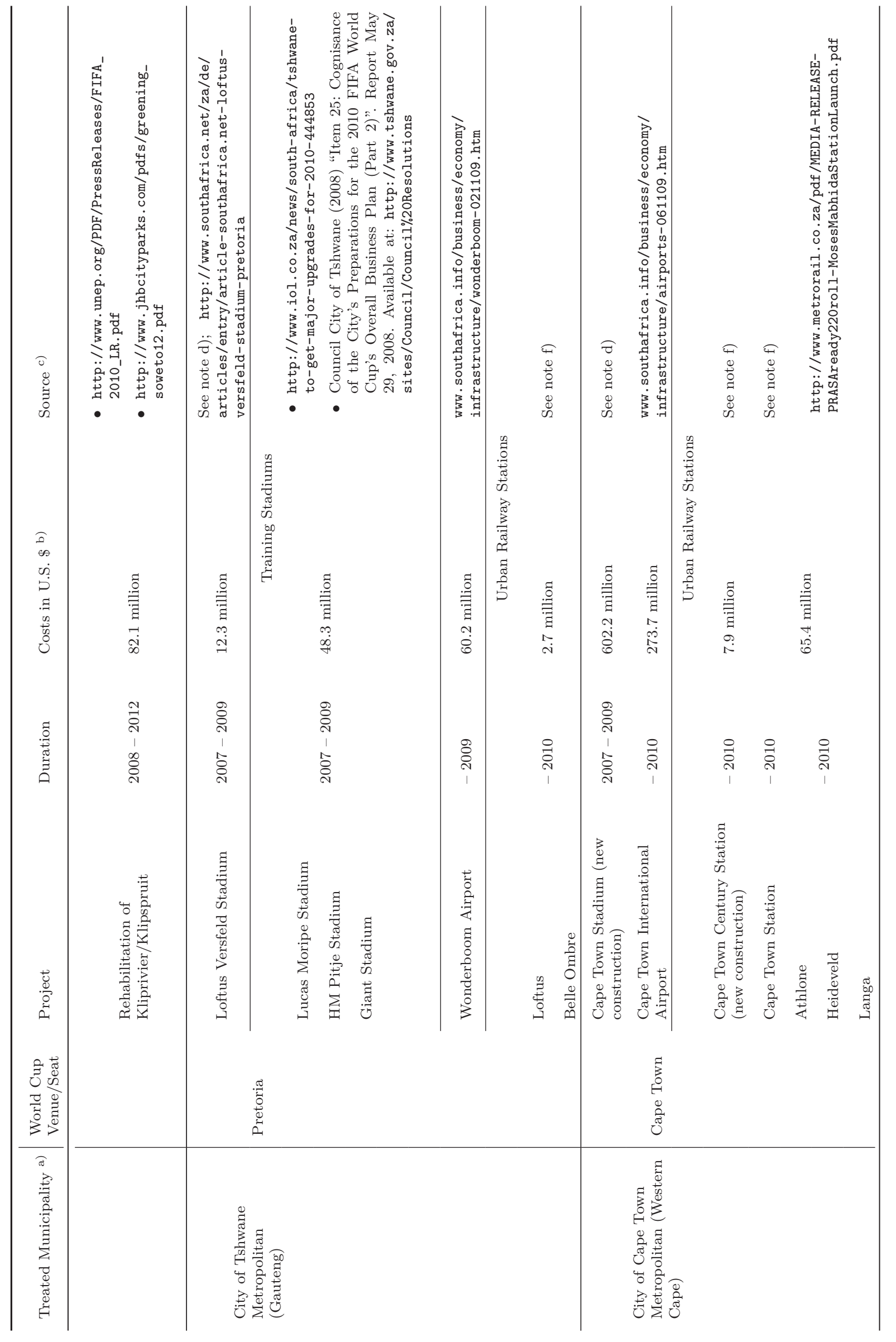




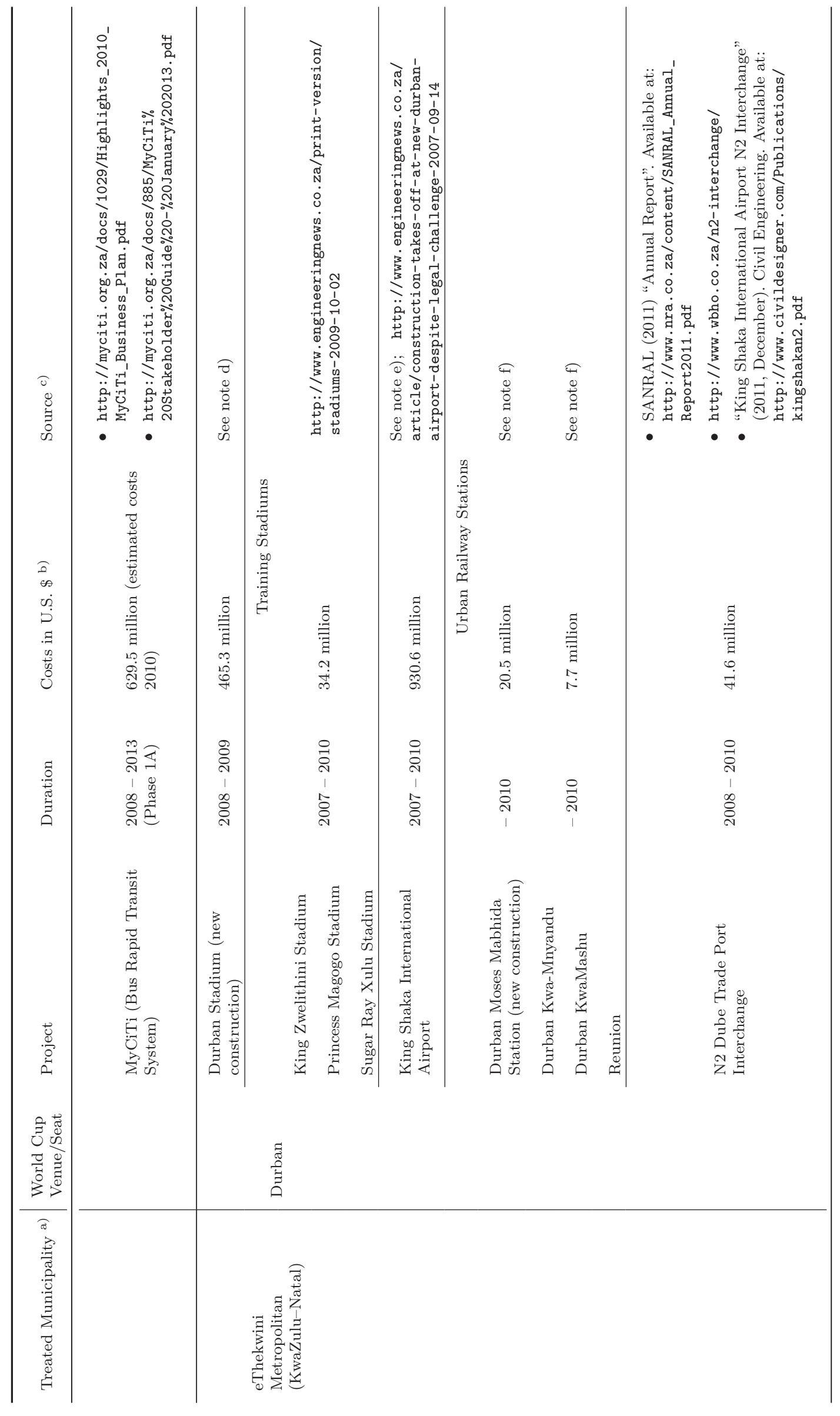




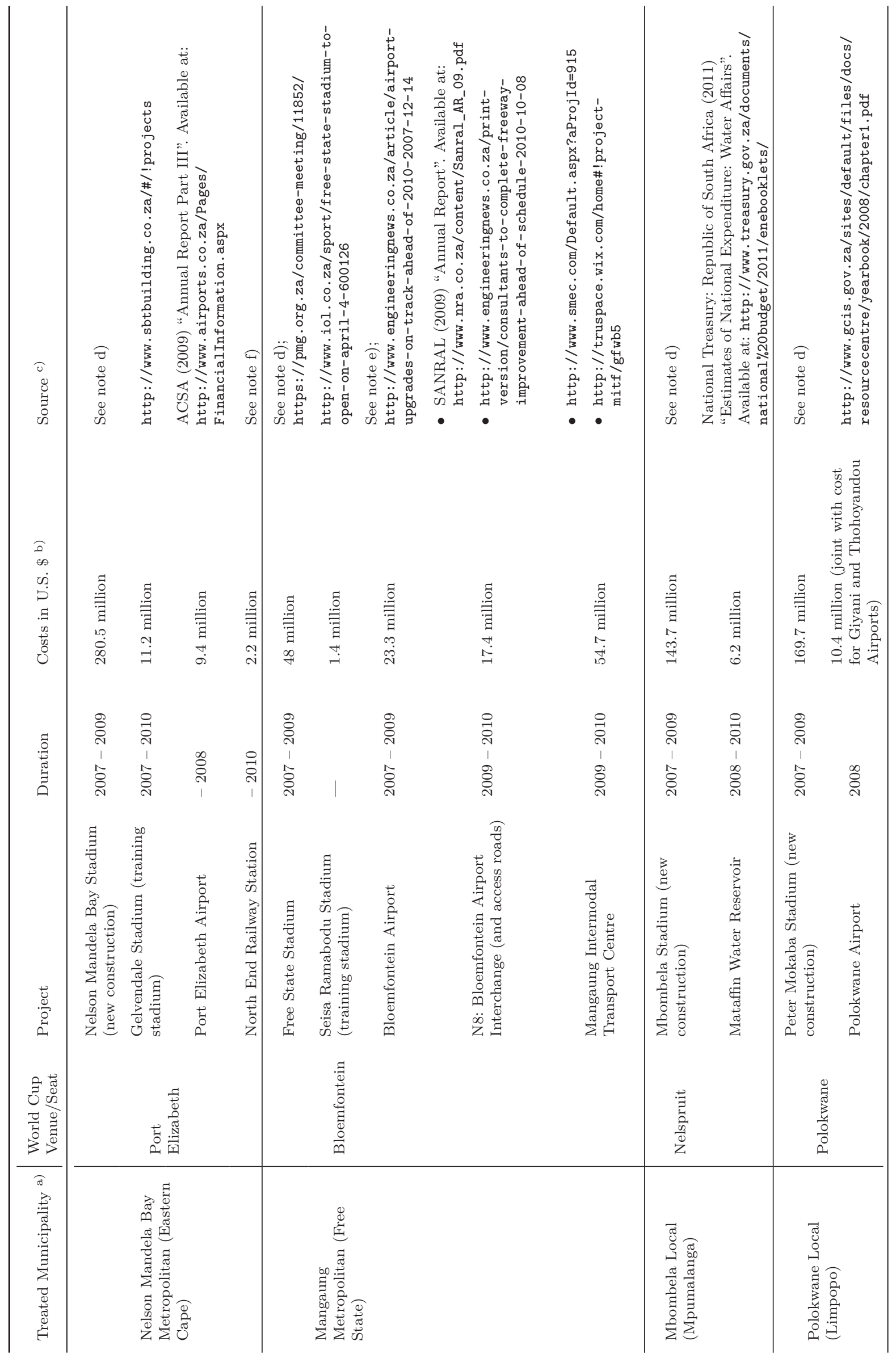




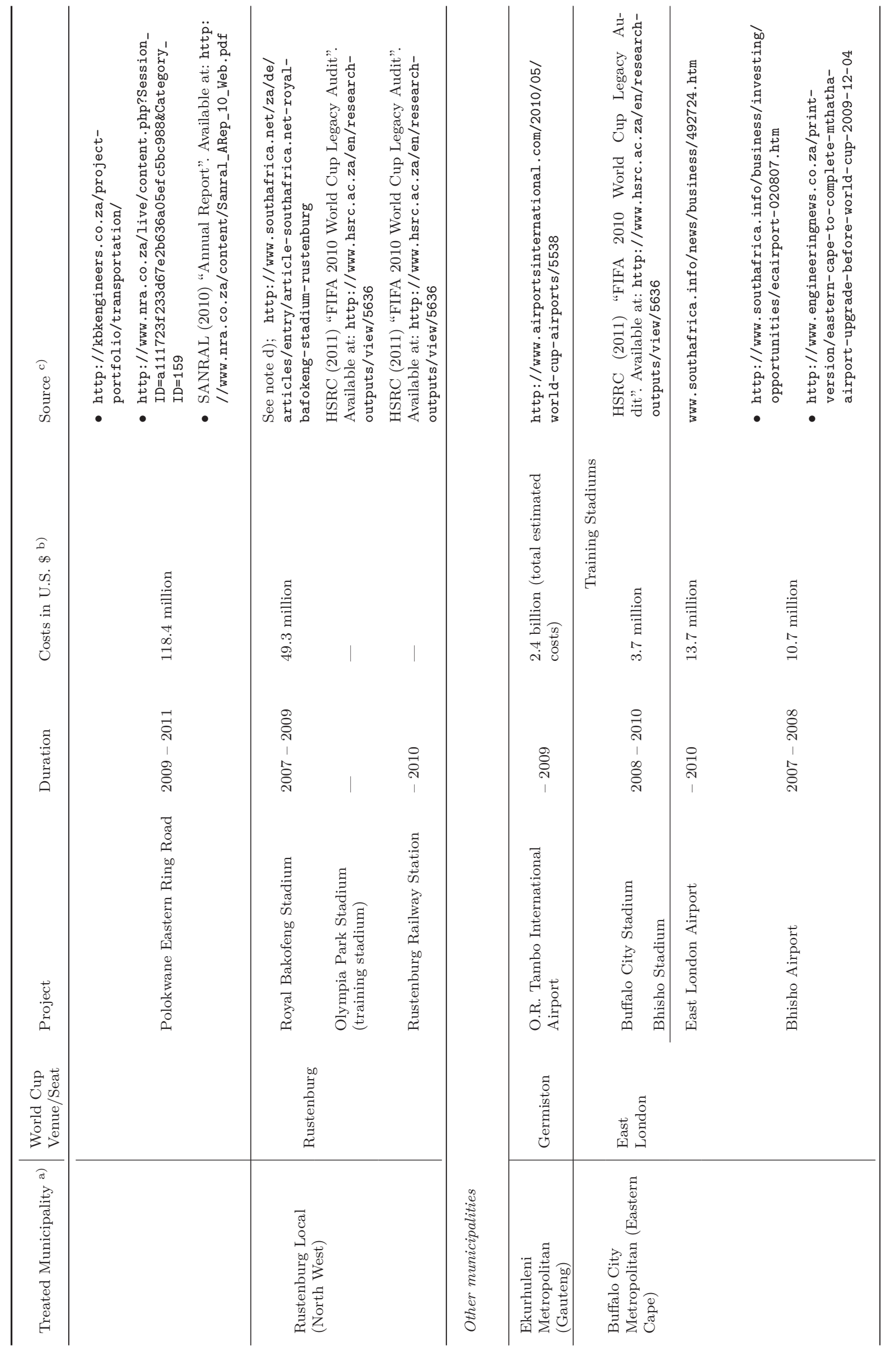




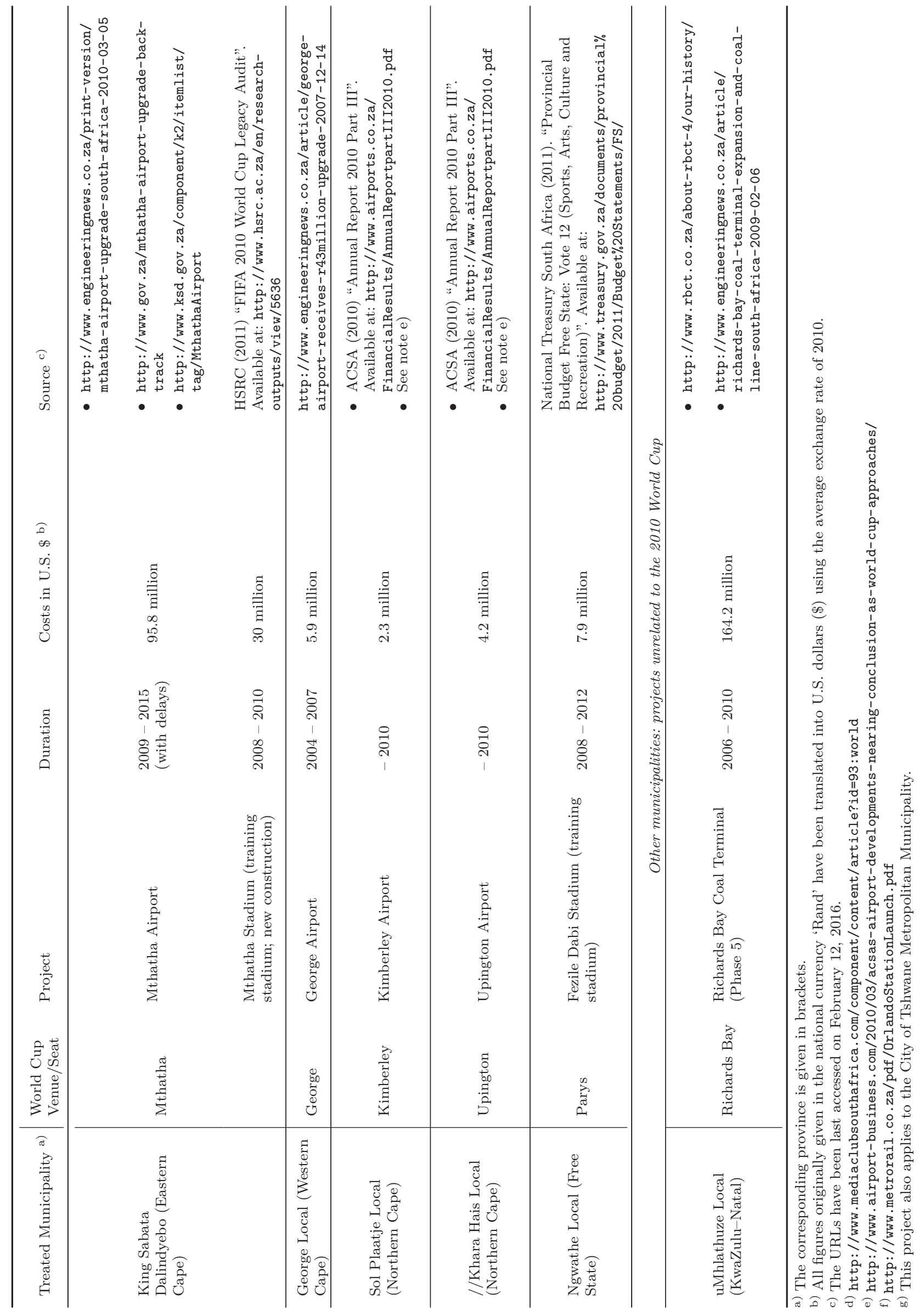




\section{Additional Tables and Figures}

\section{C.1 Tables}

Table C1.1: Descriptive Overview of the Muncipality Level Data Set

\begin{tabular}{lccccc}
\hline Variable & Obs. & Mean & Std. Dev. & Min. & Max. \\
\hline Luminosity & 5,192 & 3.117 & 6.432 & 0 & 58.107 \\
Area & 5,192 & $5,203.189$ & $5,395.449$ & 251.434 & $36,127.950$ \\
Distance to Railway & 5,192 & 2.045 & 6.854 & 0 & 44.842 \\
Elevation & 5,192 & 986.556 & 477.231 & 53.303 & $1,922.893$ \\
GDP per capita & 702 & $26,896.73$ & $9,828.787$ & $12,986.54$ & $56,768.83$ \\
Income per capita & 237 & $15,781.66$ & $11,986.76$ & $1,113.61$ & $82,477.9$ \\
Share Indigenous People & 472 & 0.008 & 0.024 & 0 & 0.206 \\
Share Tertiary Education & 708 & 0.02 & 0.019 & 0 & 0.125 \\
Soil Quality & 5,192 & 36.214 & 13.419 & 0.023 & 64.255 \\
Unemployment Rate & 944 & 33.714 & 16.356 & 6.100 & 84.07 \\
\hline
\end{tabular}

Table C1.2: Average World Cup Venue: Means of Economic Predictors (Pre-Treatment)

\begin{tabular}{lrr}
\hline Predictor & Actual & Synthetic \\
\hline Luminosity & 18.8757 & 18.74631 \\
Area & 3722.812 & 1111.97 \\
Distance to Railway & 0 & 0 \\
Elevation & 907.6775 & 332.8766 \\
Share Indigenous People & 0.033037 & 0.0330786 \\
Share Tertiary Education & 0.0660153 & 0.057515 \\
Soil Quality & 39.97758 & 49.94023 \\
Unemployment Rate & 37.65556 & 40.74773 \\
\hline
\end{tabular}

Note: Means for all economics predictors over the pre-treatment period (1992-2003). Predictors are explained in Section 2 and Appendix B. 
Table C1.3: Descriptive Overview of Ward Level Data Set for eThekwini

\begin{tabular}{lccccc}
\hline Variable & Obs. & Mean & Std. Dev. & Min. & Max. \\
\hline Luminosity & 2,266 & 47.251 & 17.103 & 2.332 & 63 \\
Area & 2,266 & 22.152 & 30.801 & 0.905 & 168.133 \\
Distance to Railway & 2,266 & 1.654 & 2.108 & 0 & 8.062 \\
Elevation & 2,266 & 185.676 & 157.428 & 9.296 & 676.806 \\
Soil Quality & 2,266 & 39.667 & 9.005 & 25 & 66 \\
\hline
\end{tabular}

Table C1.4: Descriptive Overview of Ward Level Data Set for Polokwane

\begin{tabular}{lccccc}
\hline Variable & Obs. & Mean & Std. Dev. & Min. & Max. \\
\hline Luminosity & 836 & 20.593 & 19.271 & 0.03 & 63 \\
Area & 836 & 99.105 & 213.076 & 2.59 & 1326.646 \\
Distance to Railway & 836 & 8.374 & 7.278 & 0 & 22.404 \\
Elevation & 836 & 1288.364 & 59.155 & 1181.695 & 1441.94 \\
Soil Quality & 836 & 54.817 & 5.921 & 33.261 & 61.892 \\
\hline
\end{tabular}

Table C1.5: Descriptive Overview of Ward Level Data Set for Rustenburg

\begin{tabular}{lccccc}
\hline Variable & Obs. & Mean & Std. Dev. & Min. & Max. \\
\hline Luminosity & 836 & 31.397 & 19.675 & 0.799 & 63 \\
Area & 836 & 90.086 & 183.592 & 0.872 & 1077.936 \\
Distance to Railway & 836 & 1.848 & 2.710 & 0 & 12.178 \\
Elevation & 836 & 1158.558 & 89.271 & 1034.207 & 1480.51 \\
Soil Quality & 836 & 53.665 & 3.965 & 40.033 & 59 \\
\hline
\end{tabular}




\section{C.2 Figures}

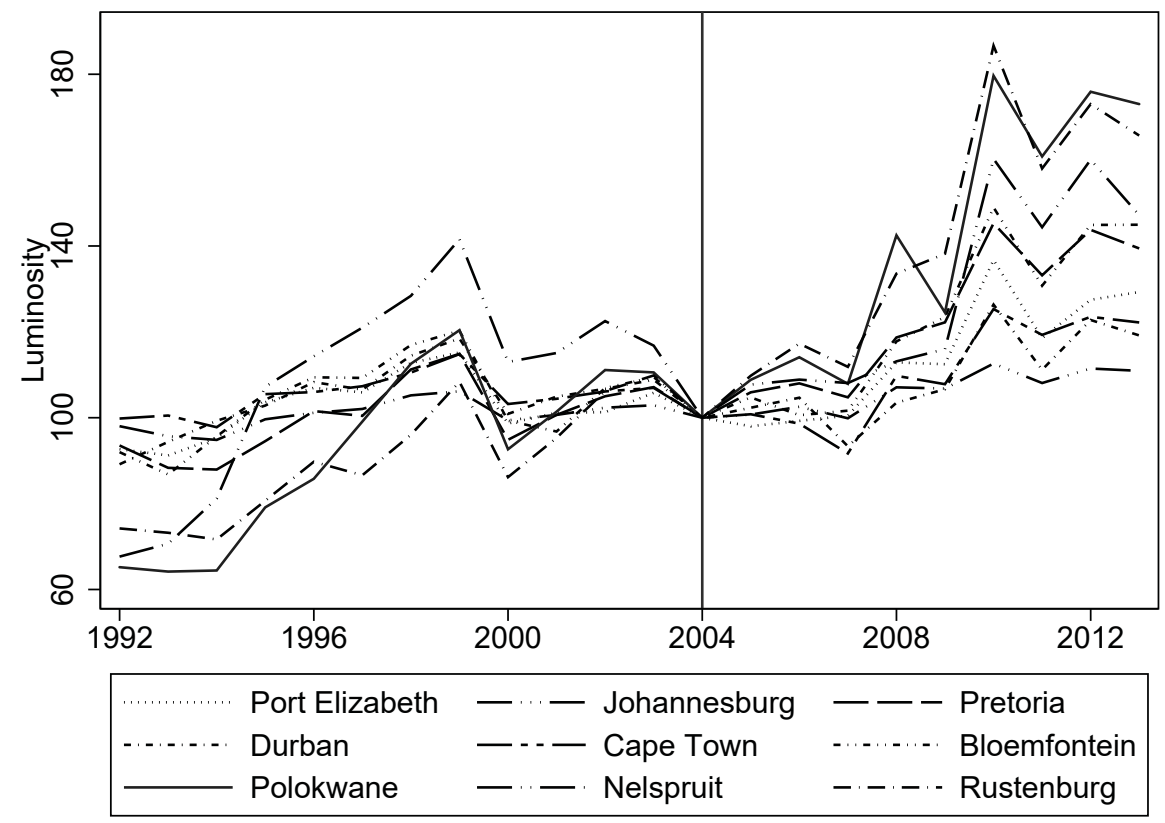

Note: The figure shows the temporal evolution of luminosity between 1992 and 2013 for each of the World Cup venues. Luminosity values are indexed with each municipality's value in 2004 being equal to 100 .

Figure C2.1: Mean Luminosity per World Cup Venue, 1992-2013

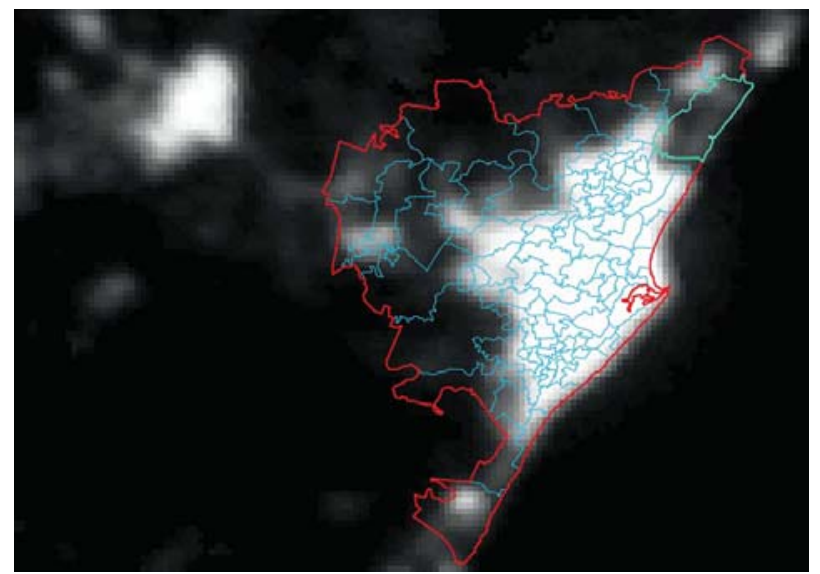

(a) Distribution of Luminosity in 2003

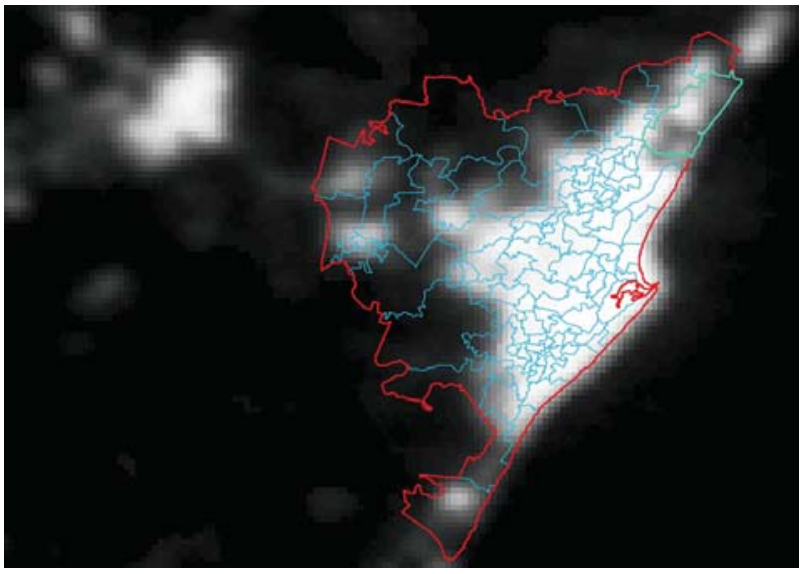

(b) Distribution of Luminosity in 2013

Note: Panel (a) displays pixel level luminosity within the eThekwini Metropolitan Municipality in the last pre-treatment year (2003). Panel (b) displays pixel level luminosity within the eThekwini Metropolitan Municipality in the last post-treatment year (2013). In both panels, the borders of the eThekwini Metropolitan Municipality are depicted in bold-type red, the wards within the municipality are colored in light-blue, and the treated wards are shown in bold-type light-green.

Figure C2.2: Pre- and Post-Treatment Pixel Level Distribution of Luminosity in eThekwini 


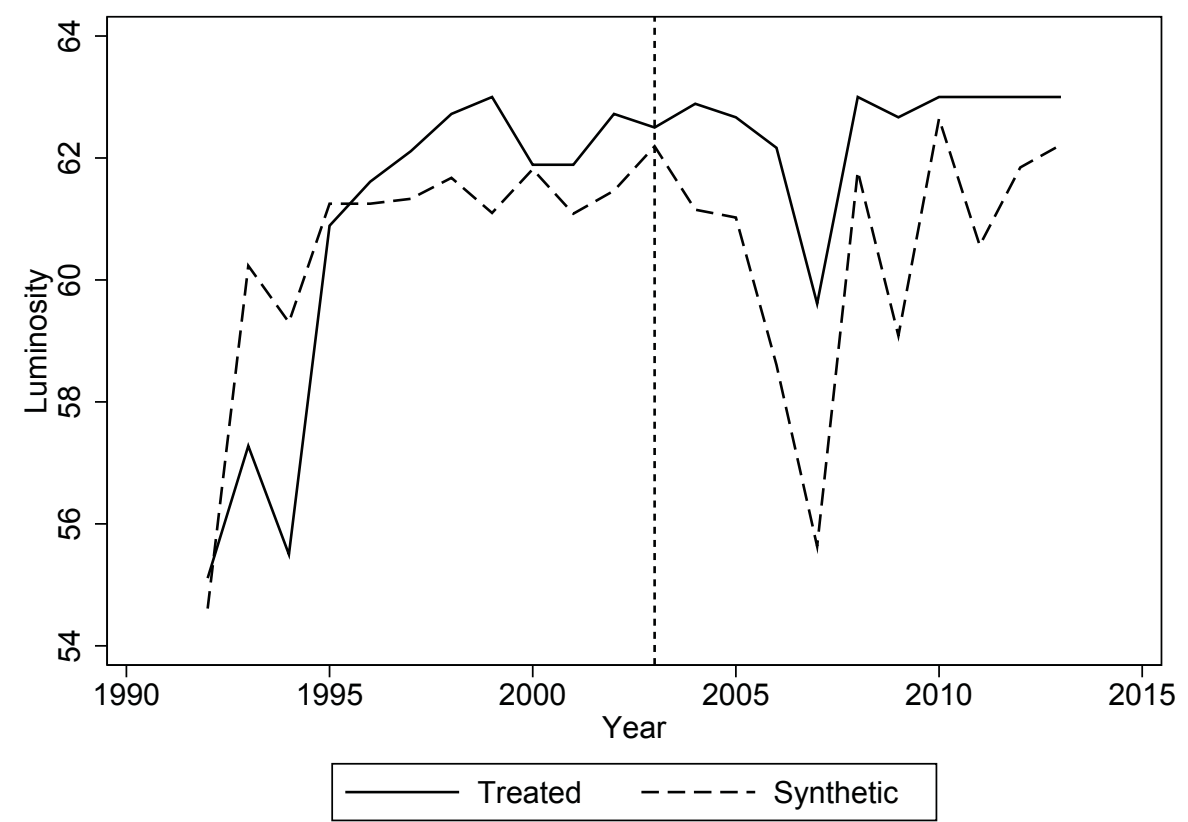

Note: The graphic displays the average World Cup venue and its synthetic counterpart.

Figure C2.3: Estimation Results for Cape Town Airport: Trends in Luminosity—Treated vs. Synthetic

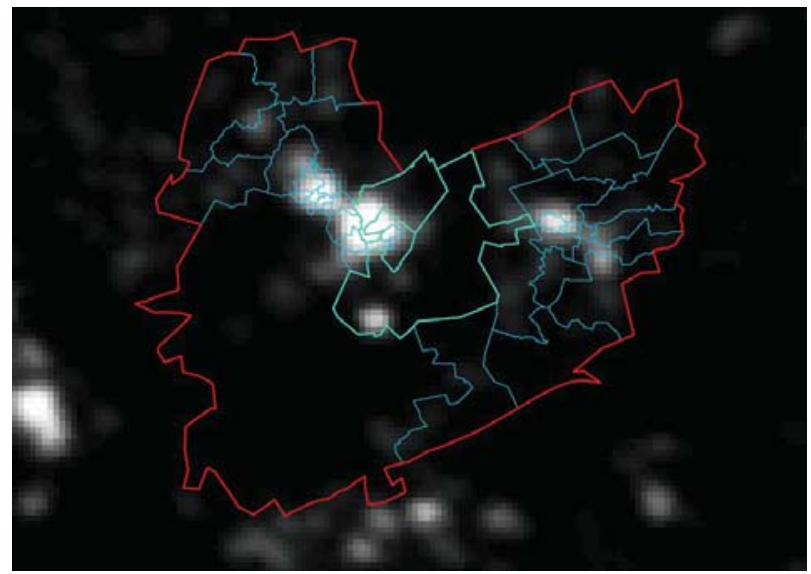

(a) Distribution of Luminosity in 2003

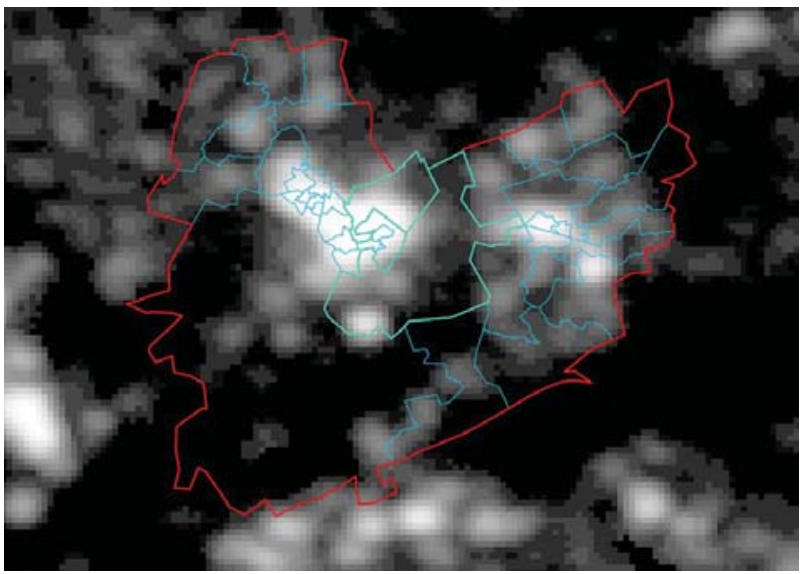

(b) Distribution of Luminosity in 2013

Note: Panel (a) displays pixel level luminosity within the Polokwane Local Municipality in the last pre-treatment year (2003). Panel (b) displays pixel level luminosity within the Polokwane Local Municipality in the last post-treatment year (2013). In both panels, the borders of the Polokwane Local Municipality are depicted in bold-type red, the wards within the municipality are colored in light-blue, and the treated wards are shown in bold-type light-green.

Figure C2.4: Pre- and Post-Treatment Pixel Level Distribution of Luminosity in Polokwane 


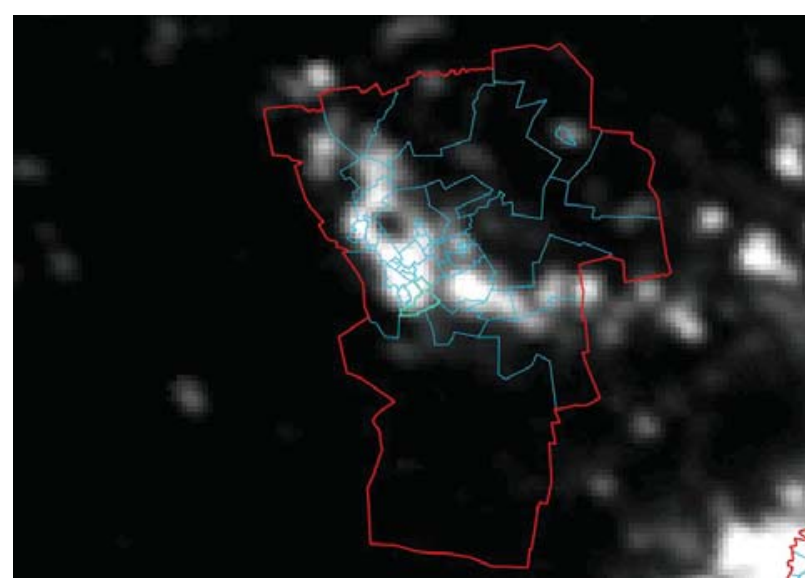

(a) Distribution of Luminosity in 2003

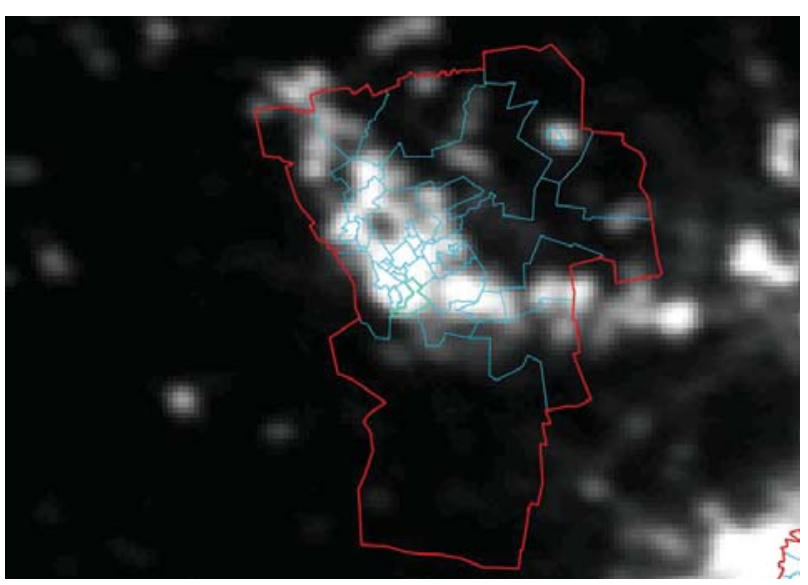

(b) Distribution of Luminosity in 2013

Note: Panel (a) displays pixel level luminosity within the Rustenburg Local Municipality in the last pre-treatment year (2003). Panel (b) displays pixel level luminosity within the Rustenburg Metropolitan Municipality in the last post-treatment year (2013). In both panels, the borders of the Rustenburg Metropolitan Municipality are depicted in bold-type red, the wards within the municipality are colored in light-blue, and the treated wards are shown in bold-type light-green.

Figure C2.5: Pre- and Post-Treatment Pixel Level Distribution of Luminosity in Rustenburg

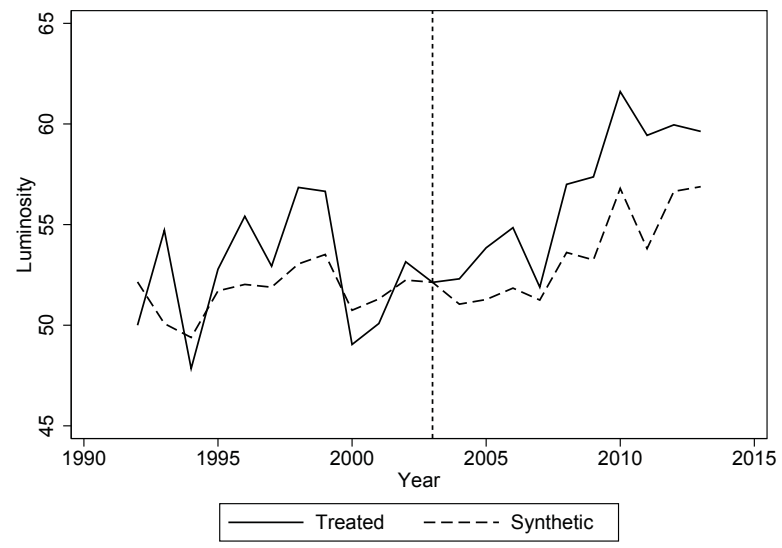

(a) Trends in Luminosity: Treated vs. Synthetic

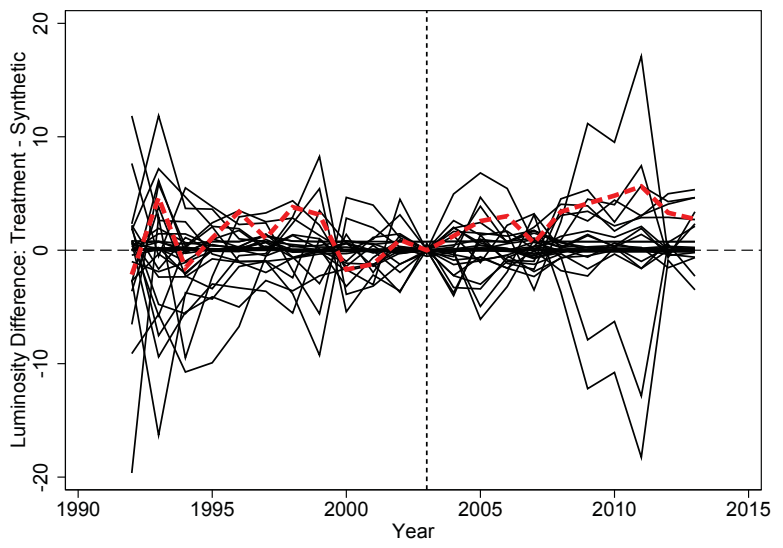

(b) Luminosity Gaps: Stadium Ward vs. Placebos

Note: The vertical dashed line indicates the end of the pre-treatment period (2003). Panel (a) displays the stadium ward and its synthetic counterpart. Panel (b) plots luminosity gaps (treatment minus synthetic) for the stadium ward and placebo units: the black solid lines and the red dashed line represent the placebos and the treated unit, respectively.

Figure C2.6: Estimation Results: Soccer City Stadium Johannesburg 


\section{Hohenheim Discussion Papers in Business, Economics and Social Sciences}

The Faculty of Business, Economics and Social Sciences continues since 2015 the established "FZID Discussion Paper Series" of the "Centre for Research on Innovation and Services (FZID)" under the name "Hohenheim Discussion Papers in Business, Economics and Social Sciences".

\section{Institutes}

510 Institute of Financial Management

520 Institute of Economics

530 Institute of Health Care \& Public Management

540 Institute of Communication Science

550 Institute of Law and Social Sciences

560 Institute of Economic and Business Education

570 Institute of Marketing \& Management

580 Institute of Interorganisational Management \& Performance

Download Hohenheim Discussion Papers in Business, Economics and Social Sciences from our homepage: https://wiso.uni-hohenheim.de/papers

Nr.

Autor

Titel

Inst.

01-2015 Thomas Beissinger, Philipp Baudy

THE IMPACT OF TEMPORARY AGENCY WORK

520

ON TRADE UNION WAGE SETTING:

A Theoretical Analysis

02-2015 Fabian Wahl

PARTICIPATIVE POLITICAL INSTITUTIONS AND

520

CITY DEVELOPMENT 800-1800

03-2015 Tommaso Proietti,

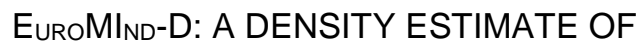

520

Martyna Marczak,

Gianluigi Mazzi

MONTHLY GROSS DOMESTIC PRODUCT FOR

THE EURO AREA

04-2015 Thomas Beissinger,

OFFSHORING AND LABOUR MARKET REFORMS:

Nathalie Chusseau,

MODELLING THE GERMAN EXPERIENCE

Joël Hellier

05-2015 Matthias Mueller,

Kristina Bogner,

Tobias Buchmann,

SIMULATING KNOWLEDGE DIFFUSION IN FOUR

520

STRUCTURALLY DISTINCT NETWORKS

- AN AGENT-BASED SIMULATION MODEL

Muhamed Kudic

06-2015 Martyna Marczak,

Thomas Beissinger

BIDIRECTIONAL RELATIONSHIP BETWEEN

520

INVESTOR SENTIMENT AND EXCESS RETURNS:

NEW EVIDENCE FROM THE WAVELET PERSPECTIVE

07-2015 Peng Nie,

Galit Nimrod,

INTERNET USE AND SUBJECTIVE WELL-BEING

IN CHINA

Alfonso Sousa-Poza

08-2015 Fabian Wahl

THE LONG SHADOW OF HISTORY

ROMAN LEGACY AND ECONOMIC DEVELOPMENT

520

- EVIDENCE FROM THE GERMAN LIMES

09-2015 Peng Nie,

Alfonso Sousa-Poza

COMMUTE TIME AND SUBJECTIVE WELL-BEING IN

URBAN CHINA 
Nr. Autor

10-2015 Kristina Bogner

11-2015 Bogang Jun, Tai-Yoo Kim

12-2015 Volker Grossmann Aderonke Osikominu Marius Osterfeld

13-2015 Martyna Marczak Tommaso Proietti Stefano Grassi

14-2015 Carolina Castagnetti Luisa Rosti Marina Töpfer

15-2015 Alexander Opitz

01-2016 Michael Ahlheim, Jan Neidhardt

02-2016 Bogang Jun, Alexander Gerybadze, Tai-Yoo Kim

03-2016 Peng Nie, Alfonso Sousa-Poza

04-2016 Peter Spahn

05-2016 Vincent Dekker, Kristina Strohmaier, Nicole Bosch

06-2016 Philipp Baudy, Dario Cords

07-2016 Robin Jessen, Davud Rostam-Afschar, Sebastian Schmitz

08-2016 Peng Nie, Alfonso Sousa-Poza, Jianhong Xue
Titel

Inst.

THE EFFECT OF PROJECT FUNDING ON

520

INNOVATIVE PERFORMANCE

AN AGENT-BASED SIMULATION MODEL

A NEO-SCHUMPETERIAN PERSPECTIVE ON THE ANALYTICAL MACROECONOMIC FRAMEWORK: THE EXPANDED REPRODUCTION SYSTEM

ARE SOCIOCULTURAL FACTORS IMPORTANT FOR STUDYING A SCIENCE UNIVERSITY MAJOR?

520

A DATA-CLEANING AUGMENTED KALMAN FILTER 520 FOR ROBUST ESTIMATION OF STATE SPACE MODELS

THE REVERSAL OF THE GENDER PAY GAP AMONG PUBLIC-CONTEST SELECTED YOUNG EMPLOYEES

520

DEMOCRATIC PROSPECTS IN IMPERIAL RUSSIA: THE REVOLUTION OF 1905 AND THE POLITICAL STOCK MARKET

NON-TRADING BEHAVIOUR IN CHOICE EXPERIMENTS

520

THE LEGACY OF FRIEDRICH LIST: THE EXPANSIVE REPRODUCTION SYSTEM AND THE KOREAN HISTORY OF INDUSTRIALIZATION

FOOD INSECURITY AMONG OLDER EUROPEANS: EVIDENCE FROM THE SURVEY OF HEALTH, AGEING, AND RETIREMENT IN EUROPE

POPULATION GROWTH, SAVING, INTEREST RATES AND STAGNATION. DISCUSSING THE EGGERTSSONMEHROTRA-MODEL

A DATA-DRIVEN PROCEDURE TO DETERMINE THE BUNCHING WINDOW - AN APPLICATION TO THE NETHERLANDS

DEREGULATION OF TEMPORARY AGENCY EMPLOYMENT IN A UNIONIZED ECONOMY: DOES THIS REALLY LEAD TO A SUBSTITUTION OF REGULAR EMPLOYMENT?

HOW IMPORTANT IS PRECAUTIONARY LABOR SUPPLY? 
Nr. Autor Titel Inst.

09-2016 Bogang Jun, Seung Kyu-Yi, Tobias Buchmann, Matthias Müller

10-2016 Vladan Ivanovic, Vadim Kufenko, Boris Begovic Nenad Stanisic, Vincent Geloso

11-2016 David E. Bloom Michael Kuhn Klaus Prettner

12-2016 Franz X. Hof Klaus Prettner

13-2016 Jung-In Yeon Andreas Pyka Tai-Yoo Kim

14-2016 Benjamin Fuchs

15-2016 Seung-Kyu Yi Bogang Jun

16-2016 Gregor Pfeifer Fabian Wahl Martyna Marczak
THE CO-EVOLUTION OF INNOVATION NETWORKS: COLLABORATION BETWEEN WEST AND EAST GERMANY FROM 1972 TO 2014

CONTINUITY UNDER A DIFFERENT NAME. THE OUTCOME OF PRIVATISATION IN SERBIA

THE CONTRIBUTION OF FEIA
ECONOMIC DEVELOPMENT

THE QUEST FOR STATUS AND R\&D-BASED GROWTH

STRUCTURAL SHIFT AND INCREASING VARIETY IN 520 KOREA, 1960-2010: EMPIRICAL EVIDENCE OF THE ECONOMIC DEVELOPMENT MODEL BY THE CREATION OF NEW SECTORS

THE EFFECT OF TEENAGE EMPLOYMENT ON

CHARACTER SKILLS, EXPECTATIONS AND OCCUPATIONAL CHOICE STRATEGIES

HAS THE GERMAN REUNIFICATION STRENGTHENED GERMANY'S NATIONAL INNOVATION SYSTEM? TRIPLE HELIX DYNAMICS OF GERMANY'S INNOVATION SYSTEM

ILLUMINATING THE WORLD CUP EFFECT: NIGHT LIGHTS EVIDENCE FROM SOUTH AFRICA 520

520 


\section{FZID Discussion Papers}

(published 2009-2014)

\section{Competence Centers}

IK Innovation and Knowledge

ICT Information Systems and Communication Systems

CRFM Corporate Finance and Risk Management

$\mathrm{HCM} \quad$ Health Care Management

$\mathrm{CM} \quad$ Communication Management

MM Marketing Management

ECO Economics

Download FZID Discussion Papers from our homepage: https://wiso.uni-hohenheim.de/archiv_fzid_papers

Nr. Autor

Titel

CC

01-2009 Julian P. Christ

02-2009 André P. Slowak

03-2009 Pier Paolo Saviotti, Andreas Pyka

04-2009 Uwe Focht, Andreas Richter and Jörg

Schiller

05-2009 Julian P. Christ, André P. Slowak

06-2009 Gabriel Felbermayr, Mario Larch and Wolfgang Lechthaler

07-2009 Steffen Otterbach

08-2009 Sven Wydra

09-2009 Ralf Richter, Jochen Streb
NEW ECONOMIC GEOGRAPHY RELOADED:

IK

Localized Knowledge Spillovers and the Geography of Innovation

MARKET FIELD STRUCTURE \& DYNAMICS IN INDUSTRIAL

IK AUTOMATION

GENERALIZED BARRIERS TO ENTRY AND ECONOMIC

IK DEVELOPMENT

INTERMEDIATION AND MATCHING IN INSURANCE MARKETS

WHY BLU-RAY VS. HD-DVD IS NOT VHS VS. BETAMAX:

IK THE CO-EVOLUTION OF STANDARD-SETTING CONSORTIA

UNEMPLOYMENT IN AN INTERDEPENDENT WORLD

MISMATCHES BETWEEN ACTUAL AND PREFERRED WORK TIME: Empirical Evidence of Hours Constraints in 21 Countries

$\mathrm{HCM}$ PRODUCTION AND EMPLOYMENT IMPACTS OF NEW

IK TECHNOLOGIES - ANALYSIS FOR BIOTECHNOLOGY

IK 
Nr.

Autor

Titel

CC

KYOTO AND THE CARBON CONTENT OF TRADE

ECO

Gabriel Felbermayr

11-2010 David E. Bloom,

ECONOMIC CONSEQUENCES OF LOW FERTILITY IN EUROPE

$\mathrm{HCM}$

Alfonso Sousa-Poza

12-2010 Michael Ahlheim, Oliver Frör

DRINKING AND PROTECTING - A MARKET APPROACH TO THE PRESERVATION OF CORK OAK LANDSCAPES

ECO

LABOUR AS A UTILITY MEASURE IN CONTINGENT VALUATION STUDIES - HOW GOOD IS IT REALLY?

ECO

Oliver Frör,

Antonia Heinke,

Nguyen Minh Duc,

and Pham Van Dinh

14-2010 Julian P. Christ

THE GEOGRAPHY AND CO-LOCATION OF EUROPEAN

IK

TECHNOLOGY-SPECIFIC CO-INVENTORSHIP NETWORKS

15-2010 Harald Degner

WINDOWS OF TECHNOLOGICAL OPPORTUNITY

DO TECHNOLOGICAL BOOMS INFLUENCE THE RELATIONSHIP BETWEEN FIRM SIZE AND INNOVATIVENESS?

16-2010 Tobias A. Jopp

THE WELFARE STATE EVOLVES:

GERMAN KNAPPSCHAFTEN, 1854-1923

$\mathrm{HCM}$

17-2010 Stefan Kirn (Ed.)

PROCESS OF CHANGE IN ORGANISATIONS THROUGH

ICT

eHEALTH

18-2010 Jörg Schiller

ÖKONOMISCHE ASPEKTE DER ENTLOHNUNG

$\mathrm{HCM}$

UND REGULIERUNG UNABHÄNGIGER

VERSICHERUNGSVERMITTLER

19-2010 Frauke Lammers,

CONTRACT DESIGN AND INSURANCE FRAUD: AN

$\mathrm{HCM}$

Jörg Schiller

EXPERIMENTAL INVESTIGATION

REAL WAGES AND THE BUSINESS CYCLE IN GERMANY

ECO

Thomas Beissinger

21-2010 Harald Degner,

Jochen Streb

FOREIGN PATENTING IN GERMANY, 1877-1932

IK

DOES DOWNWARD NOMINAL WAGE RIGIDITY

DAMPEN WAGE INCREASES?

ECO

Thomas Beissinger

23-2010 Mark Spoerer,

GUNS AND BUTTER - BUT NO MARGARINE: THE IMPACT OF Jochen Streb

NAZI ECONOMIC POLICIES ON GERMAN FOOD

ECO CONSUMPTION, 1933-38 
Nr.

Autor

Titel

24-2011 Dhammika Dharmapala, Nadine Riedel

25-2011 Michael Schuele, Stefan Kirn

26-2011 Marcus Müller, Guillaume Stern, Ansger Jacob and Stefan Kirn

27-2011 Monnet Benoit, Patrick Gbakoua and Alfonso Sousa-Poza

28-2011 Nadine Riedel, Hannah SchildbergHörisch

29-2011 Nicole Waidlein

30-2011 Dominik Hartmann, Atilio Arata

31-2011 Peter Spahn

32-2011 Fabian Wahl

33-2011 Giorgio Triulzi, Ramon Scholz and Andreas Pyka

34-2011 Claus D. MüllerHengstenberg, Stefan Kirn

35-2011 Andreas Pyka

36-2011 David Bell, Steffen Otterbach and Alfonso Sousa-Poza

37-2011 Lukas Scheffknecht, Felix Geiger

38-2011 Yin Krogmann, Ulrich Schwalbe
EARNINGS SHOCKS AND TAX-MOTIVATED INCOME-SHIFTING: EVIDENCE FROM EUROPEAN MULTINATIONALS

ECO

ICT

QUALITATIVES, RÄUMLICHES SCHLIEßEN ZUR KOLLISIONSERKENNUNG UND KOLLISIONSVERMEIDUNG AUTONOMER BDI-AGENTEN

VERHALTENSMODELLE FÜR SOFTWAREAGENTEN IM ICT PUBLIC GOODS GAME

ECO

ENGEL CURVES, SPATIAL VARIATION IN PRICES AND

DEMAND FOR COMMODITIES IN CÔTE D'IVOIRE

ASYMMETRIC OBLIGATIONS

ECO

CAUSES OF PERSISTENT PRODUCTIVITY DIFFERENCES IN THE WEST GERMAN STATES IN THE PERIOD FROM 1950 TO 1990

MEASURING SOCIAL CAPITAL AND INNOVATION IN POOR AGRICULTURAL COMMUNITIES. THE CASE OF CHÁPARRA PERU

DIE WÄHRUNGSKRISENUNION

DIE EURO-VERSCHULDUNG DER NATIONALSTAATEN ALS SCHWACHSTELLE DER EWU

ECO

DIE ENTWICKLUNG DES LEBENSSTANDARDS IM DRITTEN REICH - EINE GLÜCKSÖKONOMISCHE PERSPEKTIVE

ECO

R\&D AND KNOWLEDGE DYNAMICS IN UNIVERSITY-INDUSTRY

IK RELATIONSHIPS IN BIOTECH AND PHARMACEUTICALS: AN AGENT-BASED MODEL

ANWENDUNG DES ÖFFENTLICHEN VERGABERECHTS AUF MODERNE IT SOFTWAREENTWICKLUNGSVERFAHREN

ICT

AVOIDING EVOLUTIONARY INEFFICIENCIES

IK IN INNOVATION NETWORKS

WORK HOURS CONSTRAINTS AND HEALTH

$\mathrm{HCM}$

A BEHAVIORAL MACROECONOMIC MODEL WITH

ECO ENDOGENOUS BOOM-BUST CYCLES AND LEVERAGE DYNAMICS

INTER-FIRM R\&D NETWORKS IN THE GLOBAL PHARMACEUTICAL BIOTECHNOLOGY INDUSTRY DURING 1985-1998: A CONCEPTUAL AND EMPIRICAL ANALYSIS 
Nr.

39-2011 Michael Ahlheim, Tobias Börger and Oliver Frör

40-2011 Tobias Börger

41-2011 Ralf Rukwid, Julian P. Christ
RESPONDENT INCENTIVES IN CONTINGENT VALUATION: THE ECO ROLE OF RECIPROCITY

A DIRECT TEST OF SOCIALLY DESIRABLE RESPONDING IN CONTINGENT VALUATION INTERVIEWS

ECO

QUANTITATIVE CLUSTERIDENTIFIKATION AUF EBENE

IK DER DEUTSCHEN STADT- UND LANDKREISE (1999-2008) 
Nr.

Autor

Titel

42-2012 Benjamin Schön,

A TAXONOMY OF INNOVATION NETWORKS

IK

Andreas Pyka

43-2012 Dirk Foremny, Nadine Riedel

BUSINESS TAXES AND THE ELECTORAL CYCLE

ECO

44-2012 Gisela Di Meglio, Andreas Pyka and

VARIETIES OF SERVICE ECONOMIES IN EUROPE

IK

Luis Rubalcaba

45-2012 Ralf Rukwid, Julian P. Christ

INNOVATIONSPOTENTIALE IN BADEN-WÜRTTEMBERG:

IK

PRODUKTIONSCLUSTER IM BEREICH „METALL, ELEKTRO, IKT“ UND REGIONALE VERFÜGBARKEIT AKADEMISCHER FACHKRÄFTE IN DEN MINT-FÄCHERN

46-2012 Julian P. Christ,

INNOVATIONSPOTENTIALE IN BADEN-WÜRTTEMBERG:

IK Ralf Rukwid BRANCHENSPEZIFISCHE FORSCHUNGS- UND ENTWICKLUNGSAKTIVITÄT, REGIONALES PATENTAUFKOMMEN UND BESCHÄFTIGUNGSSTRUKTUR

47-2012 Oliver Sauter

ASSESSING UNCERTAINTY IN EUROPE AND THE

ECO US - IS THERE A COMMON FACTOR?

IK

SEN MEETS SCHUMPETER. INTRODUCING STRUCTUR
DYNAMIC ELEMENTS INTO THE HUMAN CAPABILITY APPROACH

49-2012 Harold ParedesFrigolett, Andreas Pyka

DISTAL EMBEDDING AS A TECHNOLOGY INNOVATION

IK NETWORK FORMATION STRATEGY

CYCLICALITY OF REAL WAGES IN THE USA AND GERMANY: NEW INSIGHTS FROM WAVELET ANALYSIS

ECO

Martyna Marczak Víctor Gómez

DIE DURCHSETZUNG VON SCHNITTSTELLEN

IK IN DER STANDARDSETZUNG:

FALLBEISPIEL LADESYSTEM ELEKTROMOBILITÄT

52-2012 Fabian Wahl

WHY IT MATTERS WHAT PEOPLE THINK - BELIEFS, LEGAL

ECO ORIGINS AND THE DEEP ROOTS OF TRUST

IK

Micha Kaiser

STATISTISCHER ÜBERBLICK DER TÜRKISCHEN MIGRATION IN BADEN-WÜRTTEMBERG UND DEUTSCHLAND

IDENTIFIZIERUNG UND ANALYSE DEUTSCH-TÜRKISCHER INNOVATIONSNETZWERKE. ERSTE ERGEBNISSE DES TGIN-

Andreas Pyka, Seda Aydin, Lena Klauß, Fabian Stahl, Ali PROJEKTES

Santircioglu, Silvia Oberegelsbacher, Sheida Rashidi, Gaye Onan and Suna Erginkoç

55-2012 Michael Ahlheim, Tobias Börger and Oliver Frör DESERT: A CONTINGENT VALUATION STUDY IN RURAL SOUTHWEST CHINA 
Nr. Autor

56-2012 Matthias Strifler Thomas Beissinger

57-2012 Peter Spahn

58-2012 Sibylle H. Lehmann

59-2012 Sibylle H. Lehmann, Philipp Hauber and Alexander Opitz

60-2012 Martyna Marczak, Víctor Gómez

61-2012 Theresa Lohse, Nadine Riedel
FAIRNESS CONSIDERATIONS IN LABOR UNION WAGE SETTING - A THEORETICAL ANALYSIS

INTEGRATION DURCH WÄHRUNGSUNION? DER FALL DER EURO-ZONE

TAKING FIRMS TO THE STOCK MARKET:

IPOS AND THE IMPORTANCE OF LARGE BANKS IN IMPERIAL GERMANY 1896-1913

POLITICAL RIGHTS, TAXATION, AND FIRM VALUATION -

ECO EVIDENCE FROM SAXONY AROUND 1900

SPECTRAN, A SET OF MATLAB PROGRAMS FOR SPECTRAL

ECO ANALYSIS

THE IMPACT OF TRANSFER PRICING REGULATIONS ON PROFIT SHIFTING WITHIN EUROPEAN MULTINATIONALS
ECO

ECO

ECO

ECO 
Nr. Autor

63-2013 David E. Bloom,

AGEING AND PRODUCTIVITY

$\mathrm{HCM}$

Alfonso Sousa-Poza

64-2013 Martyna Marczak,

MONTHLY US BUSINESS CYCLE INDICATORS:

ECO Víctor Gómez

A NEW MULTIVARIATE APPROACH BASED ON A BAND-PASS FILTER

65-2013 Dominik Hartmann,

INNOVATION, ECONOMIC DIVERSIFICATION AND HUMAN

IK

Andreas Pyka

DEVELOPMENT

66-2013 Christof Ernst,

CORPORATE TAXATION AND THE QUALITY OF RESEARCH

ECO

Katharina Richter and AND DEVELOPMENT

Nadine Riede

67-2013 Michael Ahlheim, Oliver Frör, Jiang Tong, Luo Jing and Sonna Pelz

68-2013 Michael Ahlheim, Friedrich Schneider

CONSIDERING HOUSEHOLD SIZE IN CONTINGENT VALUATION STUDIES

69-2013 Fabio Bertoni, Tereza Tykvová

WHICH FORM OF VENTURE CAPITAL IS MOST SUPPORTIVE OF INNOVATION?

EVIDENCE FROM EUROPEAN BIOTECHNOLOGY COMPANIES

70-2013 Tobias Buchmann, Andreas Pyka

THE EVOLUTION OF INNOVATION NETWORKS:

THE CASE OF A GERMAN AUTOMOTIVE NETWORK Pyka, J. A. La Poutré and A. G. de Kok

72-2013 Beatriz Fabiola López Ulloa, Valerie Møller and Alfonso SousaPoza

73-2013 Wencke Gwozdz, Alfonso Sousa-Poza, Lucia A. Reisch, Wolfgang Ahrens, Stefaan De Henauw, Gabriele Eiben, Juan M. Fernández-Alvira, Charalampos Hadjigeorgiou, Eva Kovács, Fabio Lauria, Toomas Veidebaum, Garrath Williams, Karin Bammann

HOW DOES SUBJECTIVE WELL-BEING EVOLVE WITH AGE? 
Nr.

Autor

74-2013 Andreas Haas, Annette Hofmann

75-2013 Yin Krogmann, Nadine Riedel and Ulrich Schwalbe

76-2013 Peter Spahn

77-2013 Sheida Rashidi, Andreas Pyka

78-2013 Benjamin Schön, Andreas Pyka

79-2013 Irene Prostolupow, Andreas Pyka and Barbara Heller-Schuh

80-2013 Eva Schlenker, Kai D. Schmid

81-2013 Michael Ahlheim, Tobias Börger and Oliver Frör

82-2013 Fabian Wahl

83-2013 Peter Spahn

84-2013 Daniel Guffarth, Michael J. Barber
RISIKEN AUS CLOUD-COMPUTING-SERVICES:

$\mathrm{HCM}$ FRAGEN DES RISIKOMANAGEMENTS UND ASPEKTE DER VERSICHERBARKEIT

INTER-FIRM R\&D NETWORKS IN PHARMACEUTICAL

ECO, IK BIOTECHNOLOGY: WHAT DETERMINES FIRM'S CENTRALITY-BASED PARTNERING CAPABILITY?

MACROECONOMIC STABILISATION AND BANK LENDING:

ECO A SIMPLE WORKHORSE MODEL

MIGRATION AND INNOVATION - A SURVEY

IK

THE SUCCESS FACTORS OF TECHNOLOGY-SOURCING THROUGH MERGERS \& ACQUISITIONS - AN INTUITIVE METAANALYSIS

TURKISH-GERMAN INNOVATION NETWORKS IN THE EUROPEAN RESEARCH LANDSCAPE

IK

ECO

CAPITAL INCOME SHARES AND INCOME INEQUALITY IN THE EUROPEAN UNION

ECO

THE INFLUENCE OF ETHNICITY AND CULTURE ON THE VALUATION OF ENVIRONMENTAL IMPROVEMENTS - RESULTS FROM A CVM STUDY IN SOUTHWEST CHINA -

DOES MEDIEVAL TRADE STILL MATTER? HISTORICAL TRADE CENTERS, AGGLOMERATION AND CONTEMPORARY ECONOMIC DEVELOPMENT

SUBPRIME AND EURO CRISIS: SHOULD WE BLAME THE ECO ECONOMISTS?

THE EUROPEAN AEROSPACE R\&D COLLABORATION

IK NETWORK

KARTELLBEKÄMPFUNG UND INTERNE KARTELLSTRUKTUREN

IK EIN NETZWERKTHEORETISCHER ANSATZ 
Nr.

Autor

86-2014 Stefan Kirn, Claus D.

INTELLIGENTE (SOFTWARE-)AGENTEN: EINE NEUE

ICT Müller-Hengstenberg HERAUSFORDERUNG FÜR DIE GESELLSCHAFT UND UNSER RECHTSSYSTEM?

87-2014 Peng Nie, Alfonso

MATERNAL EMPLOYMENT AND CHILDHOOD OBESITY IN $\mathrm{HCM}$ Sousa-Poza CHINA: EVIDENCE FROM THE CHINA HEALTH AND NUTRITION SURVEY

88-2014 Steffen Otterbach, Alfonso Sousa-Poza

JOB INSECURITY, EMPLOYABILITY, AND HEALTH:

$\mathrm{HCM}$ AN ANALYSIS FOR GERMANY ACROSS GENERATIONS

89-2014 Carsten Burhop, Sibylle H. LehmannHasemeyer

THE GEOGRAPHY OF STOCK EXCHANGES IN IMPERIAL GERMANY

ECO

90-2014 Martyna Marczak, OUTLIER DETECTION IN STRUCTURAL TIME SERIES Tommaso Proietti MODELS: THE INDICATOR SATURATION APPROACH

Andreas Pyka

92-2014 Bogang Jun, Joongho Lee

THE TRADEOFF BETWEEN FERTILITY AND EDUCATION: EVIDENCE FROM THE KOREAN DEVELOPMENT PATH

NON-FINANCIAL HURDLES FOR HUMAN CAPITAL ACCUMULATION: LANDOWNERSHIP IN KOREA UNDER JAPANESE RULE

94-2014 Michael Ahlheim, Oliver Frör, Gerhard Langenberger and Sonna Pelz

95-2014 Harold ParedesFrigolett, Andreas Pyka, Javier Pereira and Luiz Flávio Autran Monteiro Gomes

CHINESE URBANITES AND THE PRESERVATION OF RARE SPECIES IN REMOTE PARTS OF THE COUNTRY - THE EXAMPLE OF EAGLEWOOD

IK

IK

RANKING THE PERFORMANCE OF NATIONAL INNOVATION SYSTEMS IN THE IBERIAN PENINSULA AND LATIN AMERICA FROM A NEO-SCHUMPETERIAN ECONOMICS PERSPECTIVE

96-2014 Daniel Guffarth, Michael J. Barber 


\section{IMPRINT}

University of Hohenheim

Dean's Office of the Faculty of Business, Economics and Social Sciences Palace Hohenheim $1 \mathrm{~B}$

70593 Stuttgart | Germany

Fon $\quad+49(0) 71145922488$

Fax $\quad+49(0) 71145922785$

E-mailwiso@uni-hohenheim.de

Web www.wiso.uni-hohenheim.de 